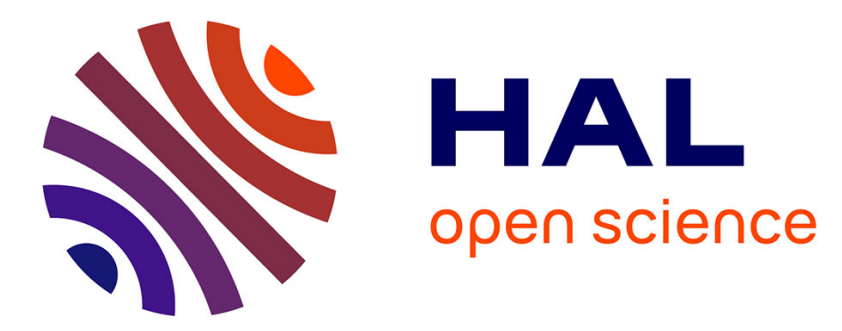

\title{
Les prémices du phénomène urbain à l'âge du Fer en Gaule méridionale: les agglomérations de la basse vallée du Rhône
}

Patrice Arcelin

\section{- To cite this version:}

Patrice Arcelin. Les prémices du phénomène urbain à l'âge du Fer en Gaule méridionale: les agglomérations de la basse vallée du Rhône. Gallia - Archéologie de la France antique, 2004, 61, pp.223269. 10.3406/galia.2004.3063 . hal-01910531

\section{HAL Id: hal-01910531 \\ https://hal.science/hal-01910531}

Submitted on 19 Jan 2020

HAL is a multi-disciplinary open access archive for the deposit and dissemination of scientific research documents, whether they are published or not. The documents may come from teaching and research institutions in France or abroad, or from public or private research centers.
L'archive ouverte pluridisciplinaire HAL, est destinée au dépôt et à la diffusion de documents scientifiques de niveau recherche, publiés ou non, émanant des établissements d'enseignement et de recherche français ou étrangers, des laboratoires publics ou privés.

\section{(ㅇ)(1) $\$$}

Distributed under a Creative Commons Attribution - NonCommercial - NoDerivatives| 4.0 


\title{
LES PRÉMICES DU PHÉNOMÈNE URBAIN À L'ÂGE DU FER EN GAULE MÉRIDIONALE
}

\author{
Les agglomérations de la basse vallée du Rhône
}

\author{
Patrice ARCELIN*
}

\begin{abstract}
Mots-clés. Sud-est de la France, basse vallée du Rhône, âge du Fer, mutation culturelle, urbanisme, agglomération, "protoville ".
Résumé. Avec la formation de l'âge du Fer, émergent dans la littérature archéologique portant sur la Gaule plusieurs paradigmes du terme "urbanisme " pour caractériser l'organisation des habitats groupés. Le sud-est de la France constitue, sous cet aspect, une région de développement précoce et dynamique jusqu’à la prime romanisation. Á partir de l'étude d'une série de cas répartis dans le temps, plusieurs habitats de la basse vallée du Rhône sont présenlés, sur leurs territoires, dans leurs modes structurels et les fonctions sociales qu'ils recouvrent.

Le concept d'habitat urbanisé, trop souvent dévoyé, est ici précisé et relu dans une perspective des âges des métaux européens. De ce tour gृhorizon se dégage une image très rurale pour la grande majorité des agglomérations. En contrepoint et dans la mouvance des premiers întacts réguliers avec le monde gréco-italique, apparaissent alentour du fleuve les facteurs d'une rapide mutation culturelle des hompulations. C'est de ce dernier courant que vont émerger des " protovilles " qui, pour la première fois, présentent les prémices d'une urbanisation.
\end{abstract}

Wu- -words. South-eastern France, lower Rhône valley, Iron Age, cultural mutation, urbanism, agglomeration, "prototown".

4.b. tract. In archaeological literature dealing with the turn of Iron Age in Gaul, several expressions of the term urbanism appear to inaracterize the organization of nucleated settlements. Southern France is from this angle a region of early and dynamic development until tise start of Romanization. Through of a series of case-studies taken at interyals in time, several settlements are being analysed in the lower Whone valley: their territory, their structure, and the social function they cover.

The concept of urbanized settlement, so often misled, is being defined and read inside the perspective of European Bronze and Iron Ages. From this survey, a rural image appears for most of the agglomerations. In counter-point and linked to the regular contacts with the Greek Italic world, the factors of a quick cultural mutation of populations are present along the river. From this last current, "prototowns" will emerge and show for the first time the starting of urbanization.

Translation : Isabelle FACIILT

Schlagwörter. Südosten Frankreichs, unteres Rhônetal, Eisenzeit, Kulturwandel, Urbanisierung, größere Ansiedlungen, frühes Städtewesen.

Zusammenfassung. In der archäologischen Literatur über Gallien finden sich zur Charakterisierung der Organisationsform größerer Ansiedlungen, wie sie im Verlauf der Eisenzeit erscheinen, mehrere Paradigmen zum Begriff “Städtebaukunst ". Der Südosten Frankreichs besitzt hier im Vorfeld der Romanisierung als eine Region vorzeitiger Entwicklungen seine eigene Dynamik. Ausgehend von einer Reihe von Fallstudien, die verschiedene Zeitstufen abdecken, stellt der Beitrag mehrere Siedlungen des unteren Rhônetals vor und erörtert ihren territorialen Umgriff, ihre inneren Strukturen und gesellschaftlichen Funktionen.

Das oft genug unreflektiert gebrauchte Konzept der stadtähnlichen Siedlung (habitat urbanisé) wird in diesem Zusammenhang präzisiert und mit breitem Bezug auf die europäischen Metallzeiten überprüft. Aus dieser Tour d'horizon ergibt sich für die Mehrzahl der Ansiedlungen zunächst ein sehr ländliches Bild. Unter dem Einfluß der ersten regelmäßigen Kontakte mit der griechisch-römischen Welt treten dann sogleich beidseits des Flusses die treibenden Kräfte eines raschen Kulturwandels in Erscheinung. Im Verlauf dieses Geschehens bilden sich endlich Frühformen der Stadt, die uns mit den ersten Anzeichen einer Urbanisierung konfrontieren.

Übersetzung : Stefan WIRTH

* LMR 6573 du CNRS : “Archéologie méditerranéenne et africaine ", Centre Camille-Jullian, Maison méditerranéenne des sciences de l’Homme, 5 rue du Château-de-l'Horloge, BP 647, F-13094 Aix-en-Provence Cedex 2. Mél : arcelin@club-internet.fr 


\section{LA FRANGE MÉDITERRANÉENNE DU MONDE CELTIQUE}

\section{LE DÉVELOPPEMENT DES AGGLOMÉRATIONS}

Un des caractères majeurs de la vie des populations protohistoriques de l'Europe continentale est celui de la formation des habitats groupés et de leur mode de structuration. Par le repérage ou la fouille, l'archéologie a mis en valeur nombre de ces agglomérations sur la façade méditerranéenne du monde celtique occidental. Pendant l'âge du Fer, leurs superficies restent modestes, de l'ordre de 0,5 à 7 ha, rarement davantage . Leur position est fréquemment perchée et des fortifications, doublées ou non de fossés, les délimitent et en assurent la protection. Plus qu'ailleurs en Gaule, cette multiplication apparente des habitats fortifiés de superficies variées a contribué à étayer le concept d'une " civilisation des oppida" définissant l'âge du Fer méridional (Jannoray, 1955, p. 272). Les progrès de ces dernières années résident dans une prise de conscience plus affirmée que l'ampleur de l'inventaire de ces regroupements humains, reconnus ou fouillés, résulte avant tout de leur situation topographique ; lieux aisément perceptibles aux investigations et souvent préservés des pratiques culturales contemporaines. En contrepartie, les terrains alentour, fréquemment recouverts d'une dense végétation arbustive, n'ont pas facilité la prospection aérienne systématique, hormis dans les terres basses des principales vallées ${ }^{2}$. Depuis une dizaine d'années, c'est le développement de l'archéologie de sauvetage liée aux grands travaux interrégionaux qui a favorisé la multiplication des prospections, puis des fouilles extensives sur les étendues de plaine ou de coteau. Avec le recensement de structures agricoles fossoyées, de chemins, de restes de constructions isolées assimilables à des fermes sur les terres d'exploitation, voire de hameaux apparemment en milieu ouvert, la recherche intègre désormais plus facilement l'idée que si l'oppidum est un élément majeur non contestable dans l'occupation des territoires protohistoriques, il n'en est pas le seul.

Ces agglomérations fortifiées de l'âge du Fer, dont on a par ailleurs pris conscience de la diversité de leur étendue, de leur implantation ou de leur structuration intérieure, apparaissent comme autant de points d'ancrage communautaires forts sur les terres exploitées, noyaux humains à vocation économique et, épisodiquement, défensive. Sur les territoires intermédiaires et souvent même au pied des implantations perchées, d'autres hameaux et installations isolées forment une trame d'occupation des sols variable, dans son importance démographique ponctuelle, au fil des siècles et des régions. Malgré des modélisations territoriales proposées en Gaule ces dernières années ${ }^{3}$,

1. Les superficies atteignent 10 à 30 ha dès la fin du premier âge du Fer à Carsac (Aude), Bèriers, Lattes, Arles, Glanon, Nîmes ou Avignon. I.es étendues bâties pourront s'accroître exceptiomellement jusqu à 35-40 ha à Nîmes et peutêtre à Arignon (Arcelin, 2001, p. 140 ; Verdin, 2003 , p. 569 , tabl. I).

2. Par exemple pour celle de l'Aude: : Passelac, 1983 ; Rancoule, $1992 ; 1993$, p. 41-43; Barthès et al., 1995, p. 110-129; Caroza et al., 1998, p. 134135.

3. Ainsi Pion et al., 1990 ; Brun P., 1993 ; Buchsenschuty et al., 1993; Gransar et al., 1999. l'archéologie est loin d'avoir aujourd'hui, faute de fouilles variées et étendues hors des habitats groupés, la capacité de saisir la nature et la portée réelles des facteurs de réciprocité qui relient ces différentes composantes.

En dépit de l'existence d'agglomérations fortifiées aux âges du Bronze et du Fer, la Gaule continentale demeure fondamentalement rurale avec de petits ensembles d'habitations ou hameaux en milieu ouvert et une multiplicité de fermes isolées. C'est seulement avec la fin de Ia Tène C2 ou l'amorce de La Tène D (à partir du deuxième quart du II $^{\prime}$ s. av. J.-C..) qu'apparaîtront, dans les régions plus septentrionales, de vastes agglomérations de plusieurs dizaines, voire de centaines d'hectares dont l'organisation interne et la composition socioéconomique s'avèrent bien plus complexes qu'auparavant (Collis, 1984a, p. 121-136 ; Audouze, Buchsenschut\%, 1989, p. 294-316 ; Buchsenschutz, 1990 et 1999, p. 357-358; Fichtl, 2000, p. 163-165).

Dans le Midi, après les aménagements fortifiés du Néolithique et de l'âge du Cuivre, le développement du phénomène de perchement des habitats groupés s'amorce dès la fin du Bronze ; la structuration de ces derniers s'accroît au premier âge du Fer (fortification et planimétrie des aires de construction), avec un usage de la pierre sèche et de la terre qui complète puis relaye celui du bois. Ce dernier matériau reste pourtant bien présent dans nombre de constructions, comme dans les superstructures de l'enceinte du Cros a Caunes-Minervois, dans l'Aude (Gascó, 2000, p. 216) ou, un peu plus au nord, le renforcement des parements de celle du Puech de Mus à Sainte-Eulalie-de-Cernon, en Rouergue (Gruat, Marty, 2000, p. 34-40 ; Gruat et al., 2003). Ces édifications sur armature de bois sont également fréquentes dans les réalisations domestiques des agglomérations littorales jusqu'au début du second âge du Fer, ainsi au Baou-Roux de Bouc-Bel-Air près de Marseille, dans la première moitié du vI" s. (Boissinot, 1990, p. 92) ou à Montlaurès, près de Narbonne, jusqu'au début du v's. (Chazelles, 1997, p. 28-29). L'usage privilégié du bois est encore plus systématique dans les implantations ouvertes de faibles ou moyennes superficies dont le nombre demeure très élevé dans les secteurs intermédiaires, à l'image du hameau de Buzerens à Bram dans la vallée de l'Aude, au premier âge du Fer (Carozza, Burens, 1995 ; Carozza et al., 2000), ou de celui, bien plus tardif, récemment fouilé aux Contras près de Lapalud, dans le Vaucluse (Escallon, Dufraigne, 1997). (ette manière de construire est pratiquement exclusive jusqu'à la romanisation en retrait des côtes ou des grands fleuves.

\section{DÉMOGRAPHIE ET GESTION DES TERRITOIRES}

Dès le début du second âge du Fer, une plus grande stabilisation des populations s'opère sur les territoires exploités, avec un cncadrement social qui paraît très hiérarchisé autour de " chefs" ou great men (Johnson, Earle, 1987 ; Godelier, 1999). Dans les régions dynamiques au plan économique et prospères par leurs échanges, les plus importants de ces dirigeants peuvent être considérés comme de véritables "aristocrates " à l'image des membres de la classe équestre, aux pouwoirs héréditaires (dunastai), que renvoient tant la statuaire d'Entremont (Salviat, 1987 ; Arcelin, Rapin, 2002) que les textes anciens sur 
la défaite de la fédération des Saluvii (Tite-Live, Epitomae, 61 ; Appien, Ihistoire romaine, IV, 12). Aux IN ${ }^{* *}$ et III" s. av. J.-C., une évolution dans l'occupation des sols de plusieurs régions méditerranćennes se manifeste par la diminution très sensible des habitats de plaine isolés, mais sans que l'on puisse toujours percevoir l'amplification simultanée du nombre et de l'étendue des agglomérations. Ce phénomène observé en plusieurs régions du Languedoc, par exemple dans la Vaunage près de Nîmes (Nuninger, Raynaud, 1998, p. 25) ou dans le Var (Bérato et al., 1995, p. 71 ; Bérato, 1997, p. 143-144 ; Brun, 1999, p. 118 120), ne doit être systématisé à l'ensemble du Midi qu'avec une extrême prudence. Une récente analyse des données disponibles autour du massif des Alpilles a souligné la probabilité d'un processus quelque peu différent, plus continu dans les occupations de plaine (Arcelin, 1999a, p. 67-68). La question de la lisibilité des artefacts contemporains a plus d'une fois été posée pour tenter d'expliquer cette déprise territoriale autrement que par une chute brutale de la démographie (récemment Mauné, 1998a, p. 6 et 1998b, p. 69). Mais l'argument, bien que non dénué de fondement et même séduisant à plus d'un titre, ne peut seul justifier de la totalité des difficultés documentaires actuclles. Au II" s. av. J.-C., les habitats de plaine réapparaissent un peu partout avec le traceur que constituent les céramiques italiques à vernis noir ou les amphores de l'Italie centrale et méridionale. Sans entrer dans une discussion polémique sur le sens des vestiges de plaine, généralement interprétés comme de probables lieux d'habitat (Mauné, 1998b et 1999 ; bilan pour le Midi, in Arcelin, 2001), ni sur leur signification dans la répartition du peuplement (Verdin, 1999, p. 55-56 ; Garcia, 2000a, p. 194-195), on retiendra la probabilité d'une occupation multivariće des sols, plus importante à la fin qu'au début du second âge du Fer. L.cs habitats groupés, sous la protection d'une fortification, constituent un mode permanent et généralisé parmi les formes de l'organisation communautaire sur les territoires. C'est sans conteste un des caractères particulièrement visibles des cultures méridionales à partir de la fin du premier âge du Fer. Mieux, dans certains secteurs géographiques, ce type d'habitat dans sa planification et l'organisation structurelle des cellules domestiques qui le composent, ne se transformera pas radicalement du $v^{\mathrm{ec}}$ au II $^{\mathrm{c}}$ s. av. J.-C. Reste alors à interpréter, dans une vision élargie, les causes de l'évolution ou de la relative stagnation structurelle de ce mode d'habitat au fil des siècles. C'est fort d'un constat de l'existence de processus différenciés dans l'évolution des sociétés méridionales (Py, 1993, p. 264-265) que l'on s'interrogera sur la portée des caractères discriminants d'une "proto-urbanisation ", reconnue par certains dès la fin du premier âge du Fer (ainsi Garcia, 2000b, p. 27-28 ; Garcia, 2003, p. 229), de même que sur les étapes éventuelles de ses prémices vers la formation avérée de la ville, car c'est en définitive de l'émergence de la cité-état dont il s'agit ici.

\section{DES INTERVENANTS MÉDITERRANÉENS}

La façade méditerranéenne de la Gaule est une aire de contacts cntre les cultures ligure, celte continentale et nordibérique, brassages réalisés pour l'essentiel dès le premier âge du Fer. Ces interactions de proximité ont été dynamisées par la présence des Phocéens, Étrusques et Ibéro-Puniques, négociants le long des côtes dès la fin du vir"s. av. J.-C. ou implantés au début du suivant (Guilaine, Rancoule, 1996; Bats, 1996 et 1998 ; Gailledrat, 1997 , p. $74-90$ et 277-310; Gras, 2000; Sourisseau, 2000a et b). Bien plus tard, au lendemain de la première guerre punique, le commerce avec le marché italien va concerner le sud de la Gaule, dans un premier temps du moins, sa frange littorale et ses agglomérations portuaires (Marseille, Arles, Lattes, Pech Maho..., voir Hermary et al. dir., 1999, p. 98-100). L'emprise économique du monde italique ne devient déterminante qu'au cours du premier quart du II $^{\mathrm{r}}$ s. av. J-C., et ce aux dépens des intérêts marseillais (Bats, 1992, p. 275-277 ; Gantès, 1992 ; Py, 1994, p. 317-331 ; Arcelin, 1995, p. 336). Ce flux croissant prend alors progressivement possession des régions méridionales de la Gaule et puis remontera plus au nord vers les territoires des Éduens (Tchernia, 1983 ; Bats, 1986 ; Plassot, Desbat, 2003) ou à l'ouest, vers le bassin de la Garonne (Domergue et al., 2002). Autre constat majeur dès la première moitié du II" s., ces liens commerciaux se doublent d'un puissant courant culturel de l'Italie gréco-romaine vers les sociétés du sud de la Gaule. Son attrait pour les élites celtes, déjà sensibilisées aux valeurs méditerranéennes, se transforme alors en un facteur de mutation social et politique. Comme ailleurs sur cette façade maritime de la Gaule, ce fut le cas pour la basse vallée du Rhône, si longtemps dominée par l'activité omniprésente des négociants marseillais et l'apparente prégnance de leur mainmise économique.

\section{L'HABITAT PROTOHISTORIQUE DU MIDI, UN CONCEPT EN RENOUVELLEMENT}

\section{LA RECHERCHE SUR LES AGGLOMÉRATIONS}

Depuis plus d'un demi-siècle, ce type d'habitat, surtout celui d'importance et fortifié, est un des champs essentiels de la connaissance archéologique des populations protohistoriques du Midi gaulois, en particulier dans son aire orientale. Sans conteste, jusqu'au début des années 1990, cette approche spécifique des modes de l'habitat a été privilégiéc sur tout autre, du fait de la grande lisibilité au sol de ce type d'installation. Le bilan des recherches 1990-1994, réalisé par le Conseil national de la recherche archéologique en 1996, souligne sans ambiguïté les orientations des investigations méridionales en ce domainc (La recherche archéologique en France, 1997, p. 218) (fig. 1). En contrepartie, dans cette même région française, l'appréhension des autres formes de l'occupation des sols est demeurée bien en retrait (ibid., carte p. 216), favorisant insidieusement l'idée que l'oppidum - ce groupement communautaire, souvent perché et fortifié -, était par excellence le mode privilégié (ce qui est déjà restrictif), voire quasi exclusif de l'habitat (ce qui est erronć) à partir de la fin du premier âge du Fer (Arcelin, 1989, p. 477 ; Dedet, 1989, p. 474 ; Py, 1993, p. 158-159). Une telle image de la morphologie et de la dimension des implantations sur le territoire pouvait paraître d'autant plus satisfaisante qu'elle semblait trouver des arguments ampliatifs dans l'évolution contemporaine d'autres cultures méditerranéennes. De fait, depuis les années 1960, cette orientation, prenant appui sur la 


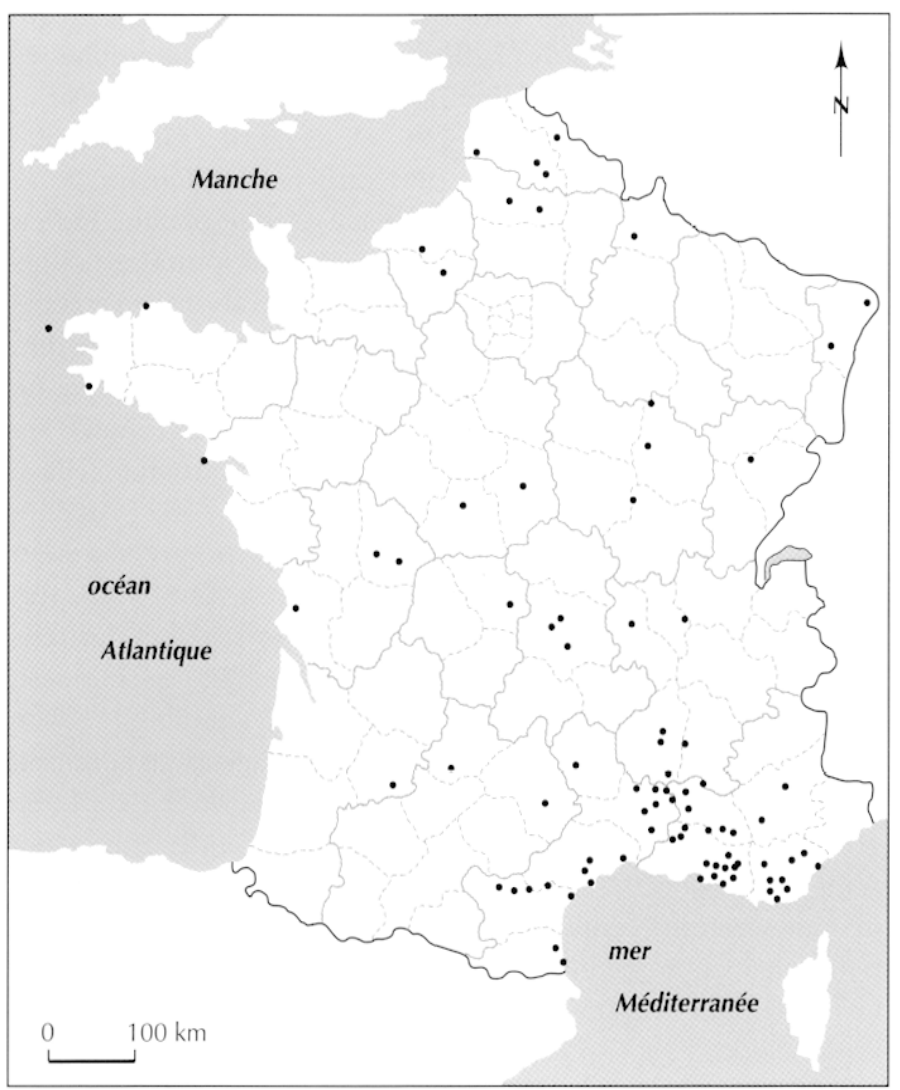

Fig. 1 - Carte de répartition des habitats groupés protohistoriques, fouillés en France entre 1990 et 1994. La concentration des recherches sur ce mode d'habitat est patente dans la région Sud-Est et en particulier dans la basse vallée du Rhône (extrait de La recherche archéologique en France, 1997, p. 218).

fouille de quelques vastes agglomérations côtières (telles SaintBlaise près de Martigues, ou Pech Maho, puis Lattes en Languedoc) ou sur de fortes particularités régionales (ainsi pour la Vaunage près de Nîmes ou dans les plaines du centre Var), avait tendance à déformer en l'édulcorant une vision de la nature des habitats protohistoriques et de leur gestion des sols, image bien plus complexe que l'on entrevoit aujourd'hui un peu partout. Dans le scénario social qui gère le processus évolutif des populations méridionales du $\mathrm{V}^{\circ}$ au II' s. av. J.-C., l'agglomération protégée, structurée dans son plan, devient pour certains la première étape conduisant à la ville des débuts de la romanisation. Ces habitats groupés se trouvent alors revêtus, en partie du fait de leur antériorité chronologique, des qualificatifs de "proto-urbanisés " dans le meilleur des cas, ou plus directement de "villes urbanisées ". Bien sûr, un état détaillé de la recherche dans cette région de la Gaule n'aboutirait heureusement pas à des constatations toutes aussi tranchées. Pourtant, même en considérant les nuances apportées par divers chercheurs sur tel site ou tel secteur géographique (par exemple dans Py, 1993, p. 169-171) ou les réflexions plus ouvertes exprimées à propos des contacts économiques (par exemple Rapin, Schwaller, 1987 ; Feugère, 1993 ; Rancoule, Schwaller, 1994 ; Feugère et al., 1994), un large tour d'horizon de la façade méditerranéenne révèle globale- ment une appréhension conceptuelle et architecturale de l'habitat qui n'intègre pas ou peu les possibles héritages communs aux cultures du monde de l'Europe celtique. Questionnements et regards comparatifs sont tournés pour l'essentiel vers les autres régions du pourtour de la Méditerranée occidentale, avec la recherche inconsciente de parallèles qui avait déjà été en partie dénoncée par Chr. Goudineau en 1980 (p. 185-186).

\section{UN NÉCESSAIRE RÉEXAMEN SÉMIOLOGIQUE}

Cette affaire va bien au-delà d'un simple problème de vocabulaire car elle recouvre en fait certains concepts sociaux fondamentaux des populations celtes (ou celtisantes) du Midi, comme leurs modes de vie communautaire ou leurs rapports aux territoires d'exploitation avec les réseaux structurants des pouvoirs économiques et politiques. Ne pas définir le champ de tolérance accordée à l'usage du terme " urbanisme ", c'est ignorer volon- tairement la signification de l'image sociale qu'il renvoie et, du même coup, prendre le risque de dévoyer profondément la désignation de son proto-état en l'accolant à n'importe quelle structuration d'habitat groupé, visiblement organisée dans sa construction planimétrique. À ce niveau de la réflexion, il paraît essentiel de filtrer doublement les données archéologiques disponibles. D'abord, en référence à des antécédents de l'âge du Bronze ou du premier âge du Fer européen, pour estimer la réalité et la portée des transformations constatées dès la fin du premier âge du Fer méridional dans la nature et la conception des habitats groupés. Ensuite, pour souligner les parallèles possibles avec les expressions formelles et juridiques de la notion d'urbanisme qui prévaut dans d'autres civilisations méditerranéennes, essentiellement gréco-italiques.

Dans les cultures de l'Antiquité, le concept d'urbanisme intègre les caractères visibles d'une forme d'autorité affirmée débordant sur un environnement territorial d'exploitation ; il gère également un système d'organi-sation spatiale de l' habitat communautaire dans sa diversité sociologique et sa complexité structurelle. Le rôle premier de l'organe urbain n'est pas de nature économique, il est avant tout politique, avec son accompagnement religieux. L'étape proto-urbaine n'est donc pas seulement celle de l'amorce de la seule dynamique économique et de ses prolongements commerciaux liés à une position privilégiée ou à un rassemblement humain conséquent et productif. Elle se définit d'abord comme le moment où transparaissent dans l'organisation spatiale et architecturale de l'agglomération les premières dichotomies sociales résultant d'un dépassement des seules activités agropastorales et artisanales. Elle reflète aussi l'émergence des notions de privé et de public qui mettent en valeur les caractères ostentatoires d'un pouvoir politique résidant, que ces marques soient issues d'une volonté individuelle ou d'une décision collégiale (Duby, 1980, p. 13-18; Gros, Torelli, 1988, p. 18-19; Huot et al., 1990, p. 27-42 et 325-327; Morris, 1991 ; Vink, 1997).

L'indispensable démarche de ce repositionnement terminologique et conceptuel est d'autant plus nécessaire pour cerner la fonction des habitats groupés que la hiérarchie visiblement très ouverte de leur superficie et de leur poids écono- 
mique pourrait suggérer une correspondance, au moins partielle, de leur vocation politique au plan régional. Tout en intégrant l'analyse spatiale de plusieurs agglomérations, ce sont les réflexions plus amples sur l'occupation et la gestion des territoires intermédiaires qui peuvent, aujourd'hui, aider à concevoir de manière moins dissociée le sens et le rôle de ces dernières dans les sociétés celtisantes du Midi. Avec d'autres, nous sommes bien conscient que cette démarche globalisante ne peut porter ses fruits qu'en s'appuyant sur une documentation fiable au plan archéologique, c'est-à-dire fouillée et publiée. La relative nouveauté de cette recherche dans le Midi condamne inévitablement le chercheur à prendre en compte les résultats de prospections de surface, parfois complétées de sondages, mais rarement de fouilles extensives. En dépit d'une méthodologie de terrain désormais bien établie, il serait naif de surestimer la véracité archéologique de tels sites de répartition, même distribués dans le temps et commentés du point de vue de la nature des découvertes comme de leur signification au sol. Mais il le serait tout autant de faire fi d'un inventaire patrimonial qui s'accroît désormais considérablement. Des recherches ponctuelles de ces dernières années sur de petits habitats découlent, en plusieurs secteurs, une information nouvelle dont certains caractères sont désormais primordiaux et incontournables pour tenter une approche sociale, économique et politique plus affinée des modes de fonctionnement des communautés celto-ligures du Midi. Nous y reviendrons.

\section{UNE OCCUPATION DIVERSIFIÉE DES TERRITOIRES INTERMÉDIAIRES}

Les réflexions sur les territoires périphériques aux agglomérations ceinturées ont mis l'accent sur les autres formes de l'habitat, reconnues dès la fin de l'âge du Bronze. D'abord, la notion même d'habitat fortifié ne concerne pas seulement les oppida perchés, mais également des regroupements en plaine, à l'exemple de l'Île de Martigues en bordure de l'étang de Berre, du Port à Salses-le-Château dans les Pyrénées-Orientales, en terrain marécageux, ou encore de Lattes en bordure de l'étang de Pérols. Parfois, ce sont de très modestes superficies peu densément utilisées qui sont ceinturées, comme dans le Var et les Alpes-Maritimes où l'occupation n'apparaît qu'épisodique. Ailleurs, une documentation désormais plus conséquente révèle la présence de " bourgs ", " hameaux " et "fermes ", autant de formes "ouvertes " de superficies variées, établies dès la fin du premier âge du Fer en divers points des territoires d'exploitation, des élévations aux rivages maritimes, mais aussi dans les plaines périphériques et intermédiaires aux agglomérations perchées (par exemple Bérato et al., 1995, p. 60-64; Bertoncello, Gazenbeek, 1997 ; Mauné, 1998b et 1998c ; Mauné dir., 1998 ; Nuninger, Raynaud, 1998, 2000 ; Ugolini et al., 1998 ; Trément, 1999 ; Landuré, 2000 ; Arcelin, 2001, p. 140-145). Avec raison, on a souligné l'importance et la fréquence des quartiers bas périphériques aux agglomérations perchées, implantations que l'on peut considérer, d'une façon globale et peu nuancée, comme des faubourgs, dépendances complémentaires ou extensions de l'habitat principal concentré (Arcelin, 1999a, p. 65-66 et 68-69 ; Garcia, 2000a, p. 195 ; bilan, in Arcelin, 2001, p. 145-146). Souvent nettement séparés de l'habitat central comme autour du Célessou à Fontès dans la vallée du l'Hérault (Mauné, 1999) (fig. 2a), ces quartiers peuvent parfois occuper les pentes du site, à faible distance des fortifications principales. Ainsi l'occupation du flanc méridional de l'habitat perché de Saint-Pierre à Martigues, près de l'enceinte, résulte peut-être, au IV $\mathrm{V}^{\mathrm{e}}$ s. av. J.-C., d'un agrandissement de l'oppidum initial de 1 ha sous la pression démographique locale (Chausserie-Laprée, 2000, p. 172) (fig. 3).

Bien d'autres facteurs de compréhension que ceux issus des seuls sites d'habitat doivent être appréhendés dans une telle démarche. Ce sont en premier les informations sur l'environnement et l'organisation agraire, les aménagements de terrasses, de drainage ou de rétention (Brun, 1990 ; Ginouvès et al., 1990, p. 389-394; Monteil et al., 1990 ; Arthuis, Ambert, 1997, p. 360 ; Berger et al., 1997, p. 173-176), d'enclos agricoles fossoyés et de leurs traces culturales (par exemple dans la plaine du Vistre près de Nîmes: Vidal et al., 1996, p. 59 ; ou en Provence : Boissinot, Brochier, 1997 ; Boissinot, 2000a, p. 29-30) ou d'autres enclos supposés à vocation pastorale comme ceux relevés sur le plateau de Sauvaire, au Lavandou et à Roquebrune-sur-Argens (Bérato et al., 2000, p. 154). On y ajoutera les structures de l'exploitation des ressources naturelles, mines et carrières (Bessac, 1986, p. 181-182 et 1996; Reille, 1998 et 1999), celles de l'artisanat comme l'atelier d'un potier récemment fouillé au Mas de Pascal près d'Aspiran, dans l'Hérault (recherches A. Pezin). On rappellera de même la place des espaces essentiels que sont les nécropoles, tels les enclos funéraires près du Mont-Cavalier à Nîmes (Séjalon $e t$ al., 2003), les vastes ensembles au pied de l'oppidum des Caisses à Mouriès (Gateau, Gazenbeek dir., 1999, p. 216-219 ; Marcadal, 2000 ; Marcadal et al., 2003), mais aussi les sépultures isolées dont la signification sociale probable a été plusieurs fois soulignèe pour les plus riches d'entre elles (Fiches, 1989; Arcelin, 1999b, p. 446-447). On ne saurait enfin oublier les sanctuaires ruraux, funéraires, collectifs ou domaniaux (Fiches, 1989 ; Arcelin et al., 1992, p. 206-209 ; Dedet et al., 1997 ; Dedet, Sauvage, 1998 ; Nin, 2000 ; Arcelin, 2000a et 2000b ; Arcelin, Gruat et al., 2003, p. 179-183 et 185-186). Récemment, des habitats de superficie limitée $(0,1$ à 1 ha), singularisés par certains traits de leur structuration et de leur système défensif, voire de catégories d'éléments contenus, ont été interprétés comme des fermes hors du commun, avec des locaux de vie et de stockage. En Provence, ont été individualisés les sites de Coudounèu à Lançon-de-Provence, un petit grenier fortifié de la fin du ves. av. J.-C. (Verdin et al., 1997 ; Verdin, 2000) (fig. 4), el de Roquepertuse à Velaux, une petite place forte du début du III $^{\mathrm{e}}$ s., pourvue d'un sanctuaire et entourée d'un hameau (Boissinot et al., 2000; Boissinot, 2004) (fig. 5). Certes modestes, ces petits habitats perchés ou de pente s'avèrent originaux, en tant que lieu de stockage protégé dans le cas de Coudounèu ou d'habitat fortifié autonome au sein d'un petit village pour Roquepertuse. Ils sont très certainement révélateurs de l'existence de familles possédantes (ou aristocratiques) et de certains aspects de leurs aménagements spécifiques : ici un grenier de réserve défendu, là leur résidence domaniale au sein de leurs indispensables dépendants (Arcelin, 1999b et 2001, p. 148-151). De telles structures n'étaient jusqu'alors que supputées à partir de la documentation du milieu funéraire et 

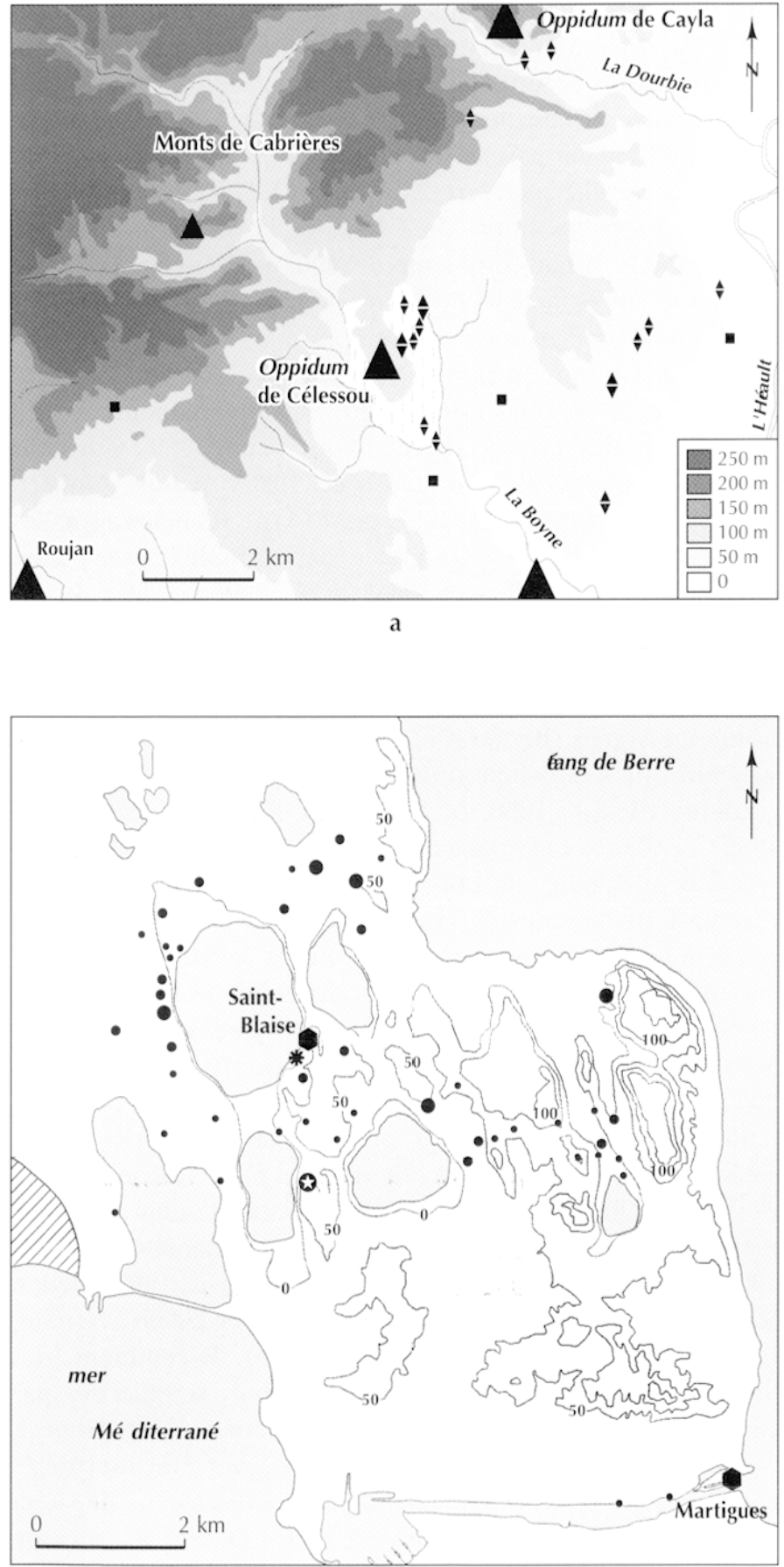

b

de l'attestation indirecte des textes anciens. Ainsi l'histoire de ce Celte du nom de Cavaras, un guerrier revenu sans doute enrichi d'Asic Mineure et qui doit résider dans un domaine de "l'arrière-pays de Marseille " (sa dénomination suggère le territoire des Cavares, dans le sud du département du Vaucluse). Il reçoit le protagoniste de l'histoire qui nous est narréc, entouré des membres de sa "maisonnée ", en somme de ses clients et dépendants (Aristodème, Histoires, I) ${ }^{4}$.

4. Cette histoire d'Aristodème de Nysa, à l'intrigue romanesque, est écrite vers le milieu du $\mathrm{I}^{\mathrm{rr}}$ s. av. J.-C., mais la tranc pourrait être puiséc dans les notes de son grand-pìre, Poseidonios d'Apamée.
Fig. 2 - Les enquêtes systématiques sur l'occupation des territoires entourant les oppida apportent depuis quelques années une image plus riche des ressources de l'habitat protohistorique autour de ces agglomérations principales. Malgré les tentatives louables de hiérarchisation qualitatize et quantitatize de l'information recueillie, linterprétation de la documentation est inévitablement floue - à l'exception des secteurs fouillés -, tant pour la nature des structures pressenties que pour leurs chronologies : a, les traces d'habitats de coteau et de plaine autour de l'agglomération perchee du Célessou ì Fontès, Hérault (losanges) et d'artefacts isolés (carrés). Elles montrent, aux vr' et $v^{\prime}$ s. av. J.-C., des installations de proximité et d'autres plus éloignées, peut-être en liaison avec une voie de cheminement (d'après Mauné, 1999, p. 112) ; b, la région. de l'agglomération perchée de Saint-Blaise à Saint-Mitre-les-Remparts (Bouches-du-Rhône) sur les rives sud-ouest de l'étang de Berre. Comme précédemment, à la fin du premier âge du Fer, il existe autour de l'oppidum majeur des habitats secondaives relativement importants répartis sur le territoire et d'autres moindres correspondant à de petits domaines ou à des fermes (d'après Trément, 1999, p. 112).

On commence à mieux entrevoir depuis quelques années l'importance des voies de circulation qui relient ces éléments constitutifs de la vie rurale. Certains tronçons, mis en place dès la fin du premier âge du Fer, ont été repérés et fouillés : ainsi à Marguerittes dans le Gard (Py, Vignaud, 1998) ou à Flassans-surIssole dans le Var (Bérato et al., 2000). D'autres sont pressentis à proximité de l'oppidum précédent du Célessou à Fontès dans l'Hérault (Mauné, 1999) ou, à date plus récente (II"s.), près de l'agglomération du Baou-Roux dans les Bouches-du-Rhône (Boissinot, 2000a, p. 29-30), à la périphérie de Glanon, des Caisses à Mouriès dans les Alpilles (Gateau, Gazenbeek dir., 1999 , p. 216-217 et 254-255) ou encore près de Nîmes (Monteil, 1999, p. 445-449). Le tracé mythique de la voie hérakléenne,

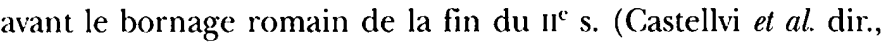
1997, p. 16 ; Monteil, 1999, p. 449-456), est très symbolique de l'importance de la circulation des populations méridionales sur les territoires de proximité comme à plus longue distance. Le rôle de ces axes est primordial dans la structuration des réseaux économiques entre les sites de stockage et ceux de l'échange. À ce propos, hors des agglomérations, on ne soulignera jamais assez le rôle majeur qui a dû être celui des lieux de négoce dans la stabilisation territoriale, la maturation politique et culturelle des populations qui s'y retrouvent. Les enclos limités de murets en pierres sèches bordant la voie précédente de Flassans-surIssole dans le Var, au V゙s. av. J.-C., peuvent suggérer la présence d'un bétail réuni pour de telles activités d'échange dans le cadre de "foires-marchés " dont le fonctionnement exact nous échappe, mais dont le souvenir subsisterait à travers les fora régionaux de l'époque romaine "s.

5. Ainsi à Forum Voromii, au (annet-des-Maures et Vidauban, dans ce même département (Bortoncello, 2002, p. 152-155). 


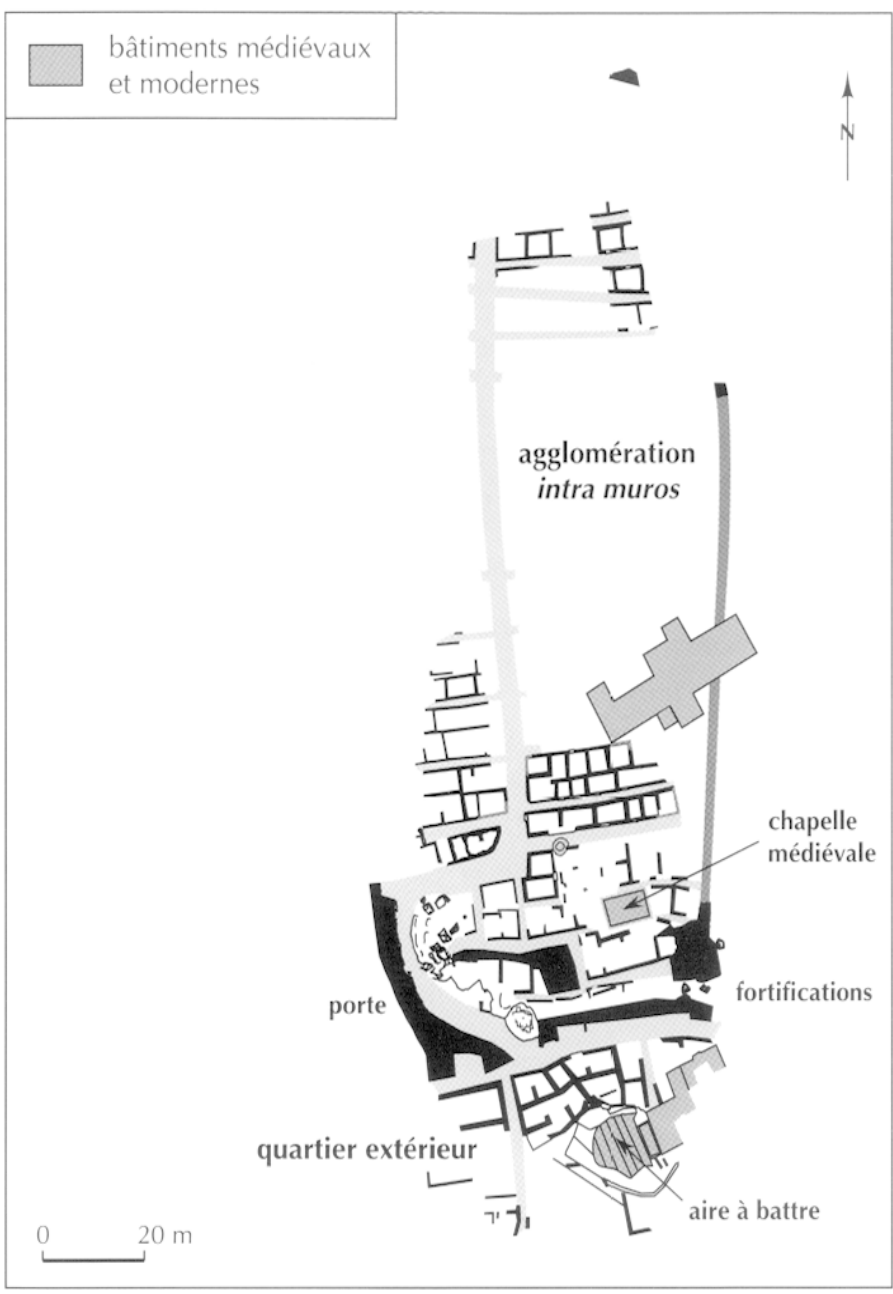

\section{L'EXEMPLE D'UNE RÉGION SPÉCIFIQUE}

\section{LA BASSE VALLÉE DU RHÔNE}

I.e midi de la Gaule ne constitue pas un ensemble unifié durant l'âge du Fer, ni dans ses antécédents de la fin du Bronze, ni dans ses sources d'influences, tant contincntales que maritimes. De grandes aires culturelles se dessinent au $\mathrm{I}^{\mathrm{r}} \mathrm{s}$. av. J.-C., dont les caractères s'accentueront au second âge du Fer par la stabilisation des hégémonies commerciales le long du littoral en regard de la dynamique propre des processus socioéconomiques régionaux. La première de ces aires est celle du Roussillon et du Languedoc occidental, limitée à l'est par l'Orb. Elle recouvre en fait le secteur septentrional des milieux culturel et économique de la Catalogne ibérique dont les particularités persisteront tardivement (Ugolini, 1993; Gailledrat, 1997 et 2000). La deuxième concerne. malgré de fortes nuances internes, la partie centrale de la façade méditerranéenne, essentiellement le Languedoc oriental et la Provence occidentale, autour de l'axe rhodanien, la région de la vallée de l'Hérault constituant une zone intermédiaire vers l'ouest. I. a troisième aire culturelle, essentiellement reliée aux précédentes par la mitoyenneté maritime, couvre la part septentrionale et orientale du Var, également les départements des

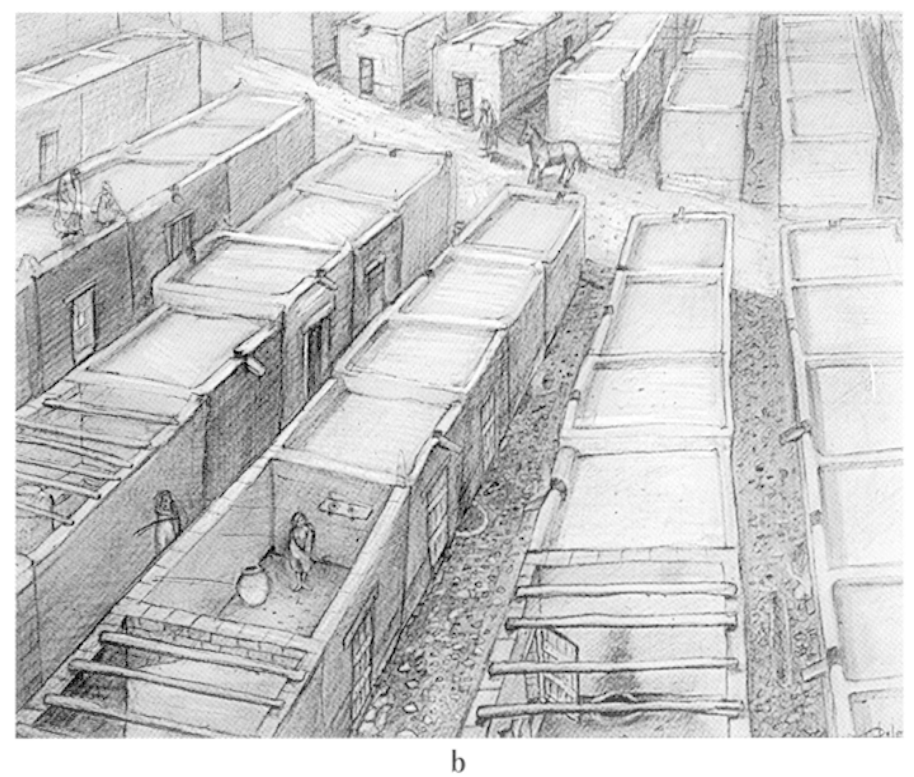

Fig. 3 - Implanté sur une colline au centre d'une plaine agricole, le bourg de Saint-Pierre à Martigues (Bouches-du-Rhône) couvre une superficie d'environ 2 ha. I es espaces d'habilation, presque tous modestes, sont rigoureusement organisés en files perpendiculairement à une voie centrale plus large qui joint apparemment les accès nord et sud. D'une remarquable longévité, cette planimétrie remonte dans son état initial au premier quart du v"s. av. J.-C. At subsistera jusqu'au rer s. apr.J.-C. Aucune aire collective n'est reconmue. À partir $d u{ }^{*}$ s., un quartier extérieur est édifié sur les pentes méridionales de la colline: a, plan de l'agglomération fortifiée et planifiée (échelle: $1 / 2000) ; b$, restitution graphique des files d'habitations domestiques (a, I)AO M. Rétif, Service archéologique de Martigues ; b, dessin D. Delpallilo d'après (hausserie-Laprée dir, 2000), p. 37 et 172).

Alpes-Maritimes et des Alpes-de-Haute-Provence. ('est un vaste ensemble montagneux et de hauts plateaux, de circulation sudnord difficile, où les formes de l'habitat et leurs évolutions au cours de l'âge du Fer sont toujours très mal connues (Garcia, 1997 ; Brun, 1999, p. 78 et 104-106).

Nous retiendrons la partie médiane de cette façade côtière pour considérer l'évolution de ses habitats groupés au second âge du Fer. Associée à d'autres domnées économiques et culturelles, nous nous intéresserons aussi à l'image que ces derniers nous renvoient du comportement social des populations dans leur rapport aux territoires d'exploitation ou dans l'affirmation de noyaux familiaux pour la domination politique des communautés. Les deux rives de la basse vallée du Rhône, grosso modo les départements actuels du Gard, et l'extrémité orientale de l'Hérault d'un côté, le Var occidental, les Bouches-du-Rhône et le Vaucluse de l'autre, composent un vaste triangle de plaines bordées de reliefs, espace géographique de circulation aiséc autour de la voic navigable majeure qu'est le fleuve (fig. 6).

\section{FACTEURS CULTURELS ET BASE DOCUMENTAIRE}

Deux arguments permettent de focaliser une interrogation sur la nature structurelle des agglomérations principales en regard des plus modestes dans le cadre géographique bas- 

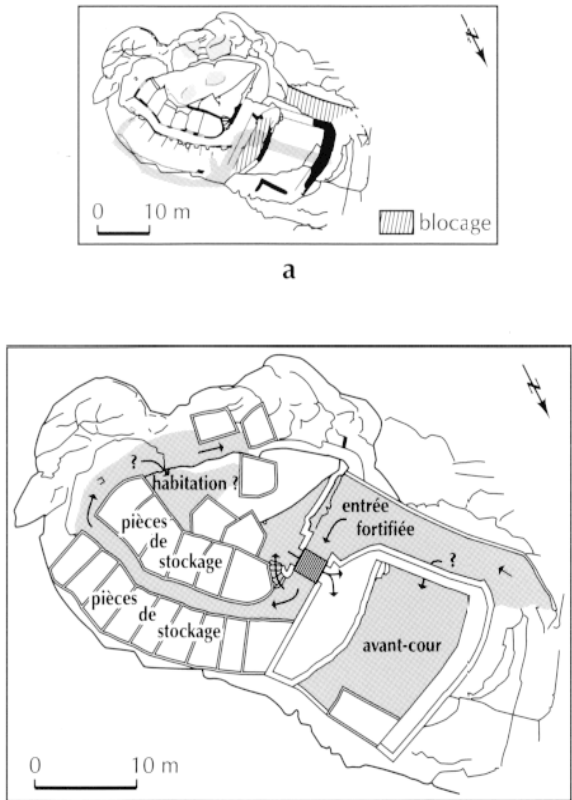

b

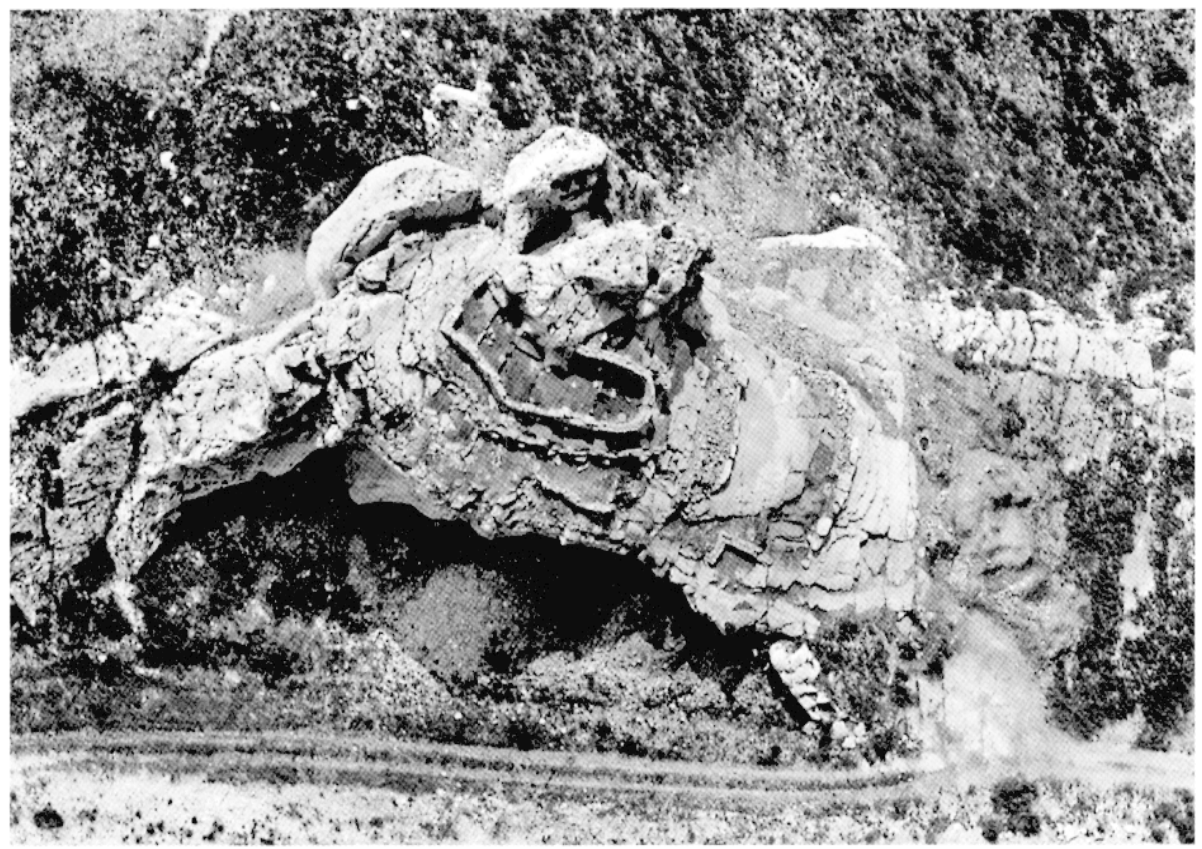

Fig. 4 - À la charnière des deux âges du Fer (vers $450-400$ av. J. C.), le site de Coudounèu à Lançon-de-Provence (Bouches-du-Rhône) n'occupe qu'une superficie de $1000 \mathrm{~m}^{2}$ sur un petit piton rocheux entouré de vallons. Les modestes cellules n'abritaient que des produits agricoles, sans traces résiduelles d'activités domestiques. De probables contrepoids de pressoirs sont reconnus. Avec l'existence de locaux hauts séparés et de quelques bijoux (dont un torque), également la présence d'un système défensif conséquent et d'une avant-cour elle-même protégée, ce sont autant de caractères qui tendent à écarter ce site du lot des autres petits habitats contemporains, malgré leur parenté structurelle. Le qualificatif prudent de " fermegrenier " lui a été attribué par son inventeur. Son apparent isolement peut conduire à assimiler cet aménagement de stockage à une des structures rurales d'un ensemble domanial plus étendu de l'élite régionale: a, plan au $1 / 2000 ; b$, plan interprétatif au $1 / 1000$; $c$, vue aérienne horizontale du site (a, d'après Verdin et al., 1997, p. 168-169; b, d'après Verdin, 2000, p. 147 ; c, cliché C. Hussy, SRA-PACA).

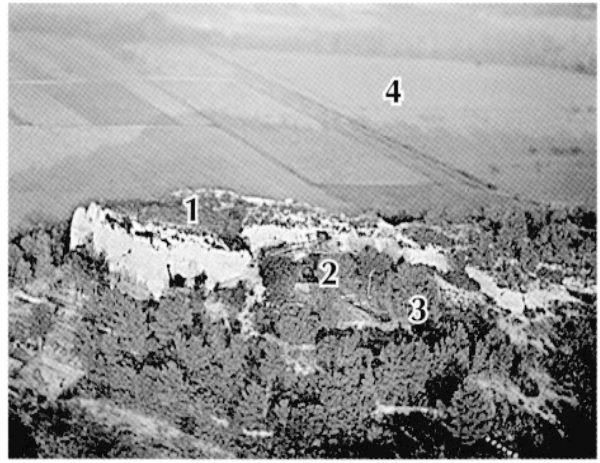

a

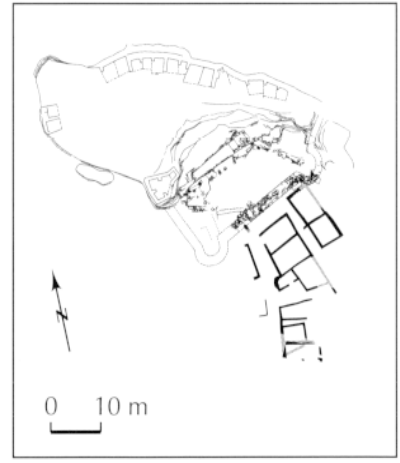

b

Fig. 5 - Vers 300 av. J.-C., l'extrémité d'un plateau dominant les basses plaines de la vallée de l'Arc à Velaux (Bouches-du-Rhône) est restructurée sur les vestiges d'une occupation de la fin du premier âge du Fer. Le site de Roquepertuse. apparaît dans la première moitié du III s. comme original, au-delà du caractère formel d'une petite agglomération organisée. On note en effet l'existence d'un hameau ou village d'environ 3000 à $5000 \mathrm{~m}^{2}$ de superficie ( $\left.n^{\prime \prime} 3\right)$, établi en terrasses sur un coteau, apparemment peu ou pas défendu. Une des ruelles mène à la porte d'une fortification accolée qui enserre uniquement la partie sommitale ( $n^{o s} 1$ et 2). Courtine et bastion(s) protègent des aménagements de vie sur environ $1500 \mathrm{~m}^{2}$, sans doute des cellules domestiques mais aussi des entrepôts de stockage de céréales. Au moment de la destruction vers 200 , des chevaux avaient été réunis dans l'enceinte, ainsi que des équipements militaires. Des fragments de piliers peints comme ceux d'une statuaire, plus ancienne au plan stylistique, ont appartenu à un lieu cultuel, en usage vers 300-225 av. J.-C. À ce moment-là, espace fortifié et village accolés (ouvert ?) forment une conjonction originale qui laisse entrevoir la probabilité d'une (modeste ?) résidence domaniale de l'aristocratie celto-ligure, habitat rural d'une famille entouré des structures villageoises et agricoles pour ses ouvriers et dépendants : a, vue du site, avec la plaine de l'Arc $\left(n^{\prime \prime} 4\right)$; b, plan général des vestiges (état en 1999 ; échelle: $1 / 2000) ; c$, plan interprétatif des trois secteurs ( $n^{\prime s} 1$ et 2 : plateau et cour basse de la partie fortifiée; $n^{\prime \prime} 3$ : secteur du village structuré accolé ; échelle : $1 / 1$ 000) (a, cliché L. Chabot ; b, d'après Boissinot, 1998b, p. 42; c, d'après Boissinot, Gantès, 2000, p. 262). 


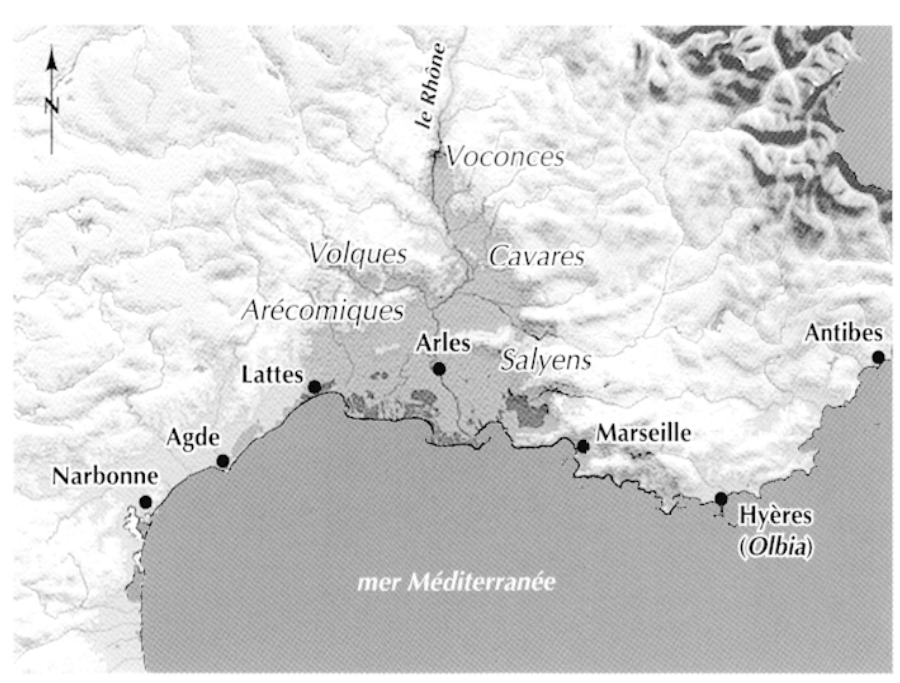

Fig. 6 - Indication de l'aire considérée sur la façade méditerranéenne de la Gaule et des principales fédérations de peuples au cours du second âge du Fer (I)AO P. Arcelin, CNRS).

rhodanien et de considérer leur degré d'évolution jusqu'à la conquête romaine de la fin du $\mathrm{II}^{\mathrm{e}} \mathrm{s}$.

Le premier est de nature culturelle et économique. Il découle d'une apparente unification qui est celle de l'étendue du domaine marchand de la colonie grecque de Marseille dont le marché atteint le maximum de son expansion au début du IV's. av. J.-C. La cité phocéenne a établi son activité à la fin du $\mathrm{VI}^{\prime \prime}$ et au $\mathrm{V}^{\prime}$ s. par le biais de ses relais rhodaniens, la tentative coloniale d'Arles sur le fleuve d'une part (Arcelin, 2000c) et de comptoirs indigènes en arrière du littoral d'autre part, comme ceux d'Espeyran à Saint-Gilles (Barruol, Py, 1978) et du Cailar, dans le Gard (Py et al., 2002). Ce véritable monopole se maintiendra au moins jusque dans les premières années du II $^{\mathrm{c}} \mathrm{s}$., cédant alors rapidement du terrain face aux importations de l'Italie romaine (Bats, 1992, p. 273-277). On a depuis longtemps souligné le rôle de ces circuits commerciaux dans la dynamique des cultures indigènes du second âge du Fer au moment de la structuration politique des grands peuples qui les composent, Volques Arécomiques sur la rive droite du fleuve, Salyens et Cavares sur l'autre. Inévitablement avec les produits de l'échange circulent hommes et idées, comme se modifient ou se cristallisent les rapports sociaux des groupes humains sollicités ou marginalisés. La fondation d'une colonie phocéenne sur le site d'Arles à la fin du $\mathrm{va}^{\mathrm{c}} \mathrm{s}$. et l'évolution de ses populations à partir de la fin du ves. (Arcelin, 1995, p. 335)336 et 2000 c, p. 17-19) ont inévitablement constitué sur le fleuve un foyer d'hellénisation dont l'empreinte transparaîtra encore à l'époque romaine dans l'école de rhétorique grecque d'un Favorinus, l'épigraphie ou les choix décoratifs de l'architecture monumentale de la ville (Constans, 1921 ; Gros, 1987). Comment alors ne pas s'interroger sur l'impact que l'apparent synœcisme des populations du port d'Arelate a pu exercer sur les cultures celtisantes voisines, entre le $\mathrm{IV}^{\mathrm{k}}$ et le $\mathrm{II}^{\mathrm{e}} \mathrm{s}$. av. J.-C. ? Surtout si l'on constate que, dans le même temps, les communautés proches de la ville grecque de Marseille entretiennent un climat de tension permanente, par leur attitude hostile et leurs pillages, essaimé de conflits violents que nous rapportent les textes anciens ! Cette apparente dichotomie comportementale au sein des sociétés indigènes régionales suggère l'existence d'un noyau de lente intégration culturelle philhellène au cœur de la vallée du Rhône qui s'oppose de fait à l'environncment plus traditionaliste de la métropole phocéenne (Arcelin, 2003 ; Arcelin, Chausserie-Laprée, 2003). Apparemment, cette dernière considérait les territoires entourant sa chôra politiké comme autant d'espaces d'exploitation économique pour ses marchés transméditerranéens.

Le second critère est de nature plus purement archéologique. Contrairement aux régions voisines, la recherche du demi-siècle écoulé dans la basse vallée du Rhône a, incontestablement, favorisé l'exploration des agglomérations de cette période (fig. 1). Elle offre aujourd'hui une bonne base documentaire tant par le nombre d'habitats explorés et répartis sur la durée de l'âge du Fer, que par les superficies dégagées dans plusieurs d'entre eux (fig. 7). Associées aux allusions historiques ou sociologiques des textes anciens, à l'iconographie sculpturale montrant l'existence d'une classe équestre et aristocratique aux III $^{\mathrm{e}}$ et II $^{\mathrm{e}}$ s. av. J.-C., comme aux précieux enseignements des mobiliers de plusieurs habitats violemment détruits par incendie, les sources d'information issues de la recherche de terrain peuvent ici, mieux qu'ailleurs dans le Midi, contribuer à l'analyse des degrés de transformation intervenue dans la structuration des habitats groupés au fil des siècles et à en percevoir les causes probables.

\section{LA CONSTITUTION DES HABITATS GROUPÉS AU PREMIER ÂGE DU FER}

\section{LA FIN DE LA PRÉHISTOIRE RÉCENTE}

La connaissance des premières agglomérations de la fin de l'âge du Bronze n'est que très superficielle dans ce secteur du Midi pour la seule raison que peu de fouilles extensives nous renseignent sur l'ordonnancement des espaces bâtis. Au vu de la documentation disponible pour la période du Bronze final et du tout début de l'âge du Fer (jusqu'au début du vic s. av. J.-C.), les premiers regroupements en plein air s'implantent en des lieux topographiques variés dont ceux perchés sur des éminences ou de petits plateaux. De même, un large éventail est constaté dans les superficies occupées, des constructions isolées assimilables à des fermes aux premières étendues de plusieurs hectares, témoins de profondes transformations dans le comportement social des communautés locales. Peu de sites ont fait l'objet de recherches de quelque ampleur, tant en plaine (ainsi au Touar dans le Var ou sur les bords de l'étang de Mauguio dans l'Hérault) qu'en hauteur (par exemple au BaouRoux près de Marseille ou à La Liquière de Calvisson dans le Gard). De l'ensemble des constatations archéologiques se dégagent quelques caractères technologiques et structurels. Les constructions, généralement de superficies modestes (10 à $15 \mathrm{~m}^{2}$ ), sont de plan ovoïde, quadrangulaire ou absidial. Elles sont édifiées sur poteaux porteurs ou sur sablières, avec parois et toiture de torchis sur armatures de végétaux souples. Ces espaces couverts sont séparés les uns des autres par des aires ouvertes. La première impression est celle d'un rassemblement 


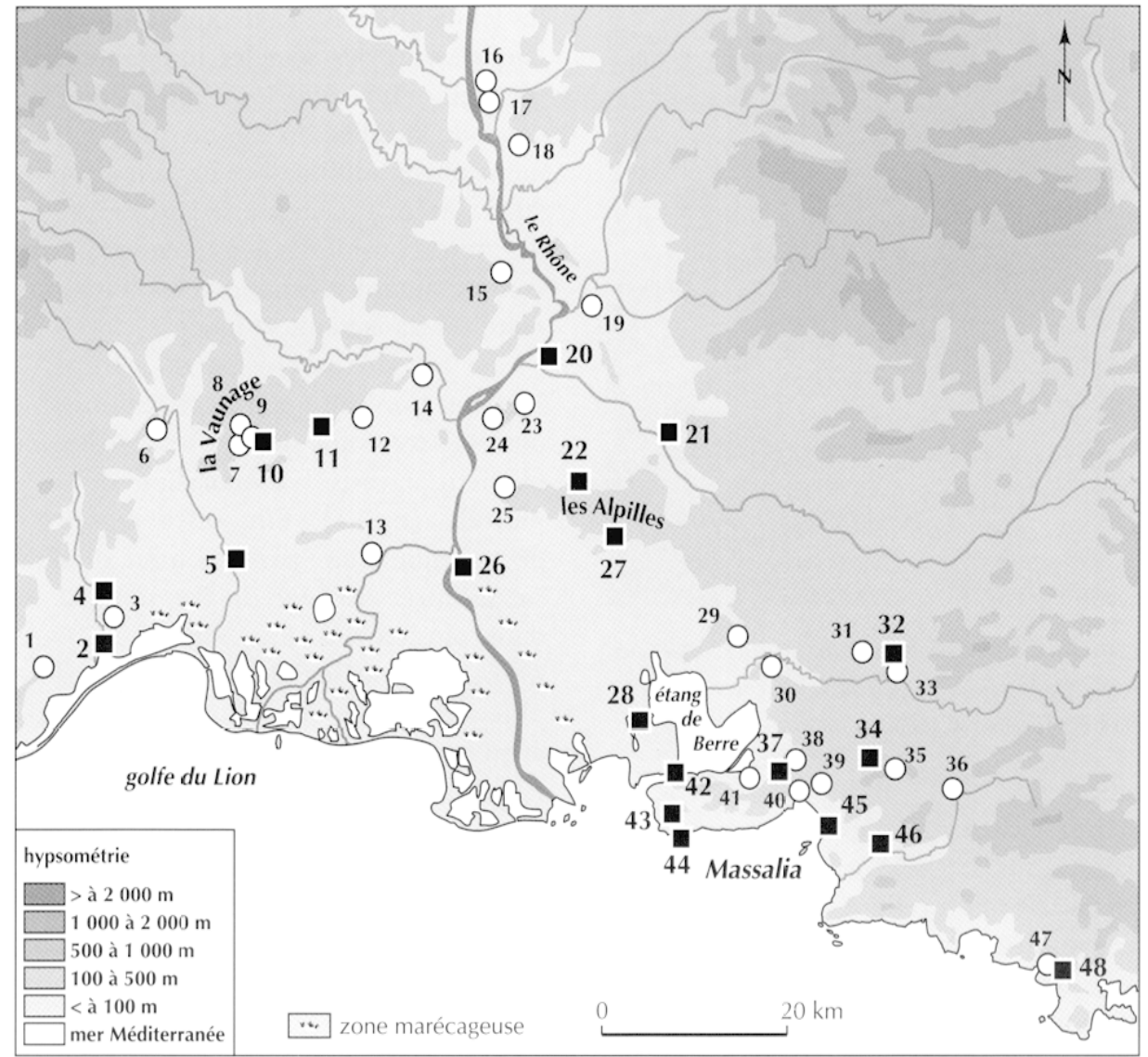

Fig. 7 - Carte de répartition dans la basse vallée du Rhône el ses abords des principaux habitats groupés (carrés noirs) et des autres aménagements ou habitats mineurs analysés dans cet article (ronds blancs) : 1, La Roque à Fabrègue; 2, Saint-Sauveur à Lattes; 3, Montpellier (ville) ; 4, Sextantio à Castelnau-le-Lez ; 5, Ambrussum à Villetelle; 6, Le Plan-de-la-Tour à Gailhan ; 7, La Liquière à Calvisson ; 8, Mauressip à Saint-Côme-et-Maruéjols; 9, Roque de Viou à Saint-Dionisy; 10, Les Castels à Nages-et-Solorgues ; 11 , Nimes (Nemausus) ; 12, Peyrouse à Marguerittes ; 13, Espeyran à Saint-Gilles ; 14, Le Marduel à Saint-Bonnet-du-Gard; 15, Saint-Vincent à Gaujac ; 16, Lapratle à Lamotte-du-Rhône; 17, Les Contras à Lapalud ; 18, Mornas (oppidum); 19, Le Mourre de Sève à Sorgues ; 20, Avignon (Avenio) ; 21, Cavaillon (Kabellio) ; 22, Le Mont Gaussier et Glanon à Saint-Rémy-de-Provence ; 23, Le Mourre Pela à Graveson ; 24, Le Pas de Bouquet à Tarascon ; 25, Saint-Gabriel et Ernaginon à Tarascon ; 26, Arles (Thelinc/Arelate); 27, Les Caisses c̀ Mouriès ; 28, Saint-Blaise à SaintMitre-les-Remparts; 29, Coudounèu à Lanfon-de-Provence; 30, Roquepertuse à Velaux ; 31, Pierredon à Égniilles ; 32, Entremont à Aix-enProvence; 33, Aix-en-Provence (Aquae Sextiae) ; 34, Le Baou-Roux à Bouc-Bel-Air; 35, La Teste-de-l'Ost à Mimel ; 36, Le Baou-Rouge à Auriol; 37, La Cloche aux Pennes-Mirabeau ; 38, Teste-Nègre aux Pennes-Mirabeau ; 39, Les Mayans à Septèmes-les-Vallons ; 40, Le Verduron ¿̀ Marseille; 41, Notre-Dame-de-Pitié à Marignane; 42, L'île à Martigues ; 43, Saint-Pierre à Martigues ; 44, Tamaris et L'Arquet à Martigues ; 45, Marseille (Massalia) ; 46, Les Baou de Saint-Marcel à Marseille, 47, Le Mont-Garou à Sanary-sur-Mer; 48, La Courtine à Ollioules (échelle : $1 / 1000000 ;$ DAO P. Arcelin, CNRS).

de bâtiments de fermes (avec des structures agricoles extérieures) dont les enclos se limiteraient désormais aux aires de mitoyenneté. L'apparente désorganisation spatiale est, en fait, le reflet de cet assemblage de constructions rurales familiales, soit distribuées en bordure de plateau comme à La Liquière ( $\mathrm{Py}$ et al., 1984, p. 295-296; Py, 2003, p. 107-109) ou le plus souvent en fonction de la topographie des licux (Arcelin, Brémond, 1977; Py, 1990a, p. 39-41 et 735-736), soit régulièrement réparties sur plusieurs hectares comme dans le hameau de Laprade à Lamotte-du-Rhône dans le Vaucluse (Billaud, 1999, p. 610, fig. 2) ou de façon plus compactée, comme au BaouRoux à Bouc-Bel-Air, semble-t-il (Boissinot, 1989). Dans la région rhodanienne, aucune fortification n'est assurée à l'extrême fin du Bronze ou au tout début du Fer, contrairement à la délimitation fossoyée et palissadée du petit village de Portal-
Vielh à Vendres (Hérault) (Carozza, 1996) ou aux enceintes en pierres sèches de Malvieu à Saint-Pons-de-Thomières (Hérault) ${ }^{6}$ et du Cros à Caunes-Minervois (Aude) (Gascó, 2000). Que la structuration soit lâche ou plus régularisće, le trait dominant est celui de la faible densité de populations regroupées par unité de superficie occupée. Autour des structures bâties abritant personnes et réserves alimentaires, chaque famille conserve un espace ouvert conséquent, encore utilisé comme une cour de ferme. Les constructions, en matériaux légers et souvent refaites, soulignent la précarité persistante des implantations sur les territoires et la mobilité toujours forte des populations concernées.

6. Fouilles A. Gorgues en cours. 


\section{LES PREMIÈRES MUTATIONS DE LÂGE DU FER}

C'est dans ce contexte humain, lié à une économie productive et donc à de forts courants d'échanges attestés par le mobilier de l'habitat précédent de Laprade (Billaud, 1999, p. 613-617), que des modifications majeures vont apparaître dans les agglomérations du premier âge du Fer. Le phénomène éclôt sur le littoral, près de la colonie grecque de Marseille, dès le deuxième quart du $\mathrm{vI}^{\mathrm{e}} \mathrm{s}$. av. J.-C., pour se répandre par étapes le long des côtes et à proximité du fleuve dès le dernier quart du siècle. On a souligné depuis longtemps le rôle stimulant des Phocéens dans ces manifestations pour ne pas y revenir (Goudincau, 1980, p. 184-185). À partir de deux exemples pris dans la région marseillaise, il est possible de définir la nature et le sens des mutations structurelles et architecturales qui interviennent alors dans l'habitat groupé.

\section{LES AJUSTEMENTS INITIAUX : L'HABITAT DE TAMARIS À MARTIgufs}

Le promontoirc de Tamaris, sur la côte méridionale de la commune de Martigues, porte un habitat de la première moitié du $\mathrm{VI}^{\circ}$ s., avec quelques traces d'unc occupation jusque vers 475 dans sa partie méridionale (fig. 8, zone 1). Sondé dans les années 1960, l'habitat de 1,5 ha de superficie fait à nouveau l'objet de fouilles extensives (Duval, 1998, 2000 et 2003). Les premiers résultats et les traces de surface montrent une occupation bâtie très regroupéc, en îlots ou en files, avec des constructions à murs porteurs sur solins de pierres sèches. Des ruelles, au sol en terre battuc, desservent l'espace de ce rassemblement selon un plan dendritique qui semble se structurer sur les axes naturels de la topographie du site. Deux lignes de défense sont repérées dont une porte à recouvrement, protégée par un bastion (point A). Outre l'observation précoce de ce phénomène de compactage des constructions sur un minimum de superficie, sous la protection de lignes défensives en pierres et terre, l'intérêt majeur de ce site est de fournir les étapes du processus de concentration, avec ses tâtonnements architecturaux et techniques. La prime implantation, datée du premier quart du $\mathrm{I}^{\mathrm{t}} \mathrm{s}$ s., est toujours caractérisée par la présence de pièces absidiales, sur poteaux porteurs. Une construction de cette nature a été fouillée sous la zone 2 (fig. 8). Peu après, durant le deuxième quart du siècle, succèdent les premières édifications en dur (sur solins de pierre) auxquelles restent associées des parois sur poteaux. Mieux encore, les salles désormais quadrangulaires, de 5 à $15 \mathrm{~m}^{2}$ de superficie, peuvent être soit seulement rapprochées ou accolées selon des alignements approximatifs (zone 2), soit à parois mitoyennes, disposćes en files ou en îlots apparemment mieux délimités (zones 1 et 3). Les pièces ainsi créées peuvent s'ouvrir individuellement sur les ruelles de circulation, ou communiquer entre elles pour former des habitations à plan complexe.

Trois éléments structurants des habitats de l'âge du Fer thodanien sont présents ensemble à Tamaris pour la première fois vers 575 . Tout d'abord, les habitations et les locaux viviers de plusieurs centaines de personnes sont regroupés et l'on peut même dire compactés sur un site de superficie restreinte, ne laissant qu'un minimum d'espaces ouverts pour la seule

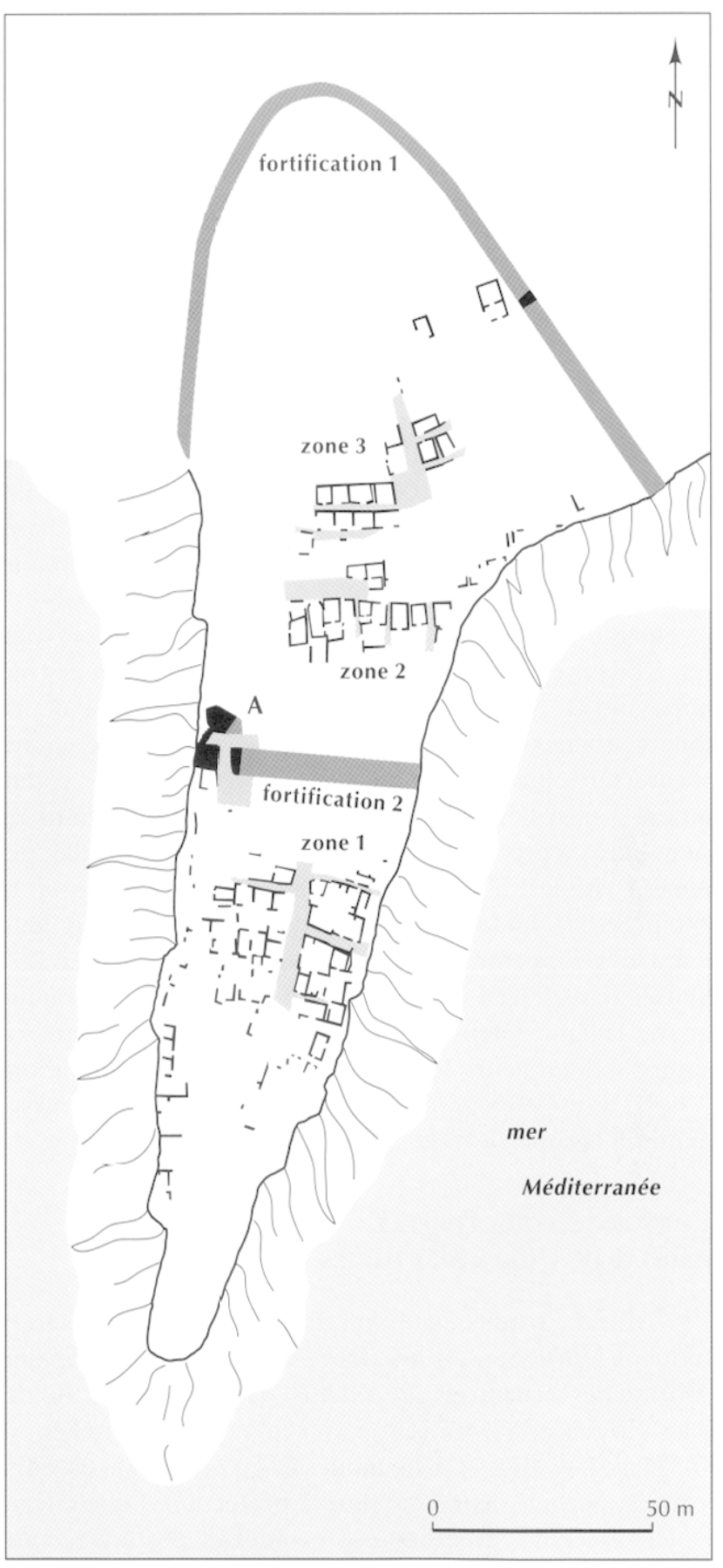

Fig. 8 - Plan des installations de l'agglomération de Tamaris a Martigues (Bouches-du-Rhône). Le premier état remonte vers 600 et la première moitié du it s. av. J.-C. correspond apparemment à la plus grande extension de l'habitat. Les traces d'une occupation existent jusque vers 475 av. J.C.C. Les trois zones explorées montrent différents modes d'édification qui soulignent les étapes et les hésitations dans le passage des constructions sur poteaux porteurs, nettement séparées, à celles à murs massifs mitoyens qui deviendront la règle dans la région à la fin du premier âge du Fer. Á la différence des réalisations en files des zones 2 et 3, celles de la zone 1 en îlots sont aujourd hui moins explorées et donc moins bien connues dans l'assemblage des espaces tant outuerts que fermés (échelle: $1 / 2000$; DAO M. Rélif, Service archéologique de Martigues, d'après

Duval, 2000, p. 168). 
desserte élémentaire des pièces, rejetant du même coup vers l'extérieur les lieux non bâtis plus amples et indispensables à toute vie communautaire (aires de battage, enclos des troupeaux, les espaces de réunion collectifs et cultuels...). Le deuxième élément de définition est d'ordre technologique et lié au précédent: la substitution, déjà très marquée ici, des élévations en torchis sur armatures de bois au profit des murs porteurs (pierres à sec et certainement briques de terre crue) (Chazelles-Gazzal, 1997). Ce mode d'édification permet la réalisation des murs mitoyens, principe dorénavant constitutif de l'architecture des agglomérations, à de rares exceptions près. Par ailleurs, elle offre l'avantage d'être un palliatif à la raréfaction des bois de construction qui doit se faire sentir dans le Midi dès cette époque (Chabal, 1997, p. 75-91 ; Vernet, 1997, p. 35-37). Troisième caractère désormais présent dans l'habitat groupé de la basse vallée du Rhône, la fortification à parements en pierres sèches (Arcelin, Dedet, 1985; Py, 1993, p. 98-100). La courtine (ou ailleurs courtine et bastions) s'inscrit clairement ici dans une volonté de défense des hommes et des biens composant la petite communauté locale, même si d'autres habitats proches et de peu ultérieurs peuvent mettre en avant des caractères jugés plus prestigieux pour le pouvoir communautaire: ainsi l'enceinte des Mayans avec ses bastions quadrangulaires repris des défenses archaïques de Marseille, pratiquement visibles depuis le site indigène (Hermary $t$ al. dir., 1999, p. 88-89). La fortification est dépendante de la limitation de son développement pour atteindre à un réel pouvoir de défense. Dans le cadre d'une communauté limitée, comme à Tamaris, la ligne défensive la plus vulnérable a tout intérêt à restreindre son ampleur; le meilleur moyen pour l'obtenir, outre le choix d'une topographie favorable, est de concentrer au maximum la superficie des espaces bâtis protégés.

\section{LA MATURITÉ STRUCTURELLE : L'HABITAT DE L'Île À MARTIGUES}

Le village fortifié établi sur l'île du chenal de Caronte, toujours à Martigues, est un autre exemple du développement des principes structurels précédents, dans un habitat de deux siècles ultérieurs, à la transition avec le second âge du Fer : vers 450-375 av. J.-C. (fig. 9). Une modeste agglomération est édifiée sur une superficie de 0,5 ha, sous la protection d'une enceinte en pierres sèches, avec bastions ovoïdes et porte à recouvrement. À l'intérieur, des cellules d'habitation de taille réduite, avec leur stockage vivrier, s'ouvrent presque toutes individuellement sur les ruelles de desserte ou de très petites placettes. Les constructions sont disposées en files ou rassemblées en îlots (Chausserie-Laprée et al., 1984 ; Chausserie-Laprée, Nin, 1990). Aucun espace ouvert de quelque ampleur ne permet d'envisager des manifestations villageoises collectives intra muros et les étroites voies de desserte sont en partie accaparées par certaines pratiques familiales telles les cuissons sur plaque-foyer (Nin, 1999, p. 225-232). Par ailleurs, l'excellent état de conservation des aménagements domestiques, suite à un incendie, montre la répétition d'un espace à l'autre des éléments du stockage familial vivrier et de son traitement au quotidien (récipients de réserve en terre crue, mouture, fours et foyers...). Toutes ces cellules révèlent les vestiges de la vie usuelle de

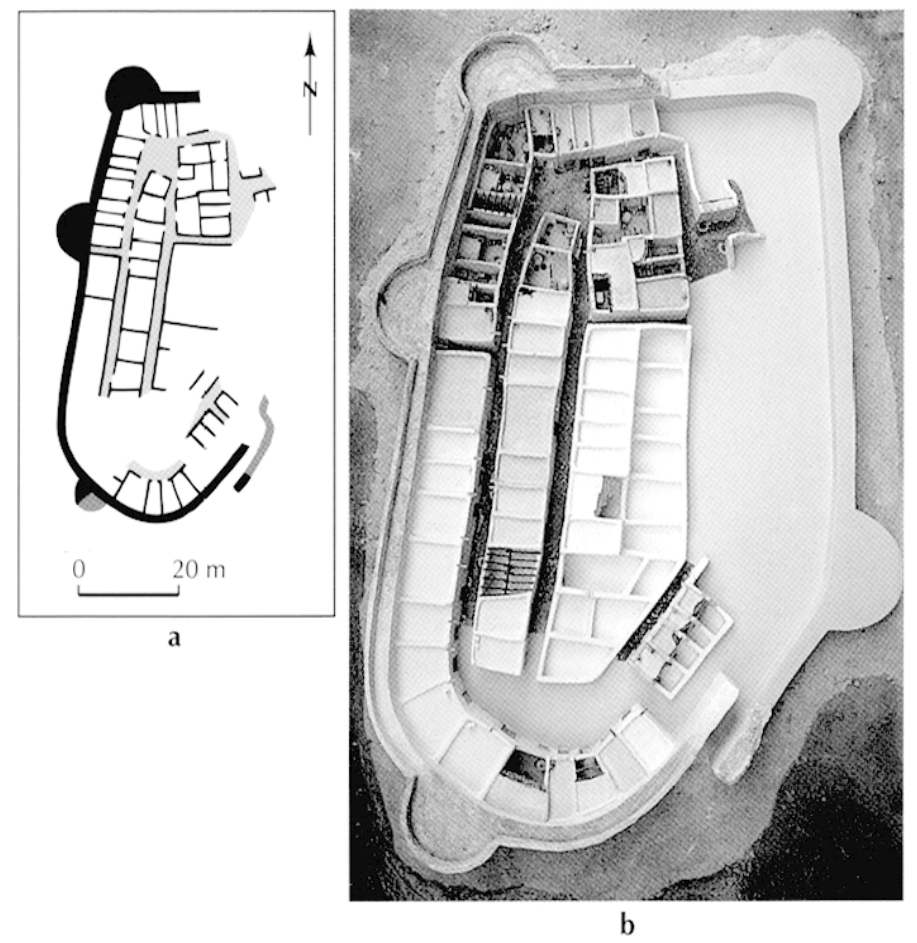

Fig. 9 - Fouillée sur plus de la moitié de sa superficie (environ $0,5 \mathrm{ha}$ ), la bourgade implantée au v' s. dans l'île de Martigues (Bouches-du-Rhône) est maintenue sur les bases de sa création jusque. vers 200 av. J.-C. Exceptionnellement conservée par des incendies successifs, elle permet de percevoir avec acuité les principes d'organisation planifiée en files et petits îlots qui sont ceux mis en auvre dans une large part des habitats groupés de la basse vallée. du Rhône dès la fin du premier âge du Fer. Aucune édification collective n'a été repérée dans cette enceinte : a, plan de l'état des années 425-375 av. J.-C.; $b$, maquette de restitution de l'habitat à la même époque ( $a$,échelle: $1 / 2000 ; D A O M$. Rétif, Service archéologique de Martigues ; b, D. Delpallilo, d'après ChausserieLaprée dir., 2000, p. 50).

noyaux familiaux relativement autonomes, modestes et de ce fait apparemment égalitaires, vivant pour l'essentiel de l'activité des pratiques agricoles et des compléments de la pêche (Chausserie-Laprée, Nin dir., 1988, p. 92-97). Sans discuter ici de l'existence ou non d'un premier étage sur les structures archéologiques en rez-de-chaussée, on peut, de l'analyse des vestiges bâtis lisibles et des mobiliers (ibid., p. 87-88; Rétif, 2000), conclure à l'absence d'éléments soulignant une éventuelle différenciation sociale entre ses habitants. De plus, aucun aménagement collectif, hormis la fortification, ne suggère ici autre chose qu'un rassemblement de familles vouées, pour l'essentiel, aux travaux des champs ou de l'élevage, et réunies dans un village au plan structuré par un pouvoir politique visiblement coercitif. Malgré son enceinte, l'habitat de l'île n'apparaît pas comme une entité sociale dans son environnement agropastoral ou économique, mais comme une composante du territoire d'exploitation, un quartier d'habitations concentré pour regrouper et protéger une petite population, « outil » essentiel de la productivité rurale. À l'évidence ici, les espaces d'usage collectif pour les travaux agricoles, ceux liés 
aux festivités et au culte sont à rechercher ailleurs, sans doute sur une des rives du chenal de Caronte.

C.c village de Martigues, assez exceptionnel par son état de conservation et l'ćtendue des fouilles qui s'y sont déroulées, est asse $z$ emblématique des agglomérations bas-rhodaniennes de la fin du premier âge du Fer, quelles qu'en soient les variantes topographiques et les réponses structurelles locales. Mais aux côtés des nombreux sites de petites et moyennes superficies, couvrant quelques milliers de mètres carrés aux environs de 4 à 5 ha, et dont les activités agropastorales paraissent dominantes, d'autres, de moyenne ou de plus vaste superficie (jusqu'à 10 ha environ), peuvent présenter un faciès davantage tourné vers l'artisanat et le commerce, déterminant du même coup l'émergence de pôles économiques régionaux. Certains, comme Le Mourre de Sève à Sorgues (Vaucluse), ont joué à la fin du vi ${ }^{\circ}$ et au $\mathrm{v}^{\prime \prime} \mathrm{s}$. un rôle actif dans la fabrication et peut-être la distribution de vaisselles céramiques en Provence occidentale et même au-delà (Arcelin-Pradelle, 1984, p. $128-129$ et 146 ; Informations archéologiques de Gallia, 42, 2, 1984, p. 428). Mais dans l'exemple présent, les retombées bénéfiques ne sont qu'immédiates pour le village qui disparaîtra peu après, au début du second âge du Fer. Pour d'autres habitats, dont la taille croissante semble résulter de la dynamique d'un commerce plus complexe et diversifié, l'évolution des mobiliers et de leurs proportions laisse entrevoir des transformations économiques profondes, aux conséquences culturelles différées. Prenons en exemple les habitats de Saint-Blaise, non loin de Martigues (Arcelin, 1986a, p. 56 et 82-84; Bouloumié, 1992, p. 270-272 ; Py, 1993, p. 112-115), de Nîmes dans le Gard (Py et al., 1981, p. 51-81 ; Monteil, 1999, p. 307-320) ou encore celui du port indigène voisin d'Espeyran à Saint-Gilles (Barruol, Py, 1978, p. 86-100 ; Bats, 1992, p. 270-273). Dans les deux premiers cas, les contacts économiques développés avec le monde marseillais et méditerranéen dans un milieu indigène culturellement favorable s'avéreront à terme déterminants dans le devenir de ces habitats et de leur communauté. Espeyran se maintiendra comme un lieu d'importation dyna-mique jusque vers les années 175 av. J.-C. (Bats, 1992, p. 274-275). C'est, en effet, au $\mathrm{II}^{\circ}$ s. av. J.-C., à travers les conséquences de leur lente ćvolution stimuléc par les nouveaux rapports au monde italique, que la portée initiale de ces anciennes relations prendront tout leur sens.

\section{Planimétrie Rationalisée ou URBanisation ?}

Demeurent à ce stade deux interrogations majeures liées. La première concerne l'origine des transformations structurelles et architecturales, avec leurs recours techniques, qui s'imposent entre 575 et 400 av. J.-C. dans les agglomérations groupées du Midi gaulois: résultent-elles pour l'essentiel de propositions méditerranéennes diffusées par Marseille grecque et ses premic̀res colonies, telle Arles? L'organisation planimétrique des habitats, les techniques mises en oeuvre pour les concevoir, ou encore leur système défensif prennent-ils naissance dans des " modèles " extérieurs aux cultures régionales? La seconde est celle de l'interprétation de ces évolutions. Par-delà l'image de groupes humains socialement très structurés et hiérarchisés dans une économie de productivité, quant à elle nettement dynamiséc par l'appel économique des négociants grecs et de leurs relais régionaux, peut-on lire dans la structuration rationalisée des pièces d'habitation, leur mode d'assemblage, leur desserte et leur système de protection, la première étape d'une forme "d'urbanisation "? En somme, serait-ce le moment d'une mutation des sociétés de la fin de la Préhistoire conduisant à l'éclosion, désordonnée certes mais inéluctable, de réseaux d'agglomérations regroupant l'essentiel des hommes et des pouvoirs sur leurs territoires d'exploitation ou en des points économiquement favorables (Garcia, $2000 \mathrm{~d}$, p. 52-56) ?

Nous avons déjà répondu pour une large part au questionnement technique et formel précédent pour la proche région de Marseille (Arcelin, 1992a, p. 318-319). On peut ici en amplifier la portée à la basse vallée du Rhône dès la fin du premier âge du Fer. L'essentiel des pratiques observées dans les habitats de cette époque correspond bien à un renouvellement en regard des usages de la fin du Bronze. Mais le savoir-faire est puisé dans un fonds culturel plus ancien, remontant au Néolithique et au début du Bronze. Ainsi les constructions aux murs porteurs en pierre trouvent-elles aisément des correspondances à ces époques dans les villages et hameaux des plateaux languedociens ou provençaux (Camps-Fabrer et al., 1985) et, depuis peu, l'usage de formes de "briques " en terre crue est reconnu à Marguerittes (Gard) ou à Montpellier, près de Port Marianne (Hérault) (Jallot, 1998). Mais en dépit des ressources inhérentes au fonds du patrimoine culturel indigène, la mise en œuvre de procédés comme l'édification de parois mitoyennes à Marseille, même dès la première génération (Gantès, Moliner, 1990), a dû être très vite un puissant stimulant pour l'éclosion des potentialités de l'environnement autochtone. De même, dans leur majorité, les systèmes défensifs des $\mathrm{VI}^{\mathrm{k}}$ et $\mathrm{V}^{\mathrm{c}} \mathrm{s}$., avec courtine, bastions ovoïdes et porte à recouvrement (fig. 10), ne font que réactualiser des réalisations indigènes de la Préhistoire récente (Camps-Fabrer et al., 1984; D'Anna, Gutherz dir., 1989). L'influence des modèles grecs qui transparaît dans la forme quadrangulaire des bastions de quelques enceintes (aux Mayans, aux portes de Marseille; au Mont-Garou près de Sanary-sur-Mer; à Graveson dans la Montagnette; plus à l'ouest, à La Roque de Fabrègues) ne prend tout son sens que dans l'ajout d'une référence plus prestigieuse à ces édifications collectives. Demeure la structuration planimétrique des regroupements de cellules familiales, disposées en files ou îlots étroits, et la conception de leur liaison par une voirie plus ou moins régularisée. Le regard que l'on porte fréquemment vers le monde méditerranéen pour tenter d'expliquer ce mode de rationalisation des habitats groupés méridionaux, avec leur processus de compactage extrême des espaces ouverts, n'est certainement pas la meilleure démarche. La documentation publiée sur la colonie phocéenne de Marseille ne précise l'existence de trames urbaines et une division de son habitat en îlots régularisés qu'au début du $\mathrm{IN}^{\mathrm{N}}$ s., même si l'on a récemment montré qu'une organisation de l'espace bâti est déjà perceptible en certains secteurs dès le deuxième quart du $\mathrm{VI}^{\mathrm{c}} \mathrm{s}^{\prime}{ }^{\prime}$

7. Cependant, les fouilles de 2002 près de la cathédrale de La Major ont montré l'existence de rues parallèles dès le deuxième quart du VI" s. av: J.C.C. (Guillaume et al., 2002, p. 111). 


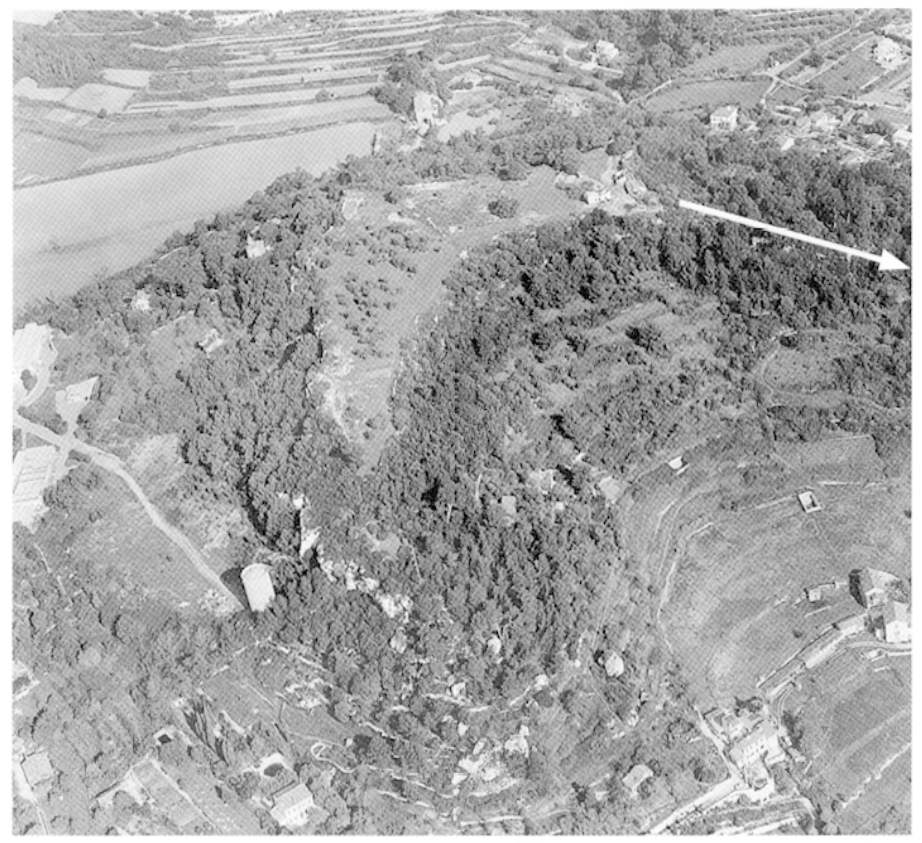

a

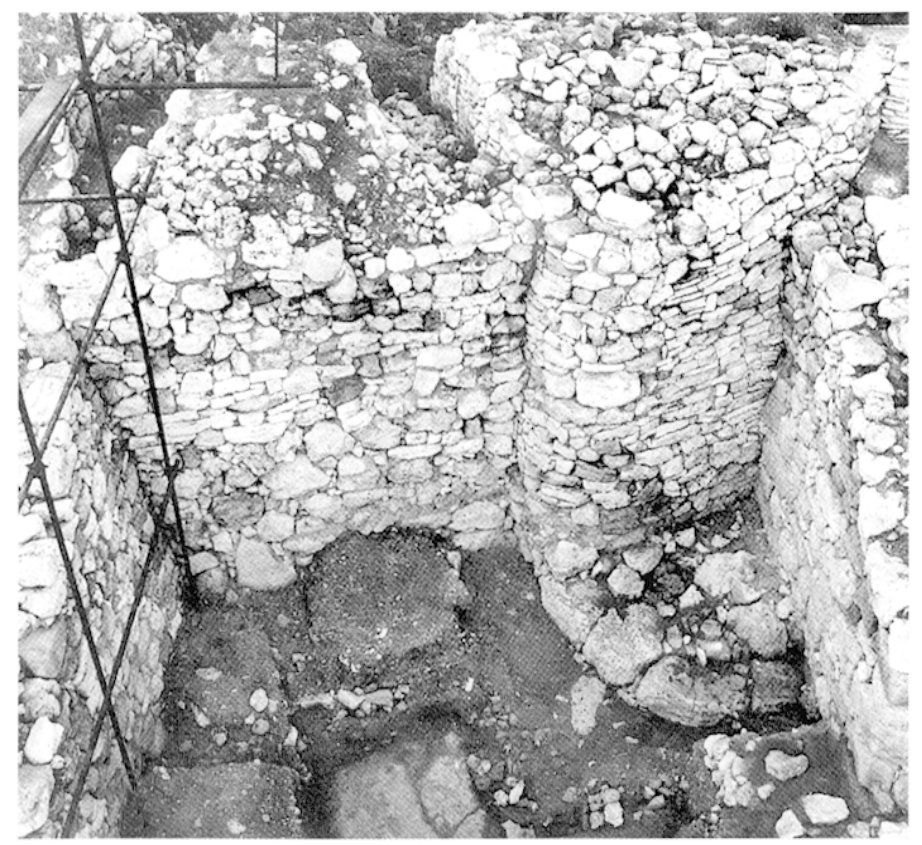

b

Fig. 10 - La fortification en pierres sèches, avec courtine et bastions ovoüdes, est un élément majeur et fondateur des habitats groupés du bas-Rhône dès le ir s. ar. J.-C. La première enceinte, qui protégeait l'accès oriental au plateau de 4 ha de superficie des Baou de Saint-Marcel à Marseille (Bouches-du-Rhône), est une des plus anciennes de cette région, vers $575-550$ av. J.-C. : a, vuce cérienne du plateau; b, état de la fortification en 1966 (clichés: a, A. Chéné, Ceentre Camille-jullian, CNRS; b, P. Arcelin, CNRS).

(Moliner, 1999, p. 84). Par ailleurs, les quartiers périphériques de la colonie d'Arles ont révélé les premières images d'une structuration planimétrique d'ampleur au tout début du v"s. av. J-C., avec des îlots orthonormés séparés par de larges rues (Arcelin, 2000c). En Grande Grèce, c'est durant là première moitić du v' s. que se répand dans les villes coloniales le concept d'un urbanisme rationalisé, en grands îlots densément occupés et séparés par des voies d'importance hiérarchisée, avec l'intégration des aires de monumentalité (Mertens, Greco, 1996, p. 252-256). Reprenant les exemples précédents et en particulier celui de l'habitat ancien de Tamaris (fig. 8), il est clair que les premières installations à solins de pierre, établies durant le deuxième quart du $\mathrm{V}^{\circ}$ s., délivrent de précieuses informations pour notre interrogation. Son implantation côtière et la proximité de la colonic phocéenne de Massalia sont à n'en pas douter déterminantes dans la précocité du processus évolutif comme dans l'adoption de certaines options technologiques ou structurelles (telles les pièces communicantes). La succession observée en unc génération des étapes, ou plutôt semble-t-il des expériences presque simultanées du passage de l'habitation isolée sur potcaux porteurs aux îlots à pièces mitoyennes, est ici bien plus révélatrice d'une transformation de la politique de vie communautaire que du seul effet d'influences extćricures. Avec d'autres informations similaires entrevues sur le site proche de Saint-Blaise (Arcelin et al., 1983, p. 139-140), celui de Tamaris met bien en évidence le moment initial où les populations indigènes, sollicitées vers plus de productivité par une activité croissante de l'échange, ressentent un impérieux besoin de s'organiser avec davantage d'efficacité dans leurs espaces de regroupement. La présence quasi systématique d'une enceinte, le caractère compacté des lieux de la vie familiale, l'absence d'édifications collectives ou d'aires ouvertes importantes intégrées, soulignent sans ambiguité la motivation défensive première des agglomérations, qu'elles soient modestes ou vastes, à vocation purement agropastorale ou plus fortement connotées par la dynamique de leurs échanges. Dans leur principe, les systèmes organisationnels adoptés découlent du rapprochement, puis de la mitoyenneté en files de cellules aux murs porteurs, encore parfois curvilignes selon des traditions antérieures (Dedet, 1990), mais asse\% rapidement édifiées sur plan quadrangulaire, forme mieux adaptée à ce type d'assemblage architectural. Les îlots eux-mêmes résultent la plupart du temps de l'accolement de pièces sur un mur axial. Fréquemment séparés les uns des autres, les modestes espaces bâtis (entre 10 et $20 \mathrm{~m}^{2}$ de superficie) s'ouvrent individuellement sur de petits axes de circulation ( 1 à $3 \mathrm{~m}$ de largeur, très rarement au-delà), aires au sol peu ou pas aménagé, sans système de drainage des eaux autre que ponctuel. Ces espaces non bâtis déterminent un réseau dendritique entre les pièces dont il constitue le prolongement naturel en l'absence d'autres superficies libres disponibles, à l'exception peut-être des terrasses et de quelques cours. Des dépôts, foyers et fours sont fréquemment observés devant les habitations. Quelques petites placettes existent, mais elles sont souvent la résultante de la convergence en un point du site de plusieurs voies. Dans sa lente généralisation vers le centre de la basse vallée du Rhône et sa périphérie, du dernier quart du $V^{\prime \prime}$ s. au début du $N^{\circ}$ s. av. J.-C.. cette pratique planimétrique compactée est révélatrice d'une société en rapide sédentarisation, très structurée autour d'une multiplicité de petits pouvoirs microrégionaux. Ces derniers parais- 
sent soucieux de disposer sur les territoires d'exploitation de lieux sécurisés pour les populations et leurs ressources, l'artisanat et les produits de consommation, mais également capables de constituer d'éventuelles places fortes en cas de conflit. Il est bien difficile de lire dans les secteurs fouillés de la majorité des habitats ainsi organisés à la fin du premier âge du Fer d'autres informations que celles résultant de l'activité des unités domestiques, de leurs besoins vivriers et du petit artisanat indispensable à la vie agricole et familiale. S'il est vrai que nous connaissons très mal nombre d'agglomérations plus importantes et peut-être plus dynamiques, entre autres dans l'élaboration des réseaux économiques méridionaux ${ }^{8}$, on reste pourtant dubitatif sur la portée réelle de leurs éventuelles spécificités structurelles et architecturales susceptibles de les différencier radicalement de celles de regroupements plus modestes.

Outre que ce mode de planification des habitats groupés ne sera pas généralisé à l'ensemble de la région concernée avant le second âge du Fer (Dedet, 1999, p. 75), son adoption ne recouvre pas obligatoirement une transformation fondamentale des manières de la vie sociale et domestique, caractères essentiels à même de séparer au plan culturel de telles agglomérations des hameaux ou fermes dispersés sur le territoire. Ce n'est souvent que la rigueur contraignante de la planimétrie des constructions, imposée à ces regroupements humains, qui les différencie des autres plus modestes et qui, en toute logique, n'en ont pas réellement le même besoin. D'ailleurs, d'autres systèmes d'occupation moins concentrée de l'espace bâti existent : ils ne sauraient être qualifiés pour cela d'inorganisés ni même de non planifiés. Dans la seconde moitié du ves s. et le début du IV' s. av. J.-C., le cas du site du Plan de la Tour à Gailhan (dans le Gard) est de ce point de vue édifiant : les habitations à murs porteurs ou en torchis, réparties en files sur la bordure du plateau, conservent une certaine tradition des espaces mitoyens ouverts sous la forme d'une cour entourée de petits locaux annexes (Dedet, 1987 et 1990, p. 30-31). Au sein des sociétés régionales du $\mathrm{v}^{\mathrm{e}} \mathrm{s}$. av. J.-C., c'est davantage la manifestation du dirigisme qui transparaît dans ce type d'organisation concentrée et rationalisée de l'habitat que la lecture d'une mutation culturelle radicale des groupes humains qui les composent, tant par l'absence d'une complexification des niveaux d'activité que dans le maintien de leurs rapports traditionnels aux territoires d'exploitation. Comme l'a fort bien perçu M. Py jugeant du caractère foncièrement rural des grands habitats régionaux, les oppida apparaissent comme des "villes campagnardes" (Py, 1990a, p. 151). Seulement, nous rectifierons dans le cas présent l'expression " ville » par celles de " bourg " et de "bourgade " qui nous semblent bien mieux appropriées au moins jusqu'au début du II $^{\mathrm{c}}$ s. av. J.-C. par la connotation de marché et plus généralement, de lieu d'échanges qu'elles recouvrent. Nous y reviendrons.

8. Tels Glanon à Saint-Rémy-de-Provence ; Saint-Gabriel à Tarascon ou Les Caisses à Mouriès dans les Alpilles ; Le Mourre Pela à Graveson ou Le Pas de Bouquet à Tarascon dans la Montagnette; Saint-Blaise à Saint-Mitre-les-Remparts près de Marseille ; Avignon dans le Vaucluse ; Nîmes, Espeyran à Saint-Gilles, Le Marduel à Saint-Bonnet-du-Gard ou encore Saint-Vincent à Gaujac dans le Gard.

\section{UN PHÉNOMÈNE EUROPÉEN BIEN ANTÉRIEUR}

Enfin, pour estimer avec justesse la portée de ce mouvement de planification en files ou îlots des constructions au sein des habitats groupés, il convient de rappeler qu'il ne s'agit pas là d'une nouveauté propre au midi de la Gaule à partir de la fin du premier âge du Fer. En se replaçant dans la dynamique des cultures européennes de la Préhistoire récente, on constate qu'une telle tendance organisationnelle apparaît en fait de façon récurrente dès le Néolithique, en parallèle avec d'autres modes de structuration plus lâches (Pétrequin el al., 1999). Ultérieurement, le principe de régularisation de l'espace occupé se rencontre par exemple au Bronze ancien dans des habitats fortifiés terrestres, comme celui de Barca à Kosice en Slovaquie (Vladár, 1973) (fig. 11) ou encore au Bronze final dans les régions nord-alpines, en limite d'étendues humides comme à Cortaillod (Est et Les Esserts), Witzwil ou Bevaix-Sud sur les bords du lac de Neuchâtel (Egloff, 1981; Audouze, Buchsenschutz, 1989, p. 262-269; Arnold, 1992) (fig. 12). Dans ces derniers exemples, composant des villages de 0,2 à 0,8 ha, les habitations sont alignées, séparées par des ruelles, et une voie isole souvent la palissade de protection des premières constructions. Un dernier parallèle peut être observé en Pologne, au nord de la Warta, près de Gniezno, au tout début de l'âge du Fer (fin du vir ${ }^{\mathrm{e}}$ s. ou première moitié du

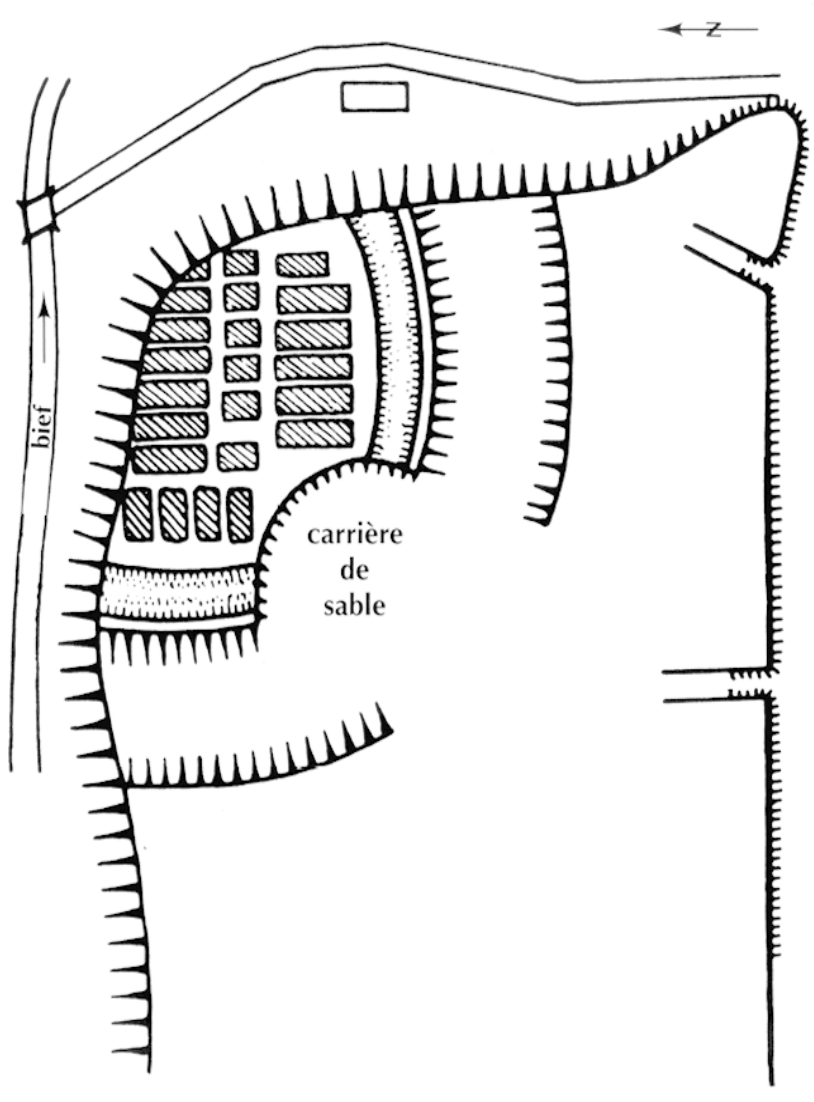

Fig. 11 - L'habitat fortifié de Barca, près de Kosice (Slovaquie), montre dès le Bronze ancien une volonté affirmée de structuration de son espace intérieur par un ordonnancement en files d'habitations à plusieurs pièces (d'après Vladár, 1973, p. 283). 


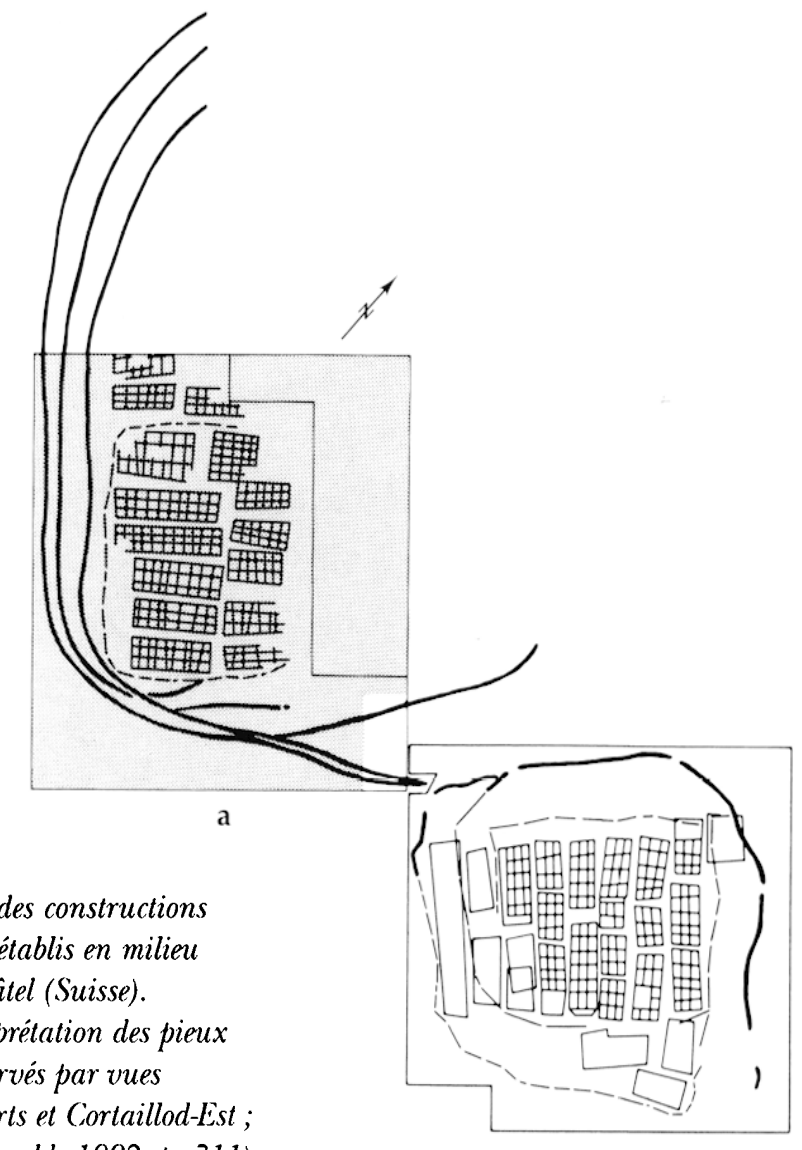

b
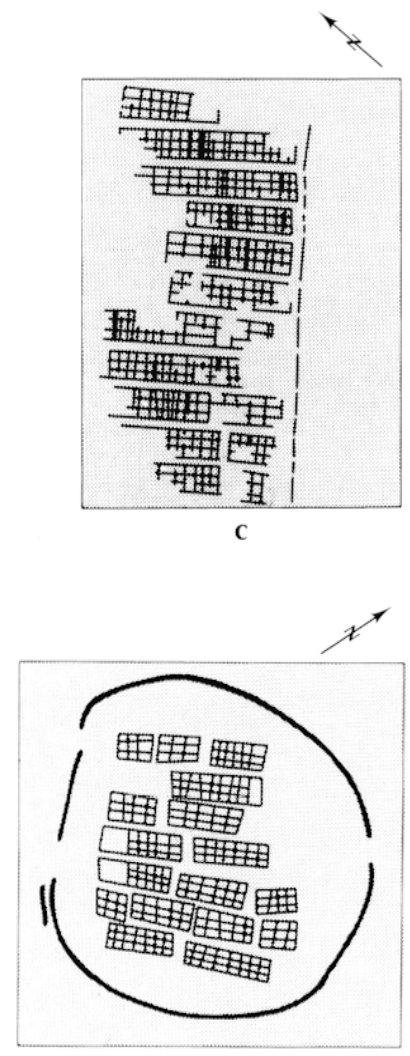

d $50 \mathrm{~m}$

$\mathrm{VI}^{\mathrm{e}} \mathrm{s}$.), avec le village fortifié de Biskupin. Ce dernier, avec une superficie totale de 2 ha entourée d'une ligne de défense élaborée, comporte une centaine d'unités d'habitation similaires réparties en 13 files resserrées, laissant un seul espace libre devant la porte (fig. 13). Aménagée sur une presqu'île marécageuse, cette édification villageoise en bois, complétée d'argile, de sable et de pierres pour les parements comme pour les soubassements de foyers, abritait derrière un puissant système défensif une population d'environ 800 à 1000 personnes (Brun, 1987, p. 153-155 ; Piotrowska, Piotrowski, 1990). À vocation agropastorale, cet habitat lusacien (et d'autres alentour de même nature) offre d'utiles rapprochements avec le système de l'organisation structurelle des agglomérations plus tardives de la basse vallée du Rhône; il permet de mieux percevoir la vocation première de ces regroupements compactés et protégés, à savoir la constitution de places fortes pour la protection des forces productives et de leurs familles, même si l'on ne peut exclure le pouvoir rassembleur de l'enceinte pour la communauté territoriale, ni son image valorisante pour ses dirigeants.

Existe-t-il en définitive des "villes " ou plus simplement, des agglomérations "urbanisées " dans la basse vallée du Rhône vers 400 av. J.-C. ? En refusant d'assimiler le mode formel de structuration en files et/ou en îlots de l'espace bâti des agglomérations fortifiées à la première étape d'une conception urbaine, la réponse sera globalement négative. Les Gaulois du Midi, comme leurs cousins plus septentrionaux, demeurent foncièrement ruraux malgré l'émergence d'un réseau de pôles économiques gravitant autour de bourgs majeurs et des formes d'une autorité édilitaire, encore aujourd'hui difficile à cerner (pour l'Europe occidentale, voir Fischer, 1999, p. 39-40). Nous aborderons plus loin un questionnement sur les lieux possibles du pouvoir, interrogation essentielle trop souvent esquivée ou contournée dans les régions méridionales de la Gaule. C'est au total vers le monde grec colonial que l'on se tournera pour proposer une réponse: la ville après les années 550, c'est Massalia, à terme facteur de transformation des cultures autochtones, avec l'appui très dynamique de sa première colonie, Theline/Arles sur le Rhône.

\section{LES AGGLOMÉRATIONS AU SECOND ÂGE DU FER \\ UNE REDÉFINITION RÉGIONALE DE NATURE ÉCONOMIQUE}

Deux caractères majeurs émergent en premier d'une analyse des habitats groupés bas-rhodaniens que l'on peut appréhender sur leurs territoires d'exploitation, entre le Iv $v^{*}$ s. et le $\mathrm{II}^{\prime \prime}$ s. av. J.-C. C'est d'abord le constat, au début de cette période, d'un arrêt, au mieux d'un ralentissement des processus de développement culturel et économique amorcés par les sociétés indigènes depuis la fin du $\mathrm{VI}^{\circ} \mathrm{s}$, dans la mouvance des propositions marchandes des Phocéens de Marscille et de ses relais. C'est ensuite celui de l'amoindrissement des formes de 

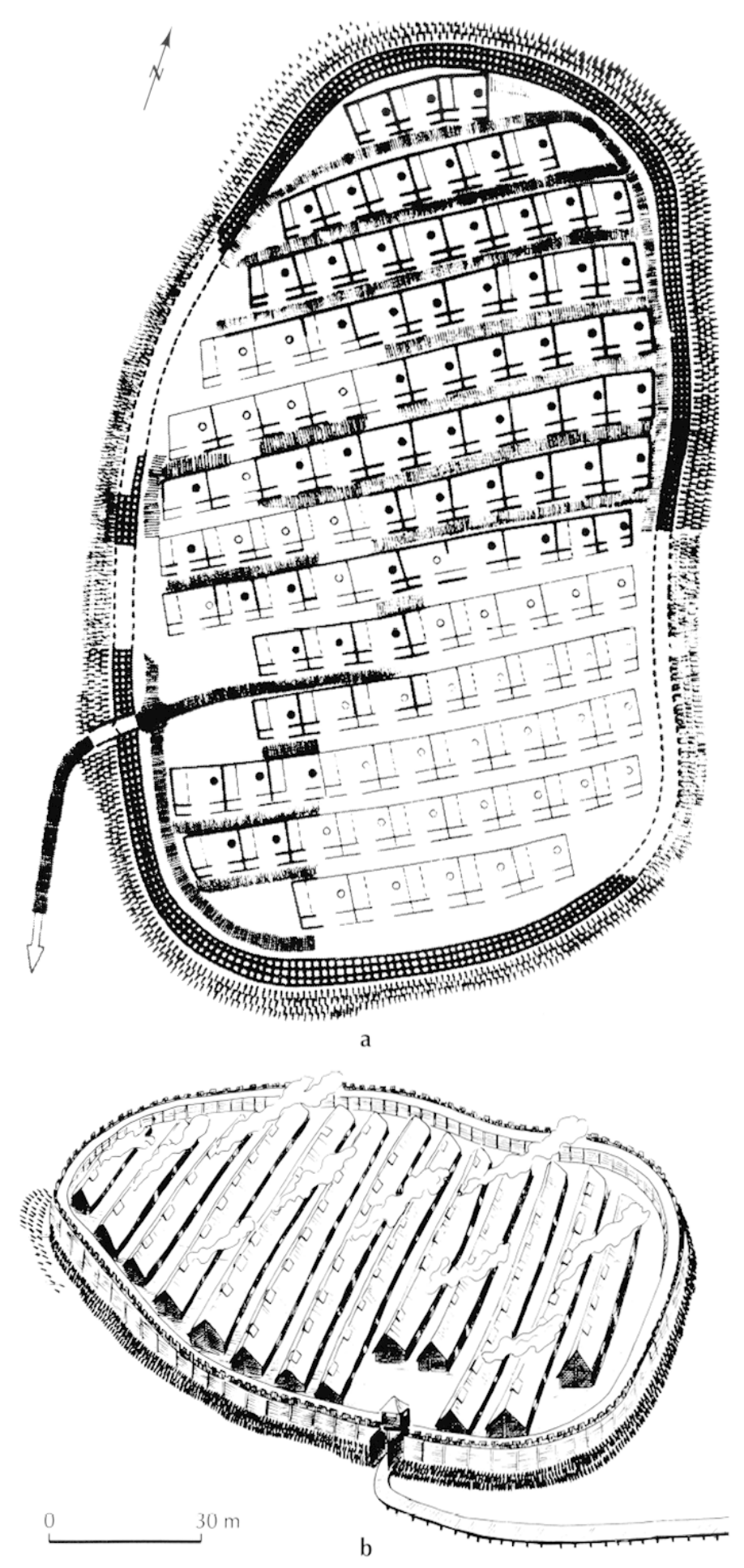

Fig. 13 - L'agglomération de Biskupin, dans le nord de la Pologne, montre au début $d u v^{\prime}$ s. av. J.-C. un très bel exemple de regroupement extrême, et puissamment défendu, d'habitations de plan répétitif sur une superficie de 2 ha. La centaine de constructions domestiques, disposées en files, est constituée d'unités à deux pièces, avec peut-être un galetas. Le seul espace libre intérieur, en arrière immédiat de la porte, est à vocation pratique et/ou stratégique (a, plan, d'après Piotrowska, Piotrowski, 1990, p. 197 ; b, restitution en vue cavalière, d'après Brun P., 1987, p. 155). l'habitat perçu dans la raréfaction apparente des informations archéologiques hors des regroupements villageois.

Ces phénomènes sociaux, entrevus assez globalement dans la basse vallée du Rhône et parfois expliqués par les seules contingences régionales (Py, 1990a, p. 182-196; Arcelin, 1992a, p. 320), s'insèrent dans une rupture de dynamique bien plus large, tant à l'intérieur de la Gaule que dans le monde méditerranéen. Les années 450-400 sont celles de la disparition dans l'arc nord-alpin des grandes principautés celtiques du Hallstatt final, plus généralement des transformations d'un mouvement commercial avec le monde méditerranéen et nord-italique (Brun, 1992 et 1997). Les répercussions pour le commerce de Marseille grecque et leurs intermédiaires plus septentrionaux ont été soulignées depuis longtemps (Villard, 1960, p. 133-134; Rolley, 1992), d'autant qu'elles se conjuguent avec une modification des réseaux politiques et économiques dans le monde méditerranéen. La focalisation du commerce de Marseille et de ses productions propres (amphores vinaires et vaisselle à pâte calcaire) sur les régions de la Gaule méridionale après 450-425, avec l'amplification de son emprise économique de l'Hérault à Gênes, conduit à un quasi-monopole de ses circuits de distribution dans la basse vallée du Rhône et ses abords immédiats, dès les années 425-375. Le seul exemple des produits transitant par le port d'Arles à cette époque souligne pleinement la mainmise commerciale de la ville grecque et de son négoce, comme son maintien jusqu'au milieu du III $^{\circ}$ s. (Arcelin, Sourisseau, 1990, p. 197 ; Sourisseau, 1997, p. 216). Mais les effets conjugués de cette fermeture de la voie rhodanienne vers les régions septentrionales et le rythme élevé des sollicitations de l'échange mis en place par la cité grecque depuis plus d'un siècle ont été apparemment des facteurs aggravants pour les fragiles économies des sociétés rurales organisées autour de chefferies aux $v^{*}$ et IV s. La restructuration politique, économique et monétaire de la ville grecque durant ce dernier siècle (Bats, 1989, p. 197-201), comme sa mise en péril par le siège d'une armée celto-ligure vers 390 (ibid., p. 197 ; Arcelin, 1986a, p. 59), de même que la lente transformation, entre 425 et 350 , de sa colonie rhodanienne de Theline en une agglomération culturellement plus composite, l'Arelate à dominante indigène (Arcelin, 2000c, p. 19), sont autant de conséquences visibles des bouleversements intervenus au sein de l'ensemble des cultures méridionales au cours de cette période. Mais contrairement à d'autres régions du Midi, si Marseille apparaît dans la basse vallée du Rhône au $\mathrm{I}^{*} \mathrm{~s}$. comme la seule interface méditerranéenne, le volume global des produits échangés (basé essentiellement sur les amphores massaliètes) est souvent en légère régression, voire plus franchement en baisse dans l'économie des habitats indigènes, surtout en remontant dans le couloir rhodanien (Py, 1990b, p. 76 ; Arcelin, Sourisseau, 1990, p. 195-198, fig. 3 ; Bats, 1992, p. 274). Le même ralentissement quantitatif est perceptible dans la ville portuaire d'Arles (Arcelin, 1995, p. 334, fig. 7) ou, sur la côte, à Lattes vers 375-325 (Py et al., 1999, p. 409, fig. 128). Le début du second âge du Fer est aussi le moment dans cette même région de la disparition soudaine ou progressive, selon les secteurs, d'un aspect économique qui fut antérieurement révélateur des effets dynamiques de la progression des échanges sur les cultures autochtones. Il concerne les ateliers de vaisselles tournées à pâte grise monochrome (Arcelin-Pradelle et al., 1982, p. 55; Arcelin- 
Pradelle, 1984, p. 145-146 ; Chausserie-Laprée, Nin, 1995, p. 345) ou à pâte claire peinte ("subgéométrique rhodanien ", voir Py, 1990a, p. 548-550), établis en milieu indigène. Sans substitution véritable au sein des circuits régionaux, ce sont seulement des vaisselles non tournées issues des ateliers des rives sud-ouest de l'étang de Berre (Arcelin et al., 1993) qui connaîtront une certaine diffusion du côté provençal jusqu'au début du $1{ }^{\mathrm{e}}{ }^{\mathrm{s}} \mathrm{s}$., en parallèle à un nombre plus limité de produits marseillais. En somme, Marseille grecque se désengage, par étapes et dès la fin du v s., de ses positions commerciales internes à la basse vallée du Rhône pour se replier sur ses activités maritimes en Méditerranée et, en ce qui concerne la Gaule, sur la seule bande littorale.

Sans s'étendre sur ces aspects pourtant révélateurs de l'émergence dans le Midi de nouveaux rapports entre sociétés indigènes et milieu colonial grec, la longue crise économique des années 425-350 a d'évidentes conséquences sur les modes de l'habitat qui prévalaient antérieurement. Ils se modifient autant dans leur lisibilité sur les territoires que dans la continuité des agglomérations antérieures. Nous avons rappelé dans l'introduction le déficit de découvertes archéologiques dans l'ensemble des prospections pour la période du $\mathrm{IV}^{\mathrm{e}} \mathrm{s}$. au début du $\mathrm{II}^{\mathrm{e}} \mathrm{s}$. av. J.-C., observations qui doivent être analysées plus finement au vu des enquêtes récentes. D'abord, le silence dans l'information n'est pas absolu car il découle pour partie de la raréfaction, entre 350 et 225 , des importations méditerranéennes à vernis noir particulièrement identifiables par opposition aux céramiques régionales, souvent peu loquaces à l'état fragmentaire. Mais il est délicat de s'appuyer en totalité sur un tel argument, même si l'on admet généralement, sur le littoral méditerranéen et plus spécifiquement dans la basse vallée du Rhône, un phénomène de raréfaction des habitats après la fin du $\mathrm{V}^{\mathrm{c}} \mathrm{s}$. (voir par exemple Bérato, 1997 ; Nuninger, Raynaud, 1998, p. 25 ; Verdin, 1999, p. 55-56). Cette carence est d'autant plus marquée qu'elle ne touche pas seulement les modestes implantations de plaine mais aussi parfois des habitats groupés, perchés et fortifiés, antérieurement prospères. Ainsi, l'oppidum de SaintBlaise était une véritable " place centrale " économique sur un territoire d'exploitation délimité durant le $\mathrm{vI}^{\mathrm{e}} \mathrm{s}$. et au moins les trois premiers quarts du $v^{*}$ s. (Trément, 1999, p. 113-120). L'analyse du fonds des recherches anciennes laisse entrevoir une forte paupérisation des activités économiques du site à partir de 400-350 et ce jusque vers 225-200 av. J.-C., moment d'une relance avec le commerce méditerranéen, désormais italique (ibid., p. 122-123 ; Cayot, 1984, p. 77 ; Bouloumié, 1992, p. 70-72). Cet exemple célèbre illustre d'une manière emblématique le phénomène des effacements temporaires ou définitifs, et plus généralement la puissante récession que les mutations économiques et les redistributions des circuits commerciaux marseillais ont déterminée au sein des structures sociales indigènes de la fin du premier âge du Fer. Au début du $\mathrm{N}^{\mathrm{e}} \mathrm{s}$., la pression militaire des armées de Catumandos contre la ville grecque, puissante opération rapportée par Trogue-Pompée (apud Justin, XLIII, 5, 4-7), trouve ici tout son sens.

Ensuite, aux éventuels effacements d'habitats répondent les créations de nouveaux, tels ceux d'Ambrussum (Hérault) à la fin du Iv' s. (Fiches, 1996, p. 70) et de Nages (Gard) dans le premier quart du III" s. (Py, 1978, p. 20-21). D'autres, créés à la fin du premier âge du Fer, prennent de l'ampleur, ainsi Saint-
Pierre à Martigues par l'adjonction de quartiers périphériques sur les pentes méridionales de la colline au cours du $\mathrm{IV}^{\mathrm{C}} \mathrm{s}$. (fig. 3). Au total le phénomène de poursuite ou de récession d'une agglomération est pour partie la résultante de son statut antérieur dans les implications du groupe humain au processus régional de l'échange, approche fort intéressante mais qu'il n'y a pas lieu de développer ici. Si l'on écarte, faute d'arguments, l'hypothèse épidémiologique (Mauné, 1998a, p. 6) ou la généralisation de celle d'un épuisement des sols après un siècle d'intense activité productive (Arcelin et al., 1982, p. 125-126), le constat d'une déprise territoriale, et pour l'essentiel dans l'habitat dispersé, appelle un certain nombre de commentaires. D'abord, elle ne se manifeste pas partout de façon radicale ainsi que les prospections le suggèrent autour de la chaîne des Alpilles pour le III" s. av. J.-C. (Arcelin, 1999a, p. 67-68). D'autre part, les vestiges d'habitats et de structures agricoles sur coteaux ou en plaine deviennent plus nombreux à partir du début du II ${ }^{\mathrm{C}}$ s., mouvement de résurgence généralisé dans le Midi mais différemment interprété, soit en tant que développement des activités productives d'une agglomération perchée voisine (fig. 14a), soit en terme de redistribution spatiale dans l'occupation des territoires de productivité d'un ancien habitat groupé (fig. 14b). Le rapprochement des résultats de trois régions différentes comme la Vaunage (près de Nîmes) aux IV et III $^{\mathrm{e}}$ s. (Nuninger, Raynaud, 2000, p. 45-46, fig. 9), le secteur des Alpilles précédemment cité et celui contemporain de l'arrière-pays de Marseille (Arcelin, 1992a, p. 320), révèle des modes variés dans la nature et la répartition des habitats, du regroupement presque total en agglomérations de hauteur très structurées à une large dispersion en plaine en passant par la multiplication de petits villages fortifiés. Quel que soit le degré de finesse de l'analyse, l'image qui se dégage de l'observation des différentes zones géographiques étudiées pour les périodes des $\mathrm{V}^{\mathrm{C}}$ et III ${ }^{\mathrm{e}} \mathrm{s}$. est celle d'une diversification conjoncturelle des réponses, tant sociales que politiques, apportées à une forte crise économique résultant d'une diminution ou d'une modification des activités de l'échange et de ce fait d'une possible transformation des rapports à la terre. L'observation d'une amplification de la culture de la vigne autour de Lattes à partir du III ${ }^{\mathrm{c}}$ s. (Py, 1990b, p. 83-84, fig. 6 ; Py, Buxó i Capdevila, 2001, p. 33-38) illustre l'expansion au second âge du Fer dans la basse vallée du Rhône et sur le littoral d'une pratique bien antérieure (Marinval, 1997, p. 159-162) ; cette dynamique agricole a d'ailleurs pu contribuer à l'amoindrissement des exportations vinaires massaliotes dès la fin du III $^{\circ}$ s., antérieurement même à l'afflux du vin italien. Avec l'émergence de la culture de l'olivier en Provence (Leveau et al., 1991, p. 89-91), l'amorce d'un développement de l'outillage métallique (Py, 1993, p. 224228) et de transformation des produits, pressoirs entre autres (Brun J.-P., 1993), émergent vers 200 av. J.-C. les premiers signes archéologiques concrets d'une maîtrise plus élaborée des pratiques agricoles, favorisées par un climat désormais mieux tempéré. Elles répondent à une adaptation de la productivité aux besoins de la consommation régionale (Boissinot, 2000a ; Marinval, 2000, p. 190) et d'un commerce méditerranéen plus ouvert à partir du milieu du siècle, en grande partie sans doute hors de l'emprise directe de Marseille grecque (Bats, 1992, p. 275 ; Arcelin, 1995, p. 336). 


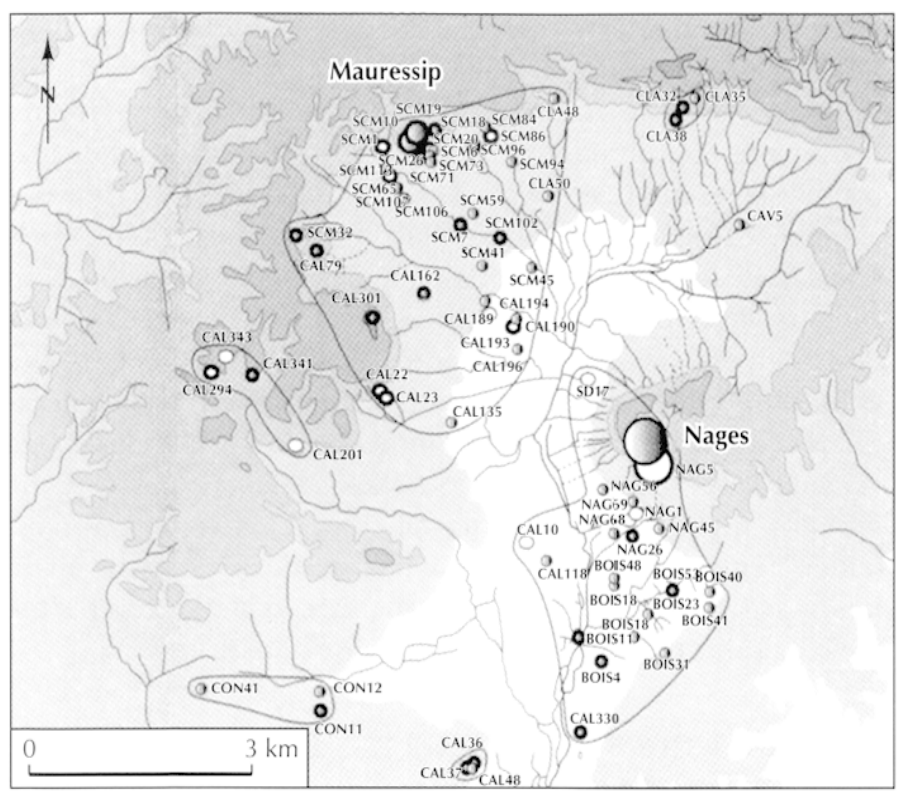

a

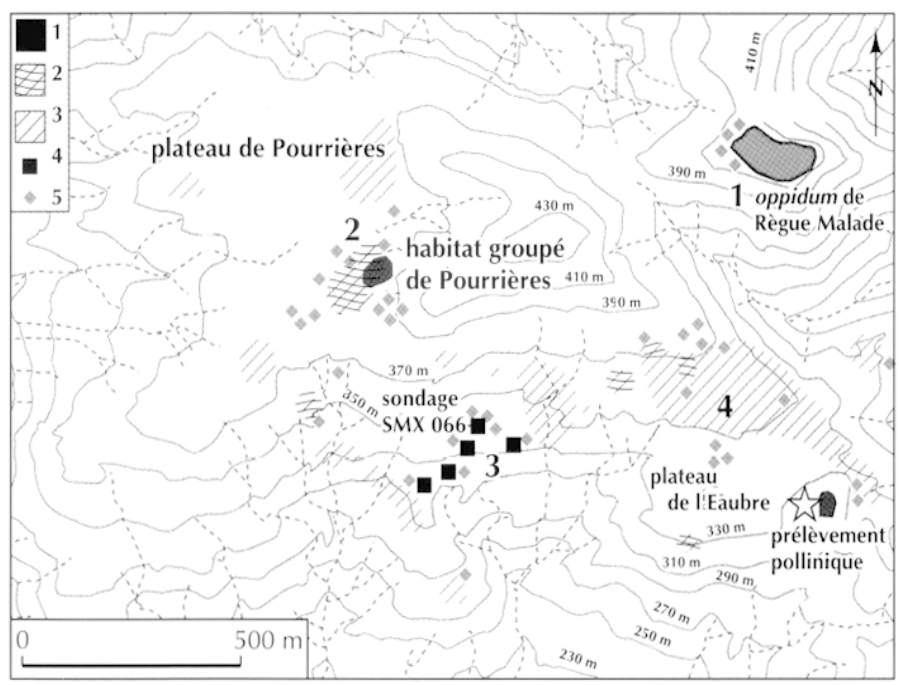

b

Fig. 14 - Deux images ponctuelles de l'occupation des coteaux et plaines autour de bourgs fortifiés, durant les II' et $I^{\prime r}$ s. av. J.-C. Une hiérarchisation est établie entre les hameaux ouverts et les structures agraires complémentaires (petites fermes ou hangars): a, dans la Vaunage près de Nîmes (Gard), autour du Serre de Mauressip et de Nages-et-Solorgues (d'après Nuninger, Raynaud, 1998, p. 24) ; b, à Saint-Maximin (Var), l'habritat du début du second âge du Fer est d'abord celui de l'oppidum de Règue Malade ( $\left.n^{\prime \prime} 1\right)$. Au II' s., après son abandon, lui succède l'agglomération ouverte (sur 0,6 ha) sur le plateau de Pourrières ( $\left.n^{\prime \prime} 2\right)$. Il est lui-même entouré de structures agricoles complémentaires (losanges) et d'autres groupements de fermes modestes apparaissent à proximité $\left(n^{\prime \prime} 3\right)$ ou sur le plateau de l'Eaubre ( $\left.n^{\prime \prime} 4\right): 1$, site; 2, épandage dense de céramique non tournée; 3 , épandage plus diffus ; 4, structure ; 5, meule (d'après Bertoncello, Gazenbeek, 1997, p. 607).

\section{L'AFFIRMATION POLITIQUE D'UNE ARISTOCRATIE}

Les élites indigènes de la basse vallée du Rhône, dont la réalité transparaît au premier âge du Fer, dès le vir's. au moins, à travers la statuaire héroïque découverte sur la rive droite du fleuve, au Marduel (Gard) et dans la région de Nîmes, puis sur la rive gauche à Glanon et à Roquepertuse (Guillaumet, Rapin, 2000, p. 81-82 ; Arcelin, Rapin, 2003, p. 195-206), vont apporter à ces nouvelles réalités d'ordre économique des réponses politiques et sociales plus différenciées qu'auparavant. Pour une frange restreinte de la population en situation favorable près des côtes, des ports et des lieux majeurs de l'échange non loin des grands axes de circulation, l'activité commerciale restera forte au cours du second âge du Fer. Elle s'amplifiera même avec une implication plus directe des communautés indigènes, perceptible par exemple dans la mainmise sur l'ancienne colonie phocéenne d'Arles, que nous avons précédemment évoquée, et plus généralement, sur les activités et le commerce fluvial ou maritime (Arcelin, 1986b, p. 20-23). Rejoignant en cela la dynamique du Languedoc occidental (Garcia, 2000c, p. 7476), cette part de la population va progressivement s'individualiser au plan culturel des communautés plus éloignées de ces secteurs de contacts. À l'inverse de cette ouverture au monde méditerranéen qui caractérise ces régions d'échanges, les populations plus reculées paraissent développer une tendance au repli sur des valeurs rurales " traditionnelles " et sur une structuration sociale guère différente de celle de la fin du premier âge du Fer. De fait, dès le début du III $^{\mathrm{c}}$ s., ces sociétés régionales, apparemment très hiérarchisées autour d'une élite autoritaire de great men, engendrent une aristocratie équestre que nous révèle avec magnificence la statuaire d'Entremont (Salviat, 1987 ; Arcelin, Rapin, 2002) et plus tardivement, les allusions des textes anciens (Verdin, 1995, p. 37-40; Arcelin, Chausserie-Laprée, 2003, p. 263-264). C'est d'ailleurs certainement le siècle de la structuration politique des fédérations de peuples rapportée par ces mêmes sources (fig. 6). Le fonctionnement social, ici comme ailleurs en Gaule, doit s'articuler autour d'une aristocratie foncière, elle-même subdivisée et établie sur la productivité de domaines de rapport avec un puissant réseau de dépendants et de clients. La population agricole et ses artisans, très encadrés, se regroupent de manière préférentielle en agglomérations d'importance variable, selon la nature et l'ampleur des pouvoirs régionaux ou les rapports de dépendance et de complémentarité. La question a été posée de la lecture archéologique de l'existence de cette élite sociale dans les habitats groupés, mais sans réponse autre que les effets valorisants des enceintes (Arcelin, 1984, p. 197-198; Py, 1993, p. 238-240). C'est en considérant les recherches récentes, hors des vastes agglomérations, que nous avons proposé une première réponse (Arcelin, 1999b) : c'est sur des propriétés domaniales que l'on peut observer des aménagements agricoles et/ou résidentiels, modestes mais sans doute à l'échelle du morcellement des pouvoirs locaux. On rappellera simplement ici les exemples de Coudounèu à Lançon-deProvence, à l'amorce du second âge du Fer (fig. 4), et de 
Roquepertuse à Velaux où un village de 0,5 à 1 ha, accolé à l'enceinte de protection de la résidence agricole, devait rassembler les dépendants, ouvriers et serviteurs indispensables à la vie du domaine de proximité (fig. 5).

\section{DES CONTACTS MÉDITERRANÉENS DÉTERMINANTS}

C'est avec le développement économique et politique du II" s., observé ici comme ailleurs en Gaule (Collis, 1984b, p. 145157 ; Buchsenschutz, Guillaumet, 1989 ; Py, 1993, p. 156-162), que la réalité d'une forme de dichotomie culturelle devient lisible dans la basse vallée du Rhône entre les deux courants précédemment suggérés. Sans insister sur l'amplification rapide et multivariée du facteur économique amorcé au III $^{\mathrm{c}} \mathrm{s}$., nous en retiendrons seulement quelques conséquences dans cette région du Midi en liaison directe avec l'évolution du mode de l'habitat groupé. Le développement artisanal et agricole des années 250-125 av. J.-C. résulte pour une bonne part de l'effet catalytique du nouvel intervenant commercial qu'est le négoce italique vers le sud de la Gaule, et même bien au-delà vers la haute vallée du Rhône et la Saône (Plassot, Desbat, 2003) ou le Sud-Ouest (Bats, 1986, p. 409-413). Par étapes, le rôle des negotiatores italiens devient primordial dans la réactivation des liens commerciaux développés avec la Méditerranée, particulièrement dans certains secteurs comme les ports de Lattes, d'Arles et même de la métropole grecque ! Dans ces points de débarquement, $60 \%$ à $94 \%$ des amphores sont italiennes vers 150 av. J.-C. (Gantès, 1992, p. 176 ; Py, 1994, p. 322-327 ; Arcelin, 1995, p. 336 ; Hesnard, 1999, p. 138-141). Il en va de même dans l'agglomération d'Entremont où la presque totalité des amphores est de provenance italique, dès le deuxième quart du II" s. (Congès, 1987, p. 158-159; Gateau, 1990). Même si le phénomène n'est pas alors généralisable avec la même ampleur à l'ensemble de la région (Bats, 1992, p. 275276), il dénote du moins la force du courant italien du côté provençal dès les alentours de 200 av. J.-C., un peu plus tardivement en Languedoc oriental. Le fait que des agglomérations majeures comme Saint-Blaise ou Entremont ne possèdent pratiquement que des amphores italiques vers 150 pourrait laisser penser à l'existence de liens commerciaux directs établis entre indigènes et Italiens, du moins pour ce type de produit accompagné d'une vaisselle de table à vernis noir (Gateau, 1990, p. 174-175). Quoi qu'il en soit, l'amoindrissement du rôle joué par Marseille grecque comme interface entre la Méditerranée et les communautés indigènes de la basse vallée du Rhône, principalement dans son arrière-pays, ne pouvait que déprécier son rôle et son autorité. Le port phocéen devient alors une entrave pour le commerce indigène régional avec l'Italie, via Saint-Blaisc - Fos ou Arles par exemple? L'affrontement des intérêts grecs avec ceux d'une aristocratic celto-ligure soucieuse d'actions glorifiantes et d'attitudes héroïques autour desquelles le vin des banquets rassemble les clients, engendrera, sur la rive gauche du Rhône, un bon siècle de confrontations larvées et de conflits militaires plus généralisés (des alentours de 200 à 90 av. J.-C., voir Goudineau, 1978, p. 685-691). En revanche, on sait que de tels heurts n'ont pas eu lieu sur la rive droite du fleuve, ni au nord de la chaîne des Alpilles. Dans ces régions, la continuité de la Protohistoire finale au début de la romanisation se fera d'une manière bien plus régulière et constructive qu'autour de la chôra marseillaise (Arcelin, 2003).

Malgré les disparités inhérentes à l'histoire des deux rives du fleuve, un certain nombre de comportements sociologiques communs peuvent se dégager par périodes des sites les plus amplement explorés, tant dans leurs principes organisationnels que dans leurs usages architecturaux. Deux courants se forment au cours du $\mathrm{V}^{\mathrm{C}} \mathrm{s}$. pour apparaître pleinement deux siècles plus tard : l'un préservant des permanences structurelles élaborées à la fin du premier âge du Fer et un autre porteur des éléments d'une lente mais profonde mutation socioculturelle davantage orientée vers l'intégration de nouvelles valeurs. L'analyse d'une sélection d'exemples permettra de concrétiser le propos pour tenter d'entrevoir les prémices du passage de la bourgade ou du bourg rural à l'agglomération urbanisée dans sa complexité sociologique et son affirmation politique naissantes.

\section{PERMANENCES STRUCTURELLES ET NOVATIONS FONCTIONNELLES DANS L'AGGLOMÉRATION}

La première série d'habitats groupés, du IV $s$. au début du $\mathrm{I}^{\text {cr }}$ s. av. J.-C., rassemble ceux dont les plans se placent dans la continuité de l'ordonnancement élaboré à la fin du premier âge du Fer (fig. 15 à 22). Deux constatations s'imposent d'emblée. La première touche aux superficies occupées, la seconde aux structurations planimétriques.

Aux IV et III' s., l'ampleur des nouvelles agglomérations ceinturées par une ligne défensive ou des restructurations complètes n'augmente pas globalement par rapport aux superficies des habitats antérieurs, ne dépassant pas des étendues de 5 à 6 ha telles à Ambrussum, Roque de Viou ou Nages "II ancien" (Fiches, 1996, p. 70-71; Py, 1990a, p. 697 et 704). D'autres sont même restreintes à quelques milliers de mètres carrés, ainsi autour de Marseille (Notre-Dame-de-Pitié à Marignane ou Teste-Nègre aux Pennes-Mirabeau), mais sans doute pour des raisons conjoncturelles (Arcelin, 1986a, p. 61). Les extensions de ces deux siècles sont plutôt à rapporter aux quartiers périphériques d'agglomérations défendues, comme ceux de Saint-Pierre à Martigues (fig. 3) ou de Mauressip dans le Gard (Nuninger, Raynaud, 2000, p. 45). C'est au II' s., vers 175-150, en relation avec la dynamique économique de l'époque ou pour des raisons de sécurité dans une région de conflits récurrents, que des habitats préexistants vont fortement s'amplifier, par adjonction ou restructuration. C'est ainsi le cas des agglomérations de La Courtine à Ollioules dans le Var (fig. 15), de l'île à Martigues (fig. 17), du Baou-Koux ou d'Entremont dans les Bouches-du-Rhône (fig. 20 et 22), ou encore des Castels à Nages-et-Solorgues dans le Gard (fig. 18c et d). Mais dans tous les cas les superficies demeurent limitées, inférieures à une dizaine d'hectares, à la différence de ce que l'on peut observer dans les régions périphériques, du Languedoc central et occidental avec les habitats de Sextantio ou d'Aumes dans l'Hérault qui atteignent les 20 à 40 ha, ou encore en position plus septentrionale, celui de Mornas dans le Vaucluse, à l'orée de la moyenne vallée du Rhône.

La seconde observation qui résulte d'un rapide tour d'horizon des vestiges analysés montre le maintien de différences dans l'organisation intérieure des habitats groupés. 


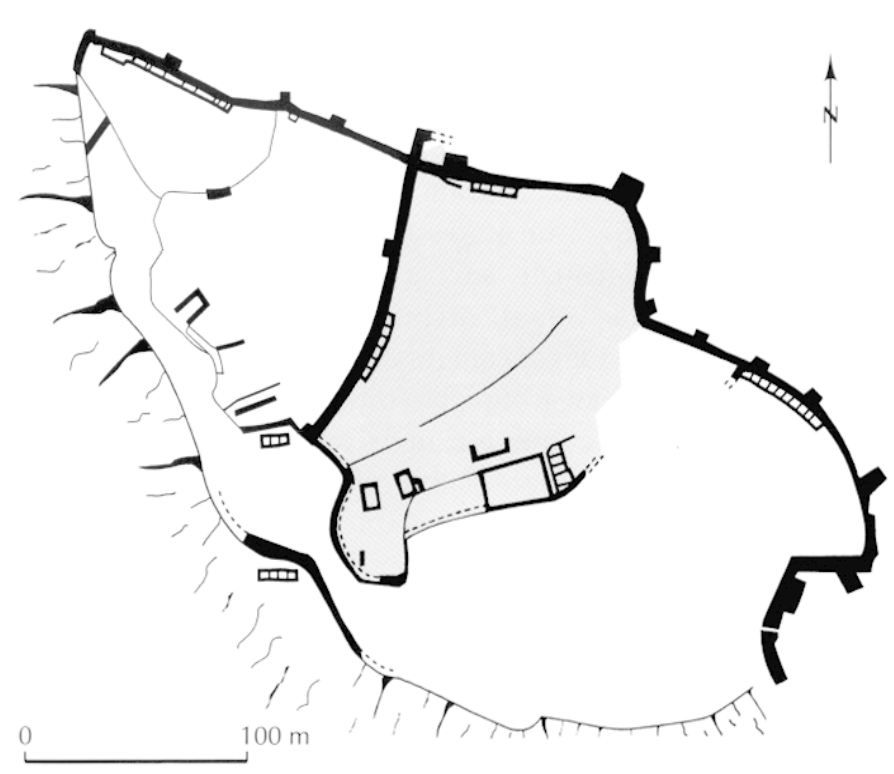

Fig. 15 - Un exemple de l'amplification des habitats groupés à la fin du second âge du Fer, celui de La Courtine à Ollioules (Var). Occupé

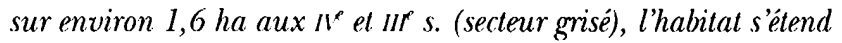
à 5,5 ha au If s. av. J.-C. On notera le nombre des bastions et la présence de quatre d'entre eux plus importants (d'après Bérato et al., 1996, p. 58).

Ainsi les contraintes de la topographie et des lignes de défenses peuvent rester déterminantes dans des sites aussi différents que Le Marduel à Saint-Bonnet-du-Gard et Roque de Viou à SaintDionisy dans le Gard ou Teste-Nègre près de Marseille, et ce malgré un souci évident de structuration en îlots (Py et al., 1989, p. 122-123 ; Gantès, 1990b ; Py, 1990a, p. 696-697). Mais pour d'autres créations contemporaines, la recherche de sites d'implantation favorable sur des terrains relativement plats répond à une volonté affirmée d'une distribution régulière des ensembles de pièces d'habitation, qu'ils soient conçus en files ou en îlots (fig. 18 ou 22 par exemple). De fait, la répartition des exemples connus dans les secteurs dynamiques au plan économique et de communications aisées révèle une volonté d'ordre esthétique dotée d'une connotation valorisante pour les élites en charge de l'habitat, souci confirmé par la monumentalisation des fortifications. Les influences de la structuration urbaine de Marseille grecque, clairement perceptible au IV s. (Moliner, 1999, p. 84 et annexe p. 160, pl. VI) ou de celles d'une clérouquie comme Olbia à IIyères (I lermary et al. dir., 1999, p. 87), transparaissent ici pleinement dans cette récupération formelle. En limite des plaines de la chôra marseillaise mais occupé par des Celto-Ligures, le petit habitat (ferme ou phrourion?) du Verduron est installé en terrasses sur un terrain en pente (fig. 16a). Sa planimétrie rigoureuse, organisée autour de deux longs escaliers orientés nord-sud, montre au III" s. des principes répondant à une impérieuse volonté de régulariser l'espace occupé (Bernard, 2000). Rien n'est plus facile que de l'opposer à d'autres habitats de régions plus périphériques, autant dans les agencements approximatifs des pièces à murs porteurs construites au $\mathrm{II}^{\mathrm{C}} \mathrm{s}$. sur le site varois de La Cabredor, aux Arcs (fig. 16b), que dans les choix de gestion
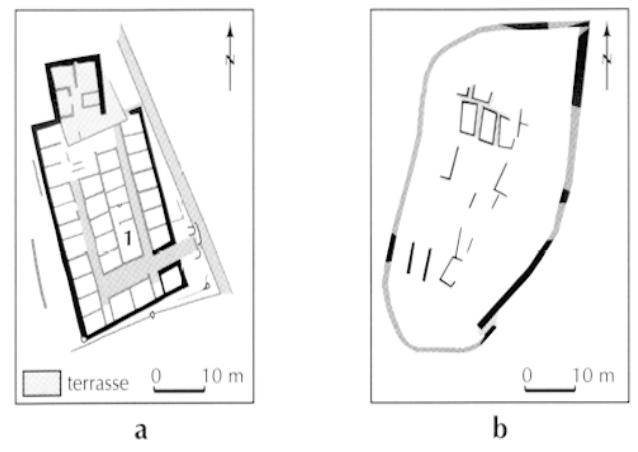

Fig. 16 - Deux petits habitats de la fin de l'âge du Fer, opposant l'extrême structuration de l'un (a) à l'organisation très approximative de l'autre qui comporte des pièces non systématiquement mitoyennes (b) : a, habitat fortifié de $1300 \mathrm{~m}^{2}$ ou structure agricole défensive du Verduron, en limite de la proche chôra de Massalia (IIt' s. av. J.-C.) ; b, habitat fortifié de La Cabredor aux Arcs dans le Var $\left(1600 \mathrm{~m}^{2}\right.$; It" s. av. J.-C.) (échelle: $1 / 2000 ; D A O M$. Rétif, Service archéologique de Martigues, d'après Bernard, 2000, p. 158 et Bérato, Borréani, 2000, p. 115).

de l'espace sur l'oppidum de Taradeau, avec les pièces distribuées seulement contre l'enceinte édifiée au début du $\mathrm{I}^{\mathrm{er}} \mathrm{s}$. av. J.-C. (Brun et al. dir., 1993, p. 29-38).

\section{LE VIllage de l'Île À MARTigues (BouChes-DU-RHône)}

Cet habitat, détruit au début du second âge du Fer (fig. 7), est rebâti pratiquement à l'identique au milieu du $\mathrm{IV}^{*}$ s. pour être à nouveau incendié dans les premières années du $\mathrm{II}^{\mathrm{c}} \mathrm{s}$. (Chausserie-Laprée, Nin dir., 1988, p. 50-57). Si l'état du début du second âge du Fer n'appelle pas d'autre commentaire sinon pour souligner la poursuite des fonctions domestiques du site que l'on opposera à la récession de nature commerciale de l'habitat voisin de Saint-Blaise, c'est la reconstruction du début du $\mathrm{II}^{\mathrm{c}} \mathrm{s}$. qui retiendra l'attention. Bien que très incomplètement exploré (fig. 17), il n'en est pas moins fort intéressant pour l'information sociologique et architecturale transmise. L'habitat regroupe dans l'île du chenal de Caronte une population supérieure à celle qui y résidait antérieurement. La superficie du bâti semble ici quasiment doublée (Chausserie-Laprée, 1997 : écrans 19 et 20, plan 11). D'autre part, on relève une structuration de l'espace différenciée par quartiers : en petits îlots irréguliers à l'ouest, en longues files articulées sur un mur axial du côté oriental. Dans ce dernier secteur gagné sur des terrains humides, on observe que les pièces d'habitation sont plus amples et moins encombrées par des conteneurs que dans le village antérieur, ce qui conduit à s'interroger sur les lieux du stockage vivrier indispensables et forcément sur leur statut (familial ou sous tutelle collective ?). Ces alignements très répétitifs de pièces, généralement uniques, représentent une forme particulièrement concentrée dans le regroupement des cellules domestiques. Avec des ruelles de desserte très étroites $(1,5$ à 2,2 $\mathrm{m}$ ), aménagées en drain pour lutter contre les remontées d'une nappe phréatique sous-jacente, on entrevoit dans ce quartier mieux qu'ailleurs la pression coercitive qui devait être exercée sur la population rurale résidente par des dirigeants 


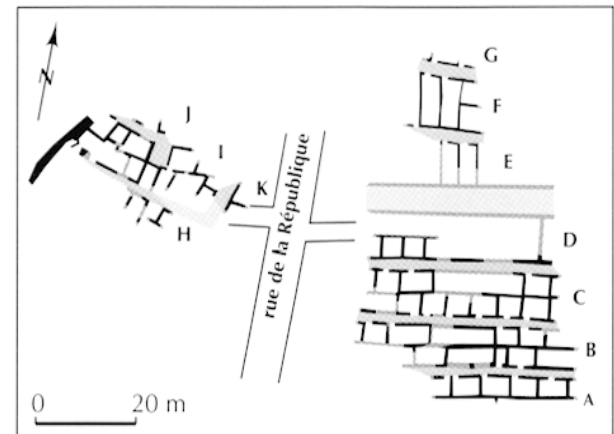

Fig. 17 - Après une destruction violente au tout début du If $s$. av. J.-C., le village de l'̂lle de Martigues (Bouches-du-Rhône) (voir fig. 9) est restructuré sur une superficie amplifiée (1 ha ?), peut-être en deux étapes, du moins selon deux schémas différents de planification : en petits îlots irréguliers du côté occidental, à l'emplacement des implantations primitives, et en longues files, simples ou doubles mais régularisées, en de nouvelles aires orientales. L'essentiel des autres différences relevées avec l'habitat antérieur réside dans une amplification de la superficie moyenne des pièces, majoritairement uniques, et peut-être une redistribution des lieux de stockage vivrier hors de ces espaces, désormais moins encombrés. En revanche, les ruelles sont toujours aussi étroites et l'apparition de caniveaux (sous un plancher de circulation ?) ne répond à l'évidence ici qu'aux besoins circonstanciels et impérieux du drainage. Le système d'organisation de ce village reprend les principes structurants déjà mis en œuvre à Saint-Pierre trois siècles auparavant (voir fig. 3) (échelle: 1/2 000; DAO M. Rétif, Service archéologique de Martigues, d'après Chausserie-Laprée, Nin dir., 1988, p. 52).

soucieux de leur regroupement très ordonné et compacté sous la protection d'une enceinte et, ici, de l'environnement aquatique. Hormis peut-être une légère amplification des espaces familiaux, on ne peut qu'être frappé par l'ancienneté de la méthode d'ordonnancement de ce quartier articulé autour d'une voie centrale plus large (fig. 17, inférée entre les alignements $\mathrm{D}$ et $\mathrm{E}$ ), selon un principe déjà mis en application dans le village voisin de Saint-Pierre dès 500 av. J.-C. (fig. 3).

\section{L'AGglomération des CASTELS À NAGES-ET-SOLORGUES (GARD)}

C'est certainement dans l'habitat de hauteur et de pente du site des Castels, au travers de la restitution proposée de son état "II ancien " (vers 250-175 av. J.-C.) (fig. 18a et c), que l'on peut appréhender le mieux cette volonté organisationnelle dans les agglomérations des communautés agropastorales. L'habitat, d'ampleur moyenne et qui englobe certainement les pentes méridionales ainsi qu'une source en contrebas (Py, 1990a, p. 704), est l'antithèse de l'aménagement spontané de groupes humains dont la vocation agricole transparaît ici clairement à travers les caractères d'un modeste outillage. Jusqu'au $\mathrm{I}^{\mathrm{er}} \mathrm{s}$. av. J.-C., la production artisanale locale demeure très limitée, répondant pour l'essentiel aux besoins élémentaires de l'habitation et des activités domestiques ou du travail aux champs (Py, 1978, p. 317-324). L'organisation totalement planifiée en files parallèles de pièces indépendantes comme autant de cellules familiales, la prévision envisagée d'un agrandissement fonctionnel sur de larges voies de circulation tracées à cet effet, la protection d'une enceinte flanquée très régulièrement de bastions ovoïdes constituant davantage un impressionnant décor valorisant qu'une réponse à un impératif militaire, l'érection enfin d'une tour monumentale sur la partie sommitale relèvent conjointement d'une volonté architecturale délibérée et autoritaire. Les choix effectués découlent en droite ligne des traditions élaborées dans l'habitat groupé bas-rhodanien au cours des trois siècles antérieurs. Ce qui est nouveau, c'est qu'au-delà du maintien du principe rationaliste de l'espace occupé déjà perceptible dans l'habitat voisin et antérieur de Roque de Viou (Py, 1990a, p. 696-699), le ou les « décideurs " à l'origine de celui des Castels se servent des potentialités économiques et militaires de ce rassemblement d'agriculteurs, artisans à leurs heures (Py, 1993, p. 224), pour développer une expression esthétisante autour de l'agglomération majeure des territoires d'exploitation (fig. 14a). En considérant la grande modestie intérieure des espaces de la vie familiale et l'ampleur de la tâche entreprise pour l'érection architecturale de cette création, on peut présumer que de telles dispositions ne relèvent pas d'une simple "décision communautaire » mais de l'autorité des élites assurant l'encadrement politique de cette force productive et défensive. Au II" s., le site des Castels, habitat groupé de l'essentiel de la population rurale des territoires de proximité (Nuninger, Raynaud, 1998, p. 24, fig. 17), affiche avec ostentation son emprise locale, mais aussi et surtout ses valeurs identitaires qui rejaillissent directement comme autant de signes magnifiants pour son élite aristocratique dont les lieux résidentiels, s'ils ont existé, ne sont pas repérés dans l'enceinte. Les agrandissements ultérieurs (état « II récent ", vers 175-125) (fig. 18b et d) confirment ces tendances à l'organisation très planifiée de l'espace bâti sous la forme de l'adjonction d'un quartier périphérique ceinturé d'une courtine. Les modifications qui interviennent alors dans l'implantation antérieure touchent à la distribution des aménagements internes aux unités domestiques agrandies (Chazelles, 1999, p. 488) et non à la planimétrie de l'habitat, ni à la conception structurelle de ses habitations. Comme dans les quelques agglomérations fouillées du premier âge du Fer, on ne connaît pas dans les quartiers explorés des Castels d'aménagements ou d'aires ouvertes à vocation collective (Py, 1990a, p. 754 756), pas plus que de structures de stockage partagées pour les produits de l'agriculture (Py, 1993, p. 220). Ce n'est qu'au I ${ }^{\text {er }} \mathbf{s}$. av. J.-C. qu'un petit édifice monumental, à dévolution cultuelle, sera inséré dans une file du quartier central (Py, 1992a). Ici, comme ailleurs dans la basse vallée du Rhône jusqu'à la prime romanisation, les systèmes d'assainissement généralisés sont inexistants, à l'exception de drains rustiques, aménagés pour des besoins localisés dont l'évacuation des eaux hors des fortifications (Py, 1990a, p. 756), ou de déflecteurs protégeant les façades et les entrées de pièces ouvertes sur les rues. Des constatations similaires pourraient être multipliées comme à La Courtine d'Ollioules (Var) dans le deuxième quart du $\mathrm{N}^{\mathrm{e}} \mathrm{s}$. (Bérato et al., 1996, p. 60 et 64, fig. 5), au Marduel vers le début du III $^{\mathrm{e}}$ s. (Py et al., 1989, p. 162-165), à Martigues au II ${ }^{\mathrm{c}} \mathrm{s}$. (Chausserie-Laprée, Nin dir., 1988, p. 53) ou encore à Entremont dans la seconde moitié du II" s. (Arcelin, 1987, p. 77; Dufraigne, 2000a, 


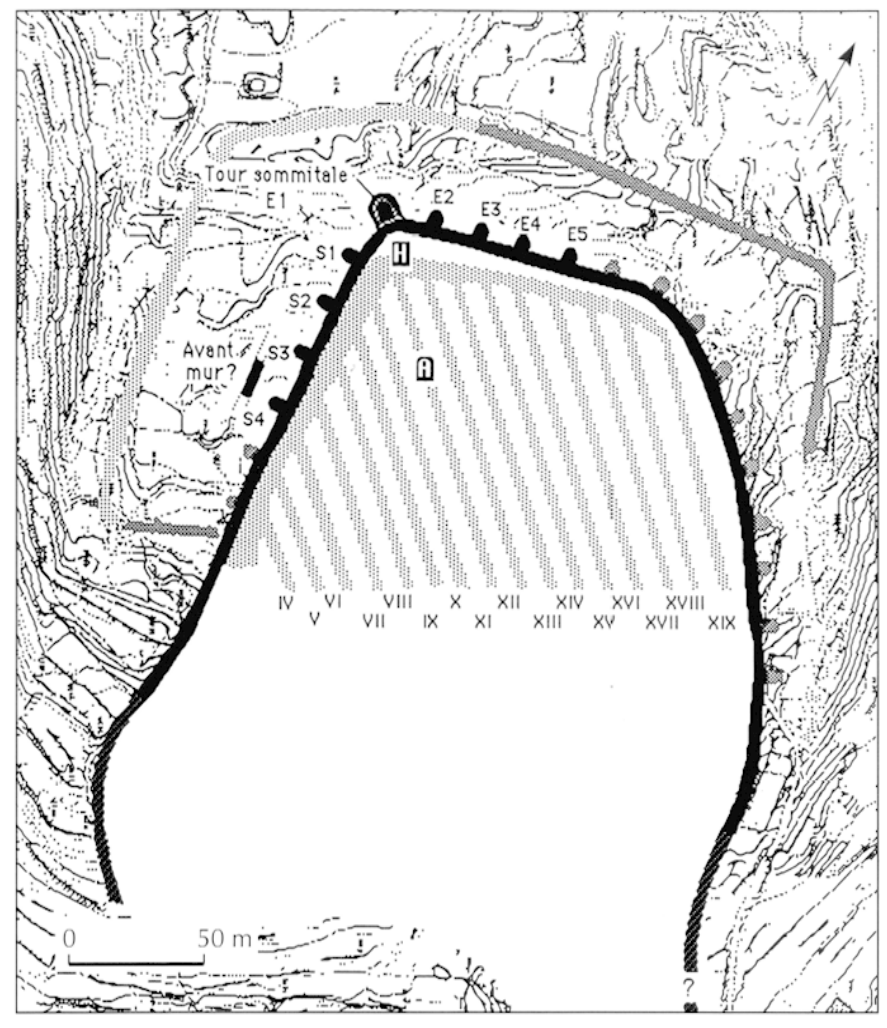

a

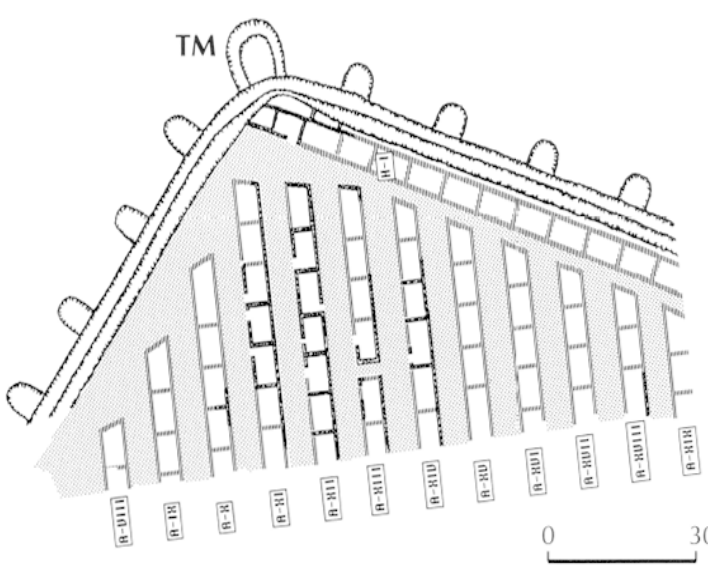

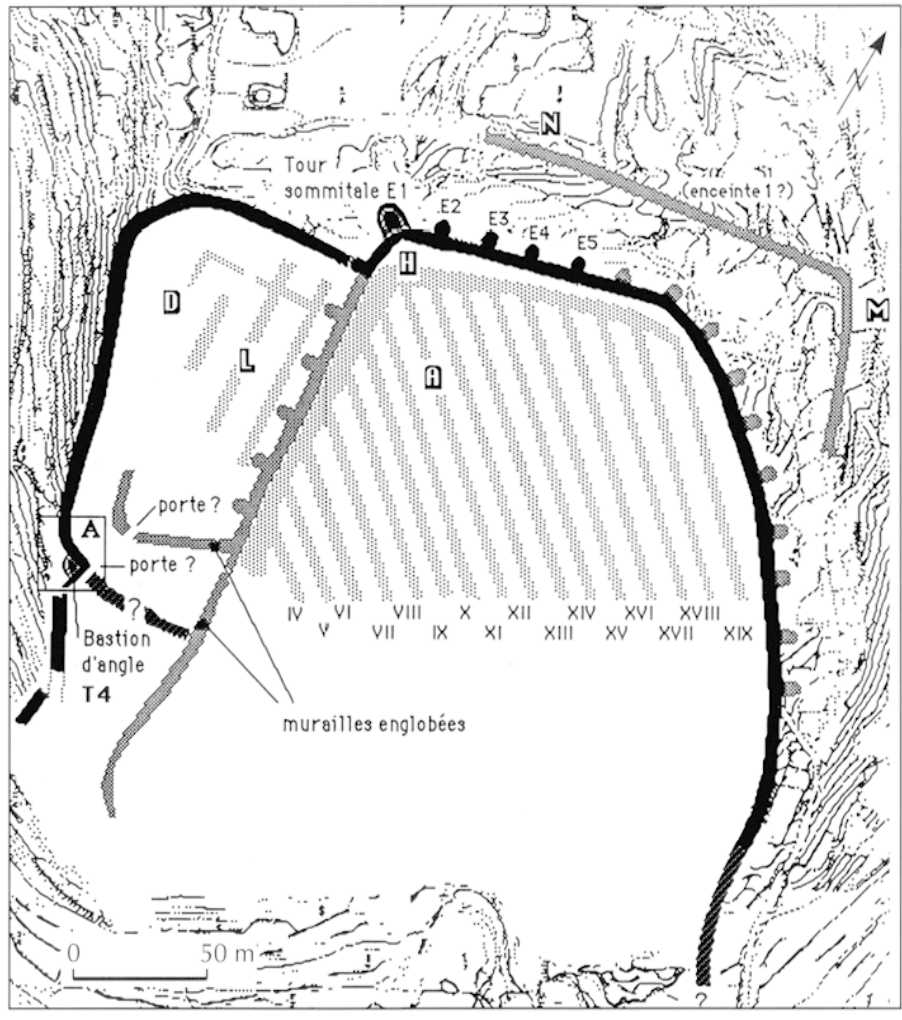

b

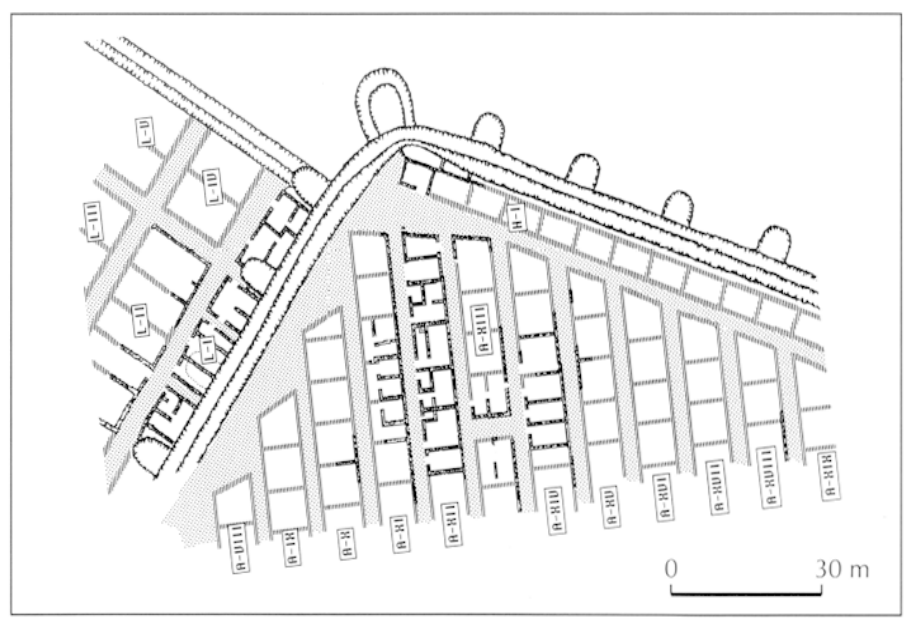

d

Fig. 18 - L'agglomération perchée des Castels à Nages-et-Solorgues (Gard) connaît plusieurs agrandissements successifs de sa superficie, du milieu du IIT s. av. J.-C. au début de notre ère, par ajouts d'aires ceinturées complémentaires. L'organisation la mieux connue commence avec la période "Nages II ancien", entre 250 et 175 av. J.-C. ; elle autorise une restitution planimétrique générale d'un quartier central (a et c). À l'intérieur d'une vaste enceinte de $6 \mathrm{ha}$, les pièces domestiques, uniques, de 20 à $25 \mathrm{~m}^{2}$ de superficie, sont strictement disposées dans le quartier exploré en longues files séparées par de larges espaces de circulation, sans aménagements collectifs d'écoulement des eaux. L'enceinte, épaisse et confortée de bastions ovoïdes régulièrement disposés, souligne le souci rationalisant et esthétisant des mâtres d'ouvrage comme leur volonté d'une affirmation de puissance par le complément d'une tour monumentale au point le plus élevé (TM). Au cours de la période "Nages II récent" (vers 175-125), l'apparition d'un nouveau quartier accolé confirme cette volonté régulatrice (b et d). Ailleurs, l'agrandissement de la largeur des files permet l'amplification des habitations et la complexification de leurs aménagements intérieurs. Aucune aire ouverte conséquente ni construction collective reconnue ne viennent troubler la monotonie de cet habitat fortement concentré. Ce n'est qu'au cours du $\Gamma^{\tau}$ s. av. J.-C. qu'un lieu cultuel à caractère monumental s'insérera dans la trame des cellules domestiques. Une mise en parallèle avec l'organisation intérieure de Biskupin (voir fig. 13) souligne dans ce quartier de Nages du It' s. l'absence de repères de ces différenciations sociales que les textes anciens laissent pourtant entrevoir dans les sociétés de la Gaule celtique, celles du Midi comprises (a et b, échelle: 1/4000; cet d, échelle: 1/2 000; d'après 13; 1990a, p. 705, $712,747,755)$. 
p. 140-141). Mais il faut convenir que l'usage du sol des rues pour la conduite des eaux de pluie ou de rejets anthropiques n'est pas propre aux communautés indigènes et qu'il se retrouve également dans maints quartiers de Marseille grecque jusqu'à l'époque tardo-hellénistique (Moliner, 1999, p. 84).

\section{LES CARACTÈRES AFFICHÉS D'UNE VOLONTÉ POLITIQUE}

La puissance communautaire de l'habitat groupé peut s'affirmer au travers de son enceinte pourvue d'une redondance de bastions, régulièrement distribués, et fortement inspirée des exemples grecs régionaux. Cette image affichée n'est cependant pas une nouveauté au milieu du second âge du Fer. Nous avions déjà reconnu cette répétitivité de bastions quadrangulaires sur l'enceinte de l'oppidum des Mayans, près de Marseille, à la fin du $\mathrm{VI}^{\mathrm{e}}$ s. (Tréziny, 1999, p. 263 et 282). Mais le développement de cette pratique dans la basse vallée du Rhône et ses pourtours se rapporte pour l'essentiel à la seconde moitié du $\operatorname{III}^{\mathrm{e}} \mathbf{s}$. et au $\mathrm{II}^{\mathrm{e}} \mathbf{s}$. av. J.-C. Elle intègre la forme ovoïde de tradition autochtone dans les vingt et un bastions de Nages-et-Solorgues, ou elle reprend le plan quadrangulaire du monde grec dans les dix-sept du Castellas de Solliès-Toucas dans le Var (Brun, Borréani dir., 1999, p. 745) ou encore dans les lignes défensives successives d'Entremont (fig. 22), les deux types pouvant être alternés comme à Ambrussum (Py, 1990a, p. 718-724). L'adjonction d'une tour monumentale sous la forme d'un bastion plus important, et sans doute plus élevé que les autres, vient amplifier la lisibilité de ce marquage territorial. Plusieurs exemples sont connus sur la rive droite du Rhône (Py, 1992b), celui de la Tour Magne à Nîmes étant le plus célèbre (fig. 19). À ce propos, la colline du Serre de Mauressip, située à $5 \mathrm{~km}$ à vol d'oiseau de Nages-etSolorgues, en bordure des plaines de la Vaunage, est occupée au $\mathrm{V}^{\mathrm{r}} \mathrm{s}$. et durant la première moitié du siècle suivant (fig. 14a). Elle voit l'édification à la fin du IV: $\mathbf{s}$. d'une tour monumentale quadrangulaire sur une partie du village arasé. Elle sera pourvue d'un parement en grand appareil de type hellénistique au début du II' $\mathrm{s}$. av. J.-C., adjonction qui porte les dimensions de la tour à $8,5 \mathrm{~m}$ de côté à sa base (Py, 1992b, p. 121-124). Cette réalisation exceptionnellement soignée, déconnectée d'une fortification et installée sur une terrasse de $200 \mathrm{~m}^{2}$, est intrigante bien que rapprochée à juste titre des tours précédentes (Py, 1993, p. $242-$ 243). À proximité des habitations de l'agglomération mitoyenne et surplombant un groupement d'habitats de bas de pente, échelonnés de 400 à 150 av. J.-C. (Nuninger, Raynaud, 2000, p. 45-46, fig. 9), cette tour est une marque monumentale sur un espace territorial défini. Compte tenu de sa qualité et de son isolement, elle peut être assimilée à la fois à un repère pour la circulation régionale et à un signe de domination sur son environnement. Elle exprime très certainement la magnificence et le prestige dont les formes du pouvoir local veulent désormais s'entourer. C'est celui d'une famille aristocratique dont la résidence est sans doute à rechercher hors de l'habitat groupé connexe, certainement une vaste ferme structurée parmi les vestiges repérés sur les coteaux voisins. C'est à des conclusions similaires que parvient l'analyse des installations rurales de la proche région nîmoise, pour l'essentiel à partir de la dispersion des monuments funéraires des $\mathrm{II}^{\mathrm{e}}$ et $\mathrm{I}^{\mathrm{er}}$ s. av. J.C. (Fiches, 1989, p. 221-229).

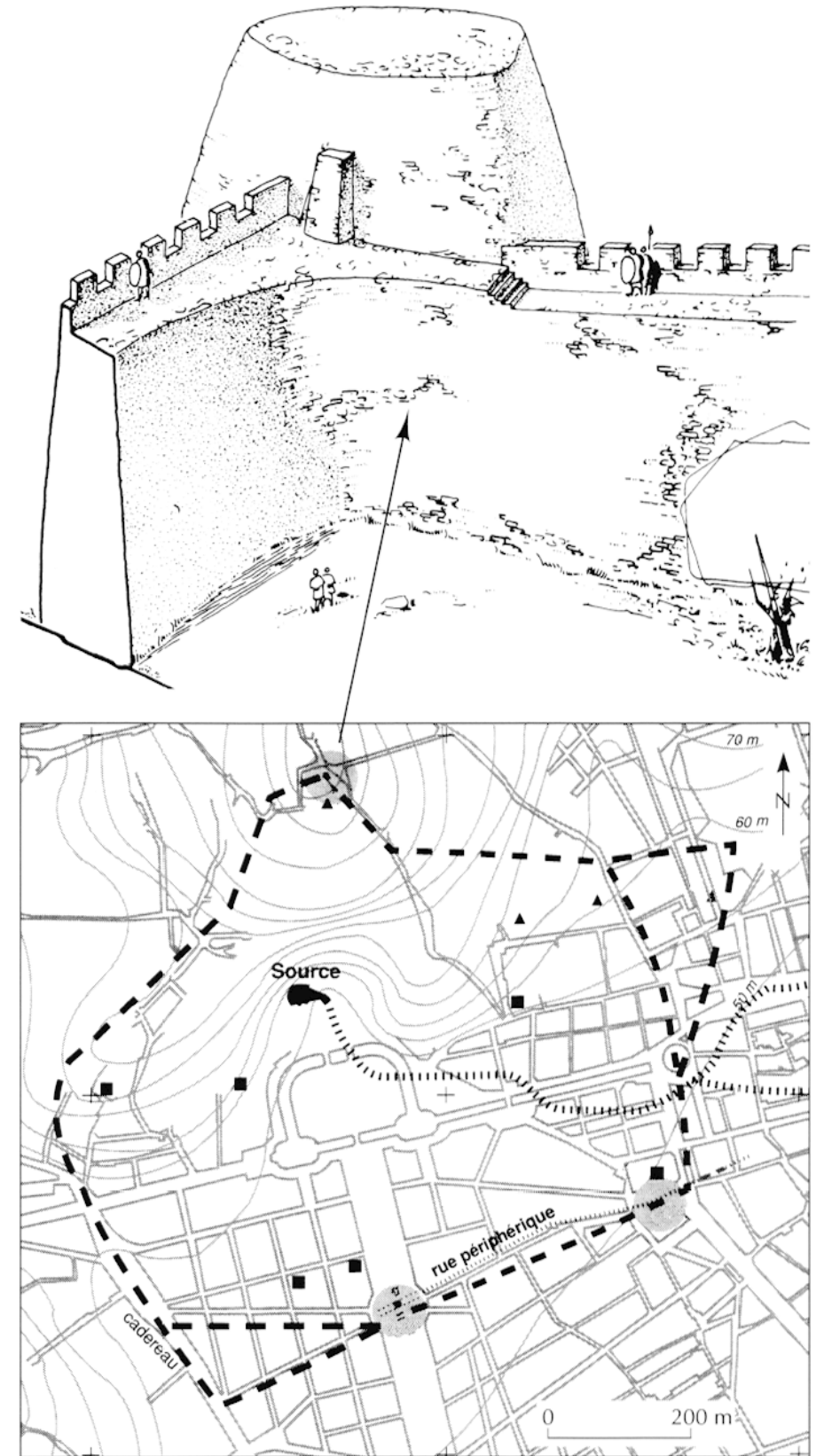

Fig. 19 - À partir de la fin du IV s., sur la rive droile du Rhône, des tours plus importantes que les autres amplifient l'aspect prestigieux de l'enceinte, pour la communauté résidante mais aussi et surtout pour leurs dirigeants. Une des plus célèbre est celle de la Tour Magne sur le Mont-Cavalier à Nîmes (Gard). Elle est édifiée au III' s. ou au début du It s. av. J.-C. sur la partie sommitale du site. Celte construction a élé englobée à l'époque romaine dans une nouvelle qui en a assuré la survie. Elle se trouve sur le tracé supposé de l'enceinte du It' s. av. J.-C. (DAO P. Varène, CNRS, d'après Monteil, 1999), p. 322-323).

Les habitats suffisamment explorés sur la rive gauche du Rhône, à l'instar des exemples précédents de Martigues, montrent la même pérennité des principes régulateurs antérieurs que ceux de la rive opposée au cours du second âge du Fer. Il en va ainsi dans la planification en îlots allongés des petits villages de L'Arquet à Martigues, de Notre-Dame-de-Pitié à Marignanc ou de Teste-Nègre aux Pennes-Mirabeau, durant 


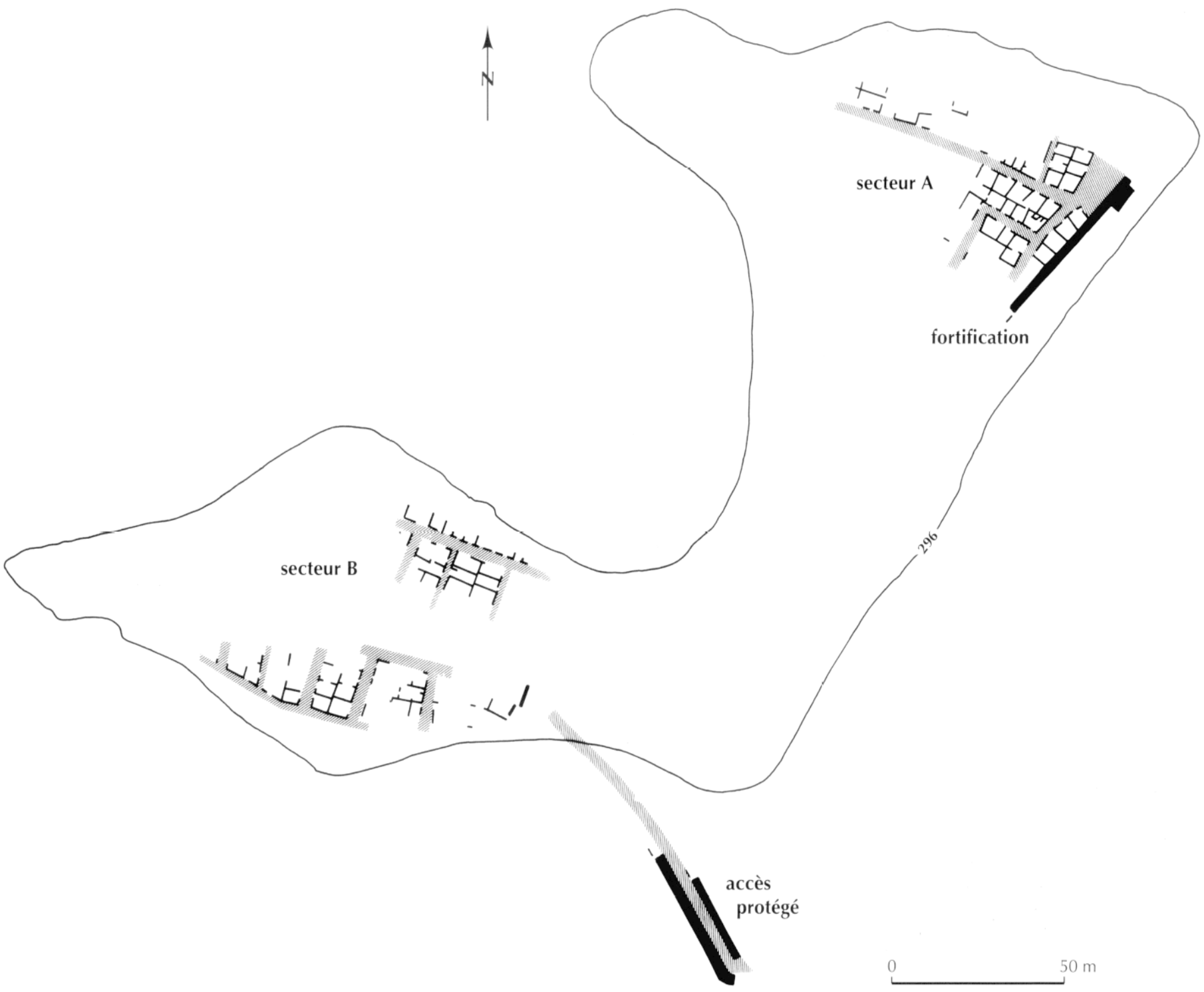

Fig. 20 - L'agglomération du Baou-Roux à Bouc-Bel-Air (Bouches-du-Rhône) révèle, entre 175 et 125 av. J.-C., la dernière étape d'une succession d'expansions, de retraits, voire d'abandons amorcés à partir du début du vt' s. av. J.-C. L'habitat occupe alors l'ensemble du plateau, soit environ 4 ha. Les espaces d'habitation, à pièce unique ou multiples, sont assemblés en îlots et s'ouvrent sur des ruelles. Les salles sont disposées autour d'un mur médian, rarement interrompu. La rationalisation de l'organisation prend en compte les contraintes de la topographie, en l'occurrence les limites d'un plateau relativement régulier. Deux secteurs ont été explorés, principalement en A, près du tronçon de l'enceinte (échelle: $1 / 2000$; d'après Boissinot, 1990, p. 91).

les $\mathrm{VV}^{\mathrm{e}}$ et III $\mathrm{s}$. (superficies de 0,2 à 0,5 ha) (Gantès, 1990a et b ; Arcelin, 1992d, p. 314-316). C'est au II $^{e}$ s., après 175, que de nouvelles agglomérations sont créées (Entremont 1, La Testede-l'Ost à Mimet, Le Baou-Rouge à Auriol : de l'ordre de 1 ha de superficie) ou que de plus anciennes s'amplifieront de façon conséquente : passage de 0,9 à 3,8 ha à Entremont dès 150 ; de 0,5 à 2 ha environ pour Pierredon à Éguilles; de 0,5 à 1 ha dans l'Île à Martigues; de 2 à 5 ha pour Le Castellas à Solliès-Toucas ou encore de 1,6 à 5,5 ha à La Courtine d'Ollioules... (fig. 15, 17 et 22) (Arcelin, 1986a, p. 66-67 ; Bérato, 1997, p. 146-147). Un choix de trois nouveaux exemples sélectionnés dans la proche région de Marseille illustre la perception structurelle et fonctionnelle de l'agglomération du $\mathrm{II}^{\mathrm{e}}$ s., comme l'image de sa place et de son rôle dans la société celto-ligure contemporaine.

\section{L'AGGLOMÉRATION DU BAOU-ROUX À BOUC-BEL-AIr (BOUCHES-DU-RIIONE)}

Le premier de ces habitats groupés est de superficie moyenne (4 ha) ; il est structuré au II' s. sur l'intégralité d'un plateau relativement horizontal. Après une longue utilisation qui remonte à la Préhistoire récente, c'est dans le deuxième quart du siècle que la nouvelle agglomération du Baou-Roux s'organise selon une trame découpée en îlots quadrangulaires et en files le long d'une fortification périphérique, enceinte renforcée de plusieurs bastions quadrangulaires (fig. 20). Les deux secteurs explorés de l'espace intérieur montrent une distribution des îlots très proche, pour ne pas dire quasiment identique à ce qu'elle était au ve s. dans la région. Ces îlots 
s'organisent au mieux, avec pragmatisme, séparés par des voies de 2,5 à $3 \mathrm{~m}$ de largeur, selon des axes imposés par les lignes de falaises et les fortifications. Aucune aire ouverte n'a été repérée, ni bâtiment à vocation collective ou entrepôt de stockage, mais il est vrai que l'essentiel du site n'a pas été exploré. À partir des fouilles du secteur $A$, deux ensembles d'observations peuvent être soulignés (Boissinot, 1984, p. 89-96 et 1990). On retiendra d'abord la structure même des îlots fouillés, constitués de pièces de 13 à $20 \mathrm{~m}^{2}$, rarement plus, et juxtaposées le long d'un mur axial. Ici, le système n'a pas la rigueur des dispositions de Nages-et-Solorgues, mais la médiocrité fonctionnelle des petites pièces indépendantes est compensée parfois par des réunifications de deux ou trois d'entre elles, mises en relation par une porte, parfois même aux dépens du mur central. Comme dans les sites de la rive droite, ou plus près à Martigues (L'île ou Saint-Pierre), aucun de ces assemblages du bâti ne s'articule autour d'une cour. Ce sont les voies de desserte qui compensent le manque d'espaces ouverts pour les besoins usuels des familles (foyers, fours...) ou de l'artisanat d'usage rural et domestique (travail du fer, du bois, de la pierre; outillages pour l'agriculture). Elles sont non seulement rétrécies par ces installations le long des façades, mais éventuellement barrées. À quelques détails près, les concepts qui régissent la mise en place de l'agglomération du Baou-Roux entre 175 et 125 av. J.-C. sont ceux de la fin du premier âge du Fer. Tout au mieux, au cours du troisième quart du II" s., perçoit-on dans les communications établies entre les pièces, dans leurs aménagements intérieurs ou le modeste artisanat pour l'outillage et la bijouterie, l'attrait d'une population foncièrement rurale pour un mode de vie un peu plus fonctionnel et pour une ouverture accrue vers la pratique de l'échange. Ici, comme ailleurs dans les principales agglomérations à partir du milieu du siècle, ce dernier phénomène est souligné par la rapide multiplication du monnayage et de ses petites divisions en bronze (Félisat, 1987).

\section{Le village de La Cloche auX Pennes-Mirabeau (Bouches-Du-Rhône)}

Le site de La Cloche est celui d'une large arrête rocheuse en forte pente vers les terrains marécageux du plan d'eau bordant les rives méridionales de l'étang de Berre. Bien que mis en place dans un premier état au début du $\mathrm{II}^{\mathrm{C}}$ s., ce village, d'une superficie d'environ 1 ha, est connu dans son extension de la première moitié du ${ }^{\text {er }} \mathbf{s}$. av. J.-C. (fig. 21). Fouillé sur pratiquement la moitié de sa superficie, la planimétrie, en terrasses avec ruelles en forte pente ou pourvues d'escaliers (Chabot, 1983 , p. 46-68), atteste toujours la continuité d'une distribution des espaces bâtis en pièces uniques d'environ 10 à $18 \mathrm{~m}^{2}$, rarement plus et avec peu de communications entre elles. Aucune aire ouverte n'existe dans les îlots agencés au mieux des contraintes de la topographie, les seules surfaces collectives étant celles qui sont peu constructibles, à l'entrée du village ou ménagées à la conjonction de voics comme au point $n^{\prime \prime} 2$ (fig. 21), également près d'une poterne dans la ligne de défense. Le besoin d'une amplification des espaces domestiques se fait ici sentir, comme au Baou-Roux, par un débord non seulement de la vie quotidienne dans les rues (fours, par exemple) mais également des façades et des massifs de montées

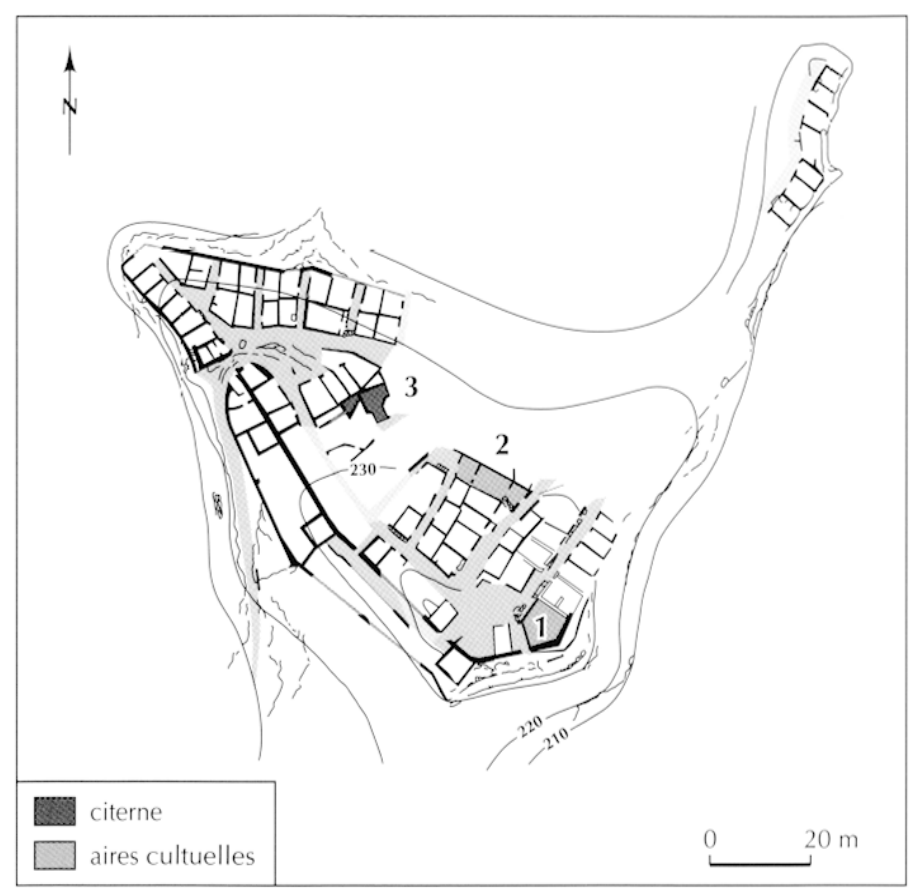

Fig. 21 - Le village de La Cloche aux Pennes-Mirabeau, près de Marseille, occupe le sommet et les pentes d'un escarpement sur les rives méridionales de l'étang de Berre. Fouillé sur la moitié de sa superficie totale (environ 1 ha), il résulte dans son plan actuel d'une restructuration au début du $I^{r r} s$. av. J.-C. d'installations mal connues du siècle antérieur. Cette petite agglomération, fossilisée par une destruction violente au milieu du $r^{r r}$ s. av. J.-C., constitue un bel exemple de la persistance des traditions organisationnelles de l'âge du Fer sur la chôra marseillaise, au moment de l'élaboration d'une lex provincia dans la Transalpine en cours de romanisation. Elle montre la présence d'un petit lieu d'offrandes près d'une poterne haute $\left(n^{\circ} 1\right)$ et suggère celle d'un herôon avec incinération ( $n^{\prime \prime} 2$ ?). L'impact romano-marseillais se fait désormais sentir par la mise en place d'une grande citerne collective maçonnée, réalisation intégrant une technologie jusqu'alors allochtone en milieu rural ( $\left.n^{\prime \prime} 3\right)$ (échelle : 1/2 000, DAO M. Rétif, Service archéologique de Martigues, d'après Chabot, 2000, p. 162).

d'escaliers édifiés pour rattraper un niveau ou, dans quelques cas, pour desservir un premier étage (voir en dernier lieu, Chabot, 2004). Nous reparlerons de cette troisième dimension architecturale à propos de l'exemple suivant. Particulièrement bien conservés du fait d'une destruction violente vers 50 av. J.-C., les vestiges du village montrent l'intégration parmi les cellules de petits locaux à vocation artisanale. On retiendra surtout dans ce contexte architectural très traditionnel, la présence de lieux cultuels et d'une citerne, cette dernière mettant en oeuvre des techniques d'origine massaliote (Chabot, 1983, p. 68-73 et 1992). Sans entrer dans les détails des découvertes, parfois très bouleversées par le pillage militaire du site, on notera l'existence d'un espace de dépôt votif, sans doute même antérieur à l'habitat dans son premier état; il est inclus dans une pièce près de la poterne haute (fig. 21, $n^{\circ} 1$ ) (Chabot, 1996). Ailleurs, une autre salle a dû abriter une urne en plomb qui pouvait contenir les cendres d'un personnage héroïsć 
(Arcelin et al., 1992, p. 205-206 ; Chabot, 2000, p. 164-165). Dès le début du second âge du Fer, lieux de dépôts propitiatoires aux divinités et cultes liés aux restes de héros peuvent être insérés dans les habitats groupés méridionaux, en concomitance avec l'accroissement du rôle de ces derniers sur les territoires. Non loin de La Cloche, la ferme défensive du Verduron a de même incorporé au III $^{\mathrm{e}}$ s. une incinération, honorée dans une cellule plus importante que les autres à proximité de la porte principale (fig. 16a, point 1) (Arcelin et al., 1992, p. 204 205 ; Bernard, 2000, p. 159-160). Dans tous les cas, les lieux cultuels dans l'habitat demeurent modestes et inclus dans le bâti existant, sans aménagement monumental même s'ils sont sans doute de nature collective. Seule la citerne apparaît, ne serait-ce que du fait de l'emploi du mortier de tuileau, comme une création de technologie allochtone mais à dévolution collective. Sa singularité dans l'habitat souligne plus ici la commande ou le " cadeau " d'origine marseillaise à un probable village perché, dépendant de sa proche chôra élargie, qu'une forte évolution des concepts structurels de cette population agropastorale.

\section{L'AGGLOMÉRATION D'ENTREMONT À AIX-EN-PROVENCE (BOUCHES-DU-RHÔNE)}

L'oppidum d'Entremont est très connu et de ce fait nous dispense d'une présentation trop détaillée (fig. 22) (Benoit, 1968 ; Coutagne éd., 1987). Couvrant une superficie totale d'un peu moins de $4 \mathrm{ha}$, cette agglomération de bord de plateau offre la particularité, comme à Nages-et-Solorgues, d'une implantation initiale somme toute modeste et qui sera fortement amplifiée une génération plus tard. Cette succession au cours du II $^{\mathrm{e}} \mathrm{s}$. permet de cerner plus finement l'évolution des besoins des communautés concernées dans un laps de temps relativement bref. C'est en effet vers 180-170 av. J.-C. qu'un premier habitat d'environ 0,9 ha est installé sur la partie sommitale, en pente douce (fig. 22a, habitat 1). Comme pour celui de Nages "II ancien" (fig. 18a), cette création est conçue dans sa totalité au travers d'une planification géométrique déployée dans l'aire losangique formée par les falaises méridionales, puis la ligne de défense parallèle. On note immédiatement le caractère presque symbolique et décoratif de cette fortification 1, mince (moins de 1,5 $\mathrm{m}$ de largeur), pourvue de bastions quadrangulaires pleins et rapprochés dont quatre subsistent sur le flanc nord. L'organisation des modestes cellules de 10 à $15 \mathrm{~m}^{2}$, sans doute comme autant d'espaces indépendants dans l'état initial (Arcelin, 1987, p. 61-62 et 70), adopte le regroupement en petits ensembles quadrangulaires de 10-11 m par $24 \mathrm{~m}$ de côté, articulés sur un mur axial. Au moins douze îlots sont ainsi régulièrement agencés dans la zone septentrionale, les six méridionaux (très dégradés par l'érosion) sont, eux, structurés plus irrégulièrement pour rattraper un alignement sur la falaise sud-est. Les rues, dépourvues de canalisation de drainage, sont en terre battue mais parallèles et de largeur suffisante (2 à $3 \mathrm{~m}$ selon les secteurs); certains angles d'îlots sont arrondis pour faciliter la circulation des véhicules de transport. On ignore si les bases de montées d'escaliers plaquées contre les façades appartiennent au premier ou au deuxième état de l'habitat. Une file de pièces est distribuée régulièrement contre les courtines septentrionale et orientale pour les renforcer. Sauf à admettre qu'il puisse se situer dans la moitié méridionale de l'habitat, aucune aire ouverte conséquente ne paraît présente dans l'enceinte, ni d'ailleurs de bâtiment d'usage collectif. On peut seulement soupçonner la présence probable, comme nous l'avons souligné pour l'habitat précédent, d'un lieu à vocation cultuelle, espace proche inféré d'après les vestiges recueillis dans un dépotoir d'objets de la deuxième occupation (Willaume, 1987, p. 130-134 et 1998, p. 59-60). En dépit du soin apporté au tracé établi sur une métrologie précise (Tréziny, 1989, p. 35-39) et à l'esthétique résolument soignée prenant référence dans le formalisme grec, l'image des modes de vie et d'organisation de la communauté agricole qui l'occupe relève à cette époque d'un profond archaïsme puisqu'ils sont peu différenciés, aux évolutions de la culture matérielle près, de ceux définis près de Marseille dès la première moitié du VI ${ }^{\mathrm{e}} \mathrm{s}$. (fig. 8) (Willaume, 1998 ; Arcelin, 1992a, p. 326-331)!

Au milieu du siècle, l'agglomération va quadrupler sa superficie. L'habitat 1 est restauré et légèrement remanié dans l'aménagement intérieur des îlots. La fortification 1 disparaît en tant que telle; elle est arasée et remplacée par une nouvelle enceinte de $380 \mathrm{~m}$ de longueur, au rôle défensif plus affirmé tout en conservant une image ostentatoire. Si, d'après les sondages de F. Benoit, l'intégralité de la superficie du plateau dans l'enceinte 2 paraît occupée, seul le secteur proche de la porte principale a été exploré de façon conséquente (fig. 22a, habitat 2).

Au plan de l'organisation du bâti de ces nouveaux quartiers, quatre constatations majeures peuvent être faites. La première est celle de la similitude des principes organisationnels de l'espace délimité avec ceux de l'habitat 1 : ainsi dans l'alignement de pièces le long des lignes de défense et dans leur rassemblement en îlots quadrangulaires ailleurs. Comme auparavant, le système est aussi suffisamment pragmatique pour permettre des rattrapages d'alignement, par exemple face à la fondation remployée de la fortification 1. D'autre part, $H$. Tréziny a souligné les parallèles métrologiques existant entre les deux habitats (Tréziny, 1989, p. 39). La deuxième observation porte sur l'augmentation systématique de la superficie des espaces couverts entre les deux états, tant dans les dimensions des pièces que dans l'ampleur de leurs associations. C'est ainsi que lors de la mise en place de l'agrandissement vers 150 av. J.-C., les salles sont assez systématiquement groupées par deux, en particulier le long de la nouvelle fortification. Au cours de deux reprises architecturales successives entre 140 et 100-90 av. J.-C., des restructurations partielles de l'espace détermineront des groupements de trois à quatre pièces. La troisième remarque porte sur les trois îlots, complètement ou partiellement fouillés, pour noter l'absence de cours intérieures assurées à de rares exceptions près : ainsi celle située devant les alandiers de trois fours et dont la vocation est certainement de nature artisanale et non domestique (Benoit, 1968, p. 19-22) ; une seconde possible dans le premier état de l'îlot 8 (inédit); une autre enfin, souvent envisagée, dans un îlot voisin, mais loin d'être établie, bien au contraire (voir en dernier lieu, Chazelles, 1999, p. 492, fig. 4). Quatrième point enfin, les fouilles des années 1980 ont conduit à développer 


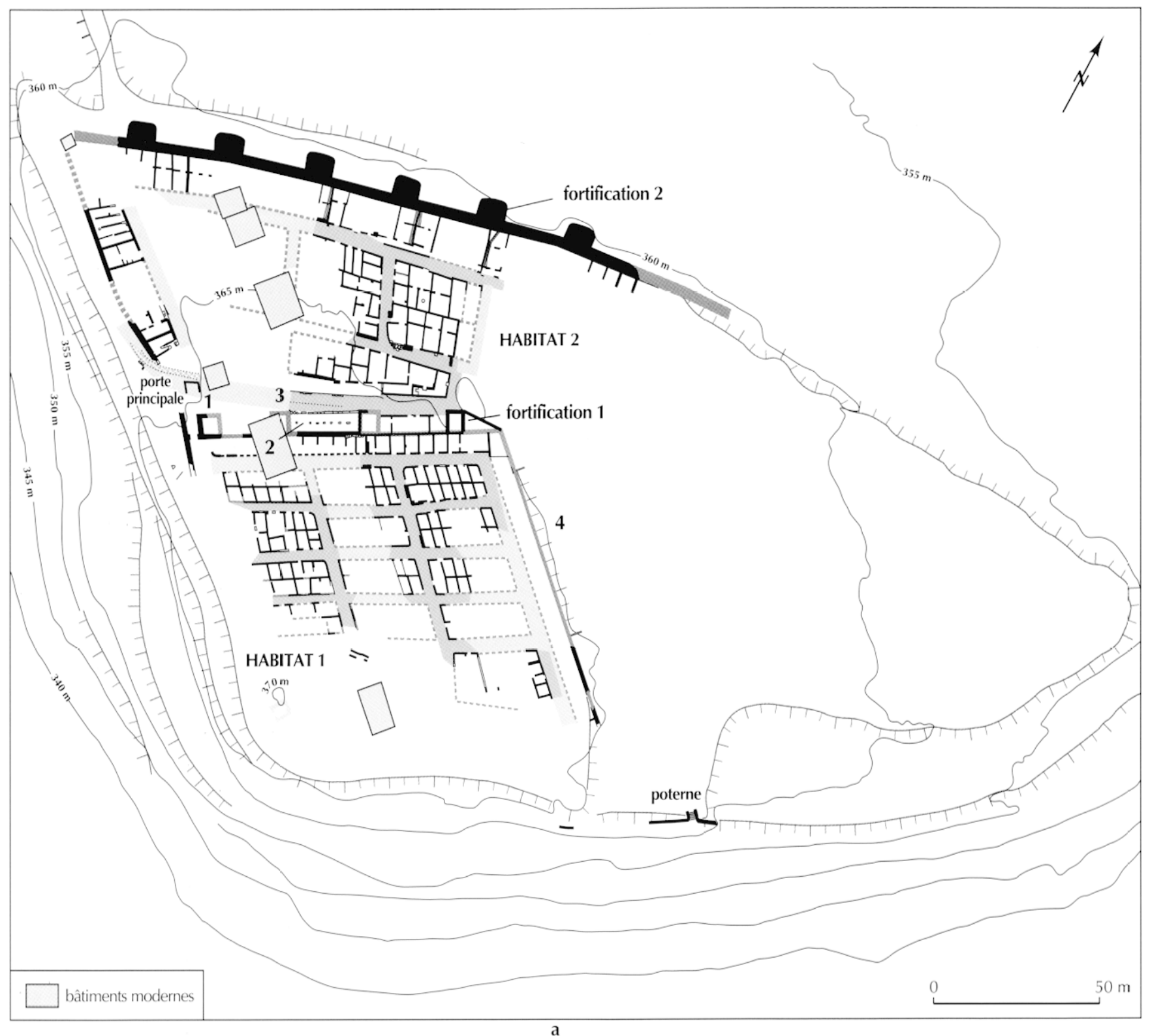

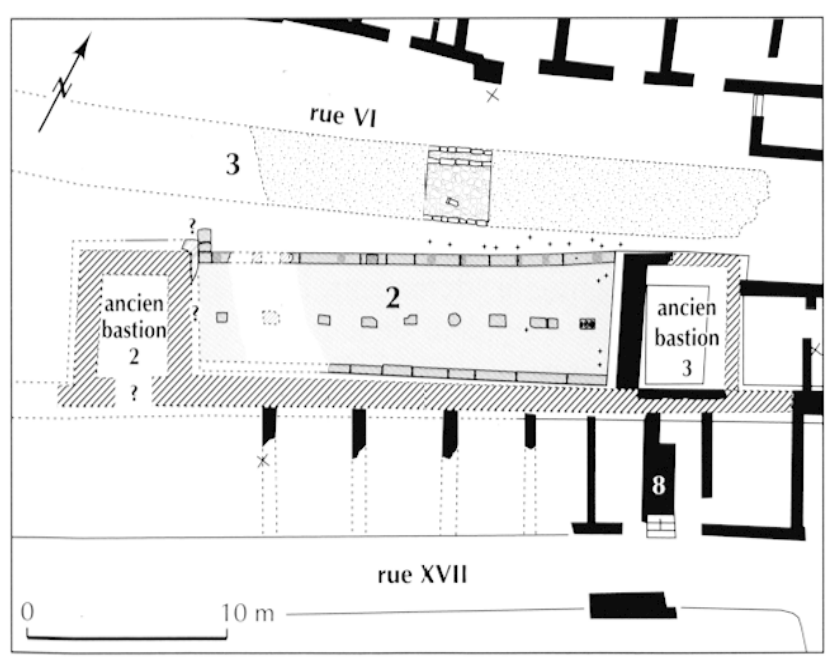

b

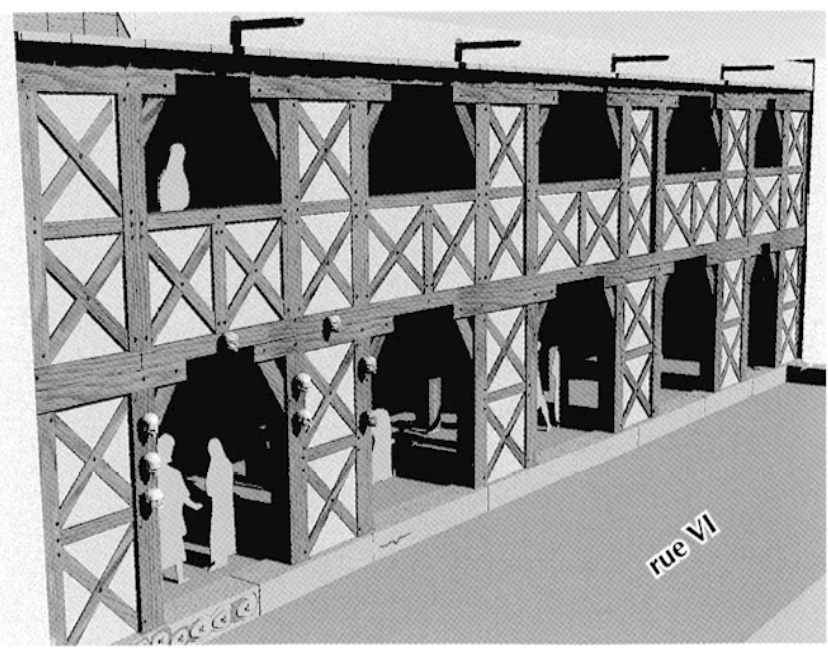

Fig. 22 - Le site d'Entremont, au nord d'Aix-en-Provence (Bouches-du-Rhône), est l'un des exemples qui illustrent usuellement l'état de l'habitat provençal à la fin du second âge du Fer. L'ampleur des dégagements réalisés depuis 1946 (a) offre, de fait, une lecture intéressante des concepts très traditionnels régissant un premier habitat au cours de la première moitié du If s. av. J.-C. (habitat 1 de 0,9 ha); elle autorise ensuite une estimation de leurs degrés de transformation durant la seconde moitié du siècle lors d'un important regroupement de populations à l'annonce de conflits opposant les communautés régionales indigènes et helléniques (habitat 2 de 3,8 ha). Au cours de l'ultime période de l'occupation du site (dernier quart du It' s.), une salle hypostyle est édifiée (ou reconstruite ? : $n^{0}$ 2) en relation avec la perspective offerte par l'aire de dégagement de l'entrée principale $\left(n^{\circ} 1\right)$ et l'aménagement d'une voie élargie (rue VI: $n^{0}$ 3) (b). Une des propositions de restitution de la salle s'ouvranl sur la rue VI (c). Il s'agit d'un des premiers exemples d'aménagement public dans le contexte communautaire des sociétés traditionalisles de la basse vallée du Rhône, mais il est vrai en parallèle à la mise en place de l'Aquae Sextiae romaine proche (échelle: 1/2 000; DAO M. Rétif, Service archéologique de Martigues et P. Arcelin, CNRS, d'après Arcelin et al., 1990, p. 128 ; complété d'après Dufraigne, 2000a, p. 139; Arcelin, Blaustein, 1998, p. 42 ; restitution M. Blaustein). 
une argumentation archéologique en faveur d'une organisation spatiale du bâti plus complexe que celle suggérée par la simple lecture planimétrique. Elle intègre la présence d'au moins un premier étage occupé ${ }^{9}$ (Arcelin, 1987, p. 71-72 ; Arcelin el al., 2001). Cette nouvelle dimension architecturale, entrevue dans l'habitat de La Cloche et d'autres, permet ici de comprendre et de mieux interpréter l'existence d'un fort artisanat et d'un abondant stockage dans les salles en rez-dechaussée. On constate en effet dans les secteurs fouillés d'Entremont 2, une présence très soutenue de l'artisanat en général, relevant ici en particulier de la transformation des produits de l'agriculture : 17 à 18 éléments ou fragments de maies de pressage et les contrepoids des leviers correspondants ont été découverts dans ce quartier (Brun et al., 1998, p. 48 et cédérom, écrans 20-28). Même si des exceptions existent, la vie domestique doit être ici envisagée pour l'essentiel au plan du premier étage plutôt qu'au niveau du sol, le plus aisément lisible par l'archéologue. L'habitat 2 d'Entremont (entre $150 \mathrm{et}$ 110-90 av. J.-C.) (Arcelin, 1987, p. 64-65) témoigne de l'émergence brutale sur le site de deux phénomènes distincts mais intimement liés : celui d'un savoir-faire dans le domaine de la transformation des produits agricoles et celui d'une véritable classe d'artisans spécialisés. Salles dédiées au pressage des raisins et/ou des olives, groupement de fours disposés autour d'une cour pour le chargement des alandiers et résidus d'un atelier de verrier constituent des arguments forts (Arcelin $e t a l$., 2001). Cette prégnance de l'artisanat participe de l'explication d'une amplification des pièces et de leur communication, par ses impératifs techniques et ses besoins du stockage, les dolia étant très nombreux. Pour justifier de l'apparente spontanéité de ces deux phénomènes, nous avions déjà avancé la proposition suivante : le quadruplement de la superficie du site après une génération d'occupation du plateau résulte d'un regroupement délibéré et organisé d'une population provenant d'autres habitats groupés ou plus certainement d'installations plus dispersées et peu fortifiées sur les territoires voisins. Vers 150 av. J.-C., la raison de ce mouvement de concentration est certainement à rechercher dans l'accélération des conflits militaires avec Marseille grecque et les premiers intervenants italiens sur la côte. C'est dans ces habitats antérieurs que l'on trouvera la source du développement des savoir-faire de l'artisanat qui caractérisent Entremont 2. Récemment, quelques indices en ce sens sont apparus dans la présence de contrepoids ou de pressoirs au sein des deux complexes ruraux singuliers présentés précédemment, celui de Coudounèu vers 400 : contrepoids (Verdin et al., 1997, p. 188-190, fig. 20 ; Verdin, 2000 , p. 148) et celui de Roquepertuse, dans le courant du III $\mathrm{s}$. av. J.-C.: maie de pressoir en remploi dans un escalier (Boissinot, 2000b, p. 153, fig. 4).

Tel qu'on l'a parfois caractérisé, le « boom » artisanal et économique d'Entremont dans la seconde moitié du II" $s$. doit être

9. I.es arguments reposent sur la présence de montées d'escaliers établies contre les façades dans les rues, comme sur l'observation de lambeaux des sols supérieurs disloqués dans les effondrements fouillés, sur lesquels reposent des vestiges de foyers culinaires, des objets entreposés et de la bijouterie. relativisé, non dans sa réalité mais du fait d'un plus large étalement dans le temps de ses antécédents. Le premier habitat groupé ne constitue pas la réponse appropriée, car sans être inexistante la composante artisanale est modeste, conséquence d'une autoconsommation traditionnelle, à l'image d'un " travail à domicile " pour reprendre l'expression de M. Py (1993, p. 224). Des témoignages archéologiques antérieurs sont disponibles. Ils proviennent d'une part de remplois dans l'habitat groupé de l'Île à Martigues au début du second âge du Fer : fragments de maies et nombreux pépins de raisins dans ce village (Chausserie-Laprée, Nin dir., 1988, p. 33 et 92-93), mais aussi du hameau et du grenier précédents, que nous avons proposé de lier à des possessions foncières aristocratiques. Ces deux exemples nous laisseraient entrevoir pour la première fois dans la basse vallée du Rhône le rôle de ces dernières dans le développement des pratiques technologiques et artisanales, avant une plus large diffusion au $\mathrm{II}^{\mathrm{e}} \mathrm{s}$., comme dans la constitution de stockages des produits agropastoraux pour l'approvisionnement des circuits de l'économie. Toutes proportions gardées, ces centres ruraux, des greniers ou de grandes fermes en somme, bien qu'encore fort mal connus faute de recherches en ce sens dans le Midi gaulois, pourraient trouver des similitudes avec les vastes exemples contemporains désormais célèbres de Saint-Symphorien à Paule, dans les Côtes-d'Amor (Ménez, Arramond, 1997) ou de Mas Castellar de Pontós dans l'Empordà (Blasco, Buxó i Capdevila dir., 1998).

Pris globalement au plan morphologique, les modes de regroupement des ensembles de pièces d'Entremont 2 sont toujours élaborés selon une planimétrie traditionnelle, en files ou en îlots articulés sur un mur axial. Nous avons vu qu'aucune cour ne contribue au regroupement des espaces de la vie familiale et artisanale pour constituer l'entité privée par excellence qu'est la « maison". Par ailleurs, les rues (autour de $3 \mathrm{~m}$ ), guère plus larges que dans l'habitat 1 , conservent toujours leur dévolution comme espace de prolongement de la vie domestique et artisanale. On y fait encore du feu, on y déverse des rebuts et l'on est même amené à les barrer partiellement. Bien qu'aménagées à l'aide de pierres, de galets, de lits de morceaux de dolia et pourvues d'un revêtement de graviers de rivière, bien que drainées aussi à intervalles réguliers en bordure de la fortification 2, ces voies de circulation demeurent toujours partiellement accaparées par les tâches de la vie quotidienne des riverains (Arcelin, 1987, p. 72-76 ; Dufraigne, 2000a, fig. 3).

\section{Premiers aménAgements POLITICO-ReligieuX À ENTREMONT}

Même si la séparation des espaces privés de ceux d'usages collectifs ne se manifeste pas avec évidence dans les rues d'Entremont 2, trois indices remarquables et localisés pourraient constituer ici les signes avant-coureurs d'une évolution des mentalités à la veille de la romanisation de la Transalpine.

Le premier est celui lié à la célèbre statuaire. Une large part des 290 fragments connus provient des découvertes fortuites de 1943, puis des fouilles de 1946-1956. Beaucoup participaient, en remblai, à l'aménagement du radier de la dernière voie de circulation en arrière de la porte principale de l'habitat 2 (fig. 22a, point 1) (Congès, 2004). Le catalogue publié par F. Salviat 
(1987) et les analyses plus récentes de A. Rapin et de nousmême (Guillaumet, Rapin, 2000, p. 83 ; Arcelin, Rapin, 2002 ; Arcelin, 2004) suggèrent que le groupe de dix-huit à vingt statues connues ${ }^{10}$ a été très certainement rapporté des territoires voisins dans l'enceinte de l'habitat 2 , vers le milieu du II ${ }^{\mathrm{e}} \mathrm{s}$. et sous la pression d'une situation conflictuelle. La répartition des sculptures en trois groupes principaux et aux composantes répétitives montre une présentation des membres masculins et féminins de familles aristocratiques disposés autour de personnages assis et héroïsés. L'analyse iconographique de la sculpture rapporte l'essentiel de ces œuvres au III $^{\mathrm{C}}$ s., plutôt même dans la première moitié, c'est-à-dire plus d'un siècle avant leur exposition probable près de l'entrée de l'habitat 2 ! Pour expliquer cette apparente contradiction, on pourrait envisager un scénario historique dans lequel les populations qui se rassemblent au milieu du $\mathrm{II}^{*} \mathrm{~s}$. dans le nouvel habitat aient non seulement véhiculé leurs connaissances techniques et leurs habitudes artisanales mais également les objets figurés de leurs pratiques cultuelles hypothétiquement menacés par la protection très limitée des installations domaniales. Un tel lieu voué au culte d'un lignage héroïsé est présent sur le site aristocratique armoricain de Paule (Ménez et al., 1999).

Le deuxième indice peut être mis en rapport avec la forte probabilité de l'existence d'une salle ou d'une " chapelle ", en relation avec un culte héroïque. Des blocs ornés de bas-reliefs ont été découverts en 1817 en remplois au centre du site, d'où ils auraient été extraits par des agriculteurs (Loqui, 1839, p. 6-7 et note 4 ; Rouard, 1851) (fig. 22a, point 4). Ces blocs, figurés et historiés, appartiennent selon toute vraisemblance à des piédroits de porte (Salviat, 1987, p. 214-219; Arcelin, Gruat et al., 2003, p. 204-205, fig. 114). Outre les incertitudes de la localisation de cette probable construction, demeure également celle du moment de sa mise en place.

Le troisième faisceau d'informations est, lui, de nature architecturale. Il s'agit d'une salle monumentale installée dans l'espace intermédiaire entre deux anciens bastions de l'enceinte 1 (fig. 22, $\mathrm{n}^{\circ} 2$ ), en bordure de la voie issue de l'entrée principale, spécifiquement aménagée pour mettre en valeur le bâtiment. Cette construction, qualifiée de "sanctuaire aux Esprits " par F. Benoit à cause des têtes humaines exposées sur sa façade, a été reconsidérée à l'occasion de deux publications récentes qui en ont proposé des restitutions tridimensionnelles (Arcelin, 1992b, p. 1423 ; Arcelin, Blaustein, 1998). La figure 22b rappelle le plan de cette salle d'environ $100 \mathrm{~m}^{2}$ au sol, hypostyle, certainement en partie ouverte sur la rue VI en rez-de-chaussée. Construite à pans de bois, elle possédait un étage dont un secteur au moins était décoré avec un certain luxe: sol de pseudo-opus signinum et parois enduites d'une couche de chaux blanche (fig. 22c). Devant elle, la rue a été

10. Comme on le sait, ces figurations, en grandeur nature et en rondebosse, sont très fragmentaires. L.es valeurs avancées correspondent donc à une évaluation prudente et minimale. Compte tenu que tout le secteur situé entre la porte $\left(n^{\circ} 1\right)$ et la salle hypostyle $\left(n^{\circ} 2\right)$ n’a pas été fouillé en totalité, un certain nombre de découvertes complémentaires sont aisément prévisibles. Ces chiffres devraient être en réalité bien plus élevés. particulièrement aménagée, avec une bande centrale de roulement (radier de pierres et couverture de graviers) et un élargissement conséquent (jusqu'à $5,5 \mathrm{~m}$ ), le tout incontestablement destiné à créer un accès soigné (pour des chars ?) ainsi qu'une véritable perspective. Le monument existait lors du dernier état de l'habitat 2 (vers 123-100/90 av. J.-C.) ; on ignore, faute d'interrogation archéologique, si sa mise en place pouvait être légèrement antérieure. Outre sa qualité architecturale et l'intégration de techniques nouvelles, l'intérêt premier de cette vaste salle réside dans la connotation politique et culturelle qu'elle semble recouvrir, alors que la statuaire précédente venait d'être volontairement brisée. On connaît d'autres exemples de vastes salles, contemporaines, voire de peu antérieures, ainsi à Mouriès dans les Alpilles (Marcadal, 1992). Mais la qualité de la construction d'Entremont revêt cet édifice, intégré dans un véritable aménagement de l'espace, d'une fonction collective de prestige. C'est une des premières constructions d'une telle ampleur observée au sein d'une agglomération indigène, même s'il est vrai que sa réalisation doit être mise en perspective avec la création historique du castellum romain voisin d'Aquae Sextiae (Strabon, Géographie, IV, 1, 5).

\section{MUTATIONS SOCIALES ET ÉMERGENCE DU FAIT URBAIN}

Dans ce panorama du mode de l'habitat groupé dans la basse vallée du Rhône, nous avons opposé deux images conceptuelles pour mieux mettre en valeur les tendances essentielles de cette région du Midi. Celle, d'abord, des cultures indigènes dont la dynamique sociale du premier âge du Fer engendre et promeut en deux siècles le principe structurel d'une planimétrie rationalisée de ce type d'habitat, quelle que soit son importance démographique. Derrière ce formalisme organisationnel qui reflète des communautés très hiérarchisées et fortement encadrées par une classe sociale qui s'individualise dès le premier âge du Fer et trouve avantage à ce mode de concentration, les composantes de ce type d'agglomération demeurent foncièrement rurales, sans aucun développement des marques d'un pouvoir résidant autre que celles que constituent les capacités productive et défensive de ces rassemblements humains. C'est en définitive à des " bourgs ", lieux de production et de marché, que l'on pourra assimiler la très grande majorité des habitats groupés rhodaniens et non à des " protovilles ". Nous les avons opposés, d'autre part, aux implantations coloniales grecques. Massalia bien sûr, dont la diversification sociale, politique et religieuse accompagnant la dynamique économique de la polis dès les années 540-530 a engendré un processus d'urbanisation structurée (Bouiron, 1999, p. 55, plan 4 ; Moliner, 1999, p. 84). Mais également, à partir du Ive s., à l'agencement plus modeste des clérouquies côtières de la métropole phocéenne dont Olbia de Provence est la meilleure illustration (Hermary et al. dir., 1999, p. 87-88). C'est dans cette opposition relativement tranchée, et qui se pérennise jusqu'au II" s. av. J.-C., que la basse vallée du Rhône s'individualise clairement des évolutions d'autres régions du Midi, en particulier du Languedoc occidental et du Roussillon (Py, 1993, p. 162169 ; Chazelles, 1999, p. 483-486 ; Garcia, 2000c). 

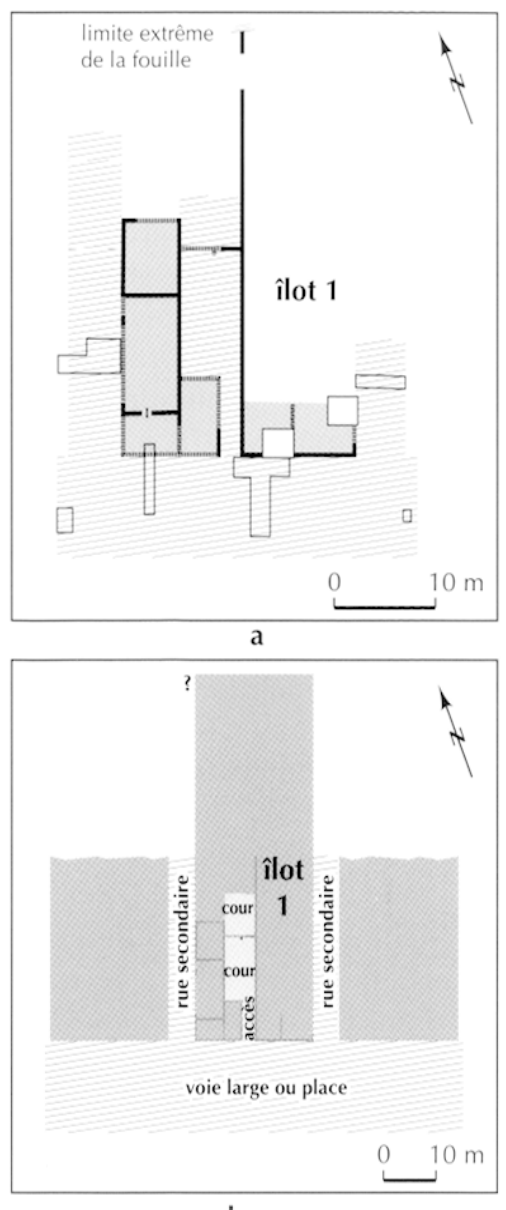

b
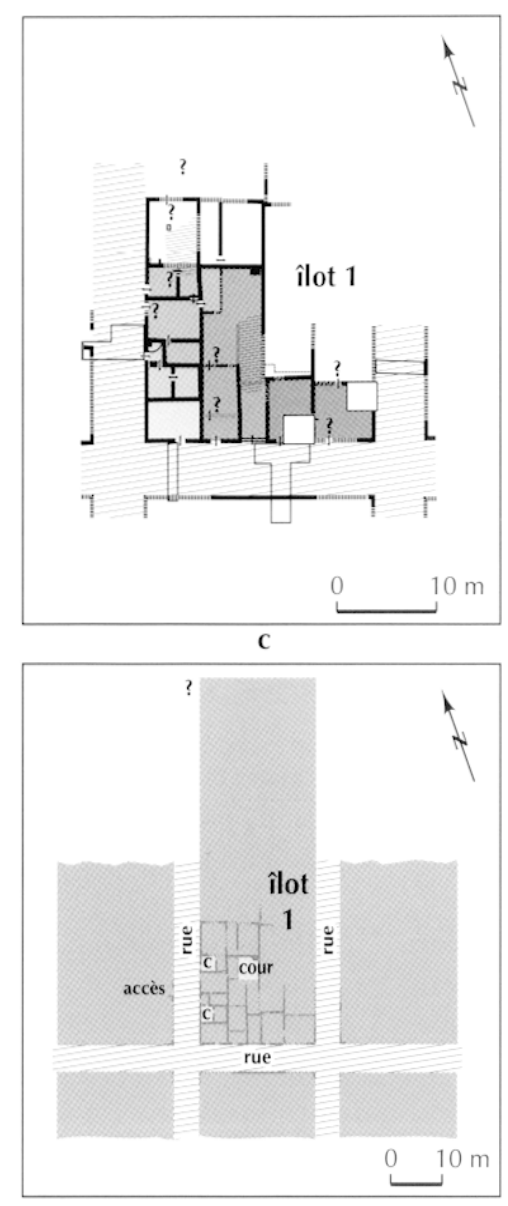

d
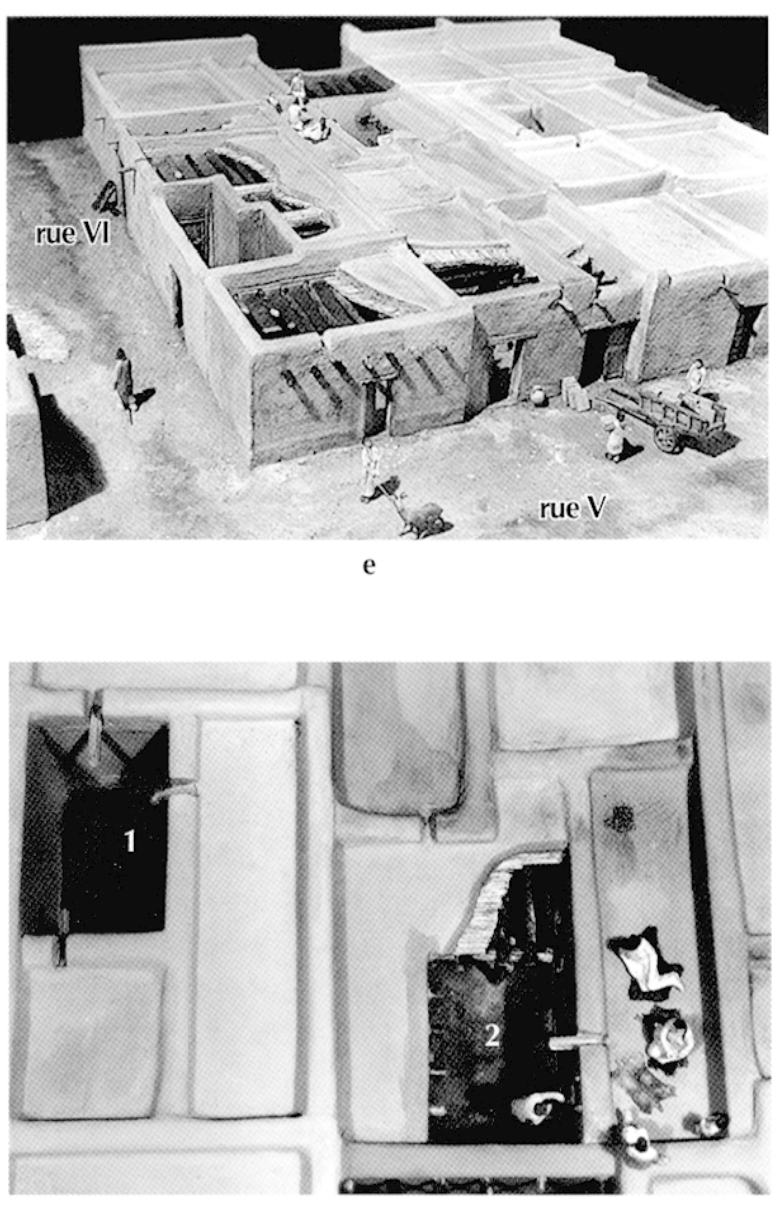

Fig. 23 - La vaste agglomération d'Arles (Bouches-du-Rhône) paraît se ranger, de la fin du Vt's. au début du It's. av. J.-C., dans un autre processus conceptuel et évolutif, celui d'une implantation coloniale grecque (jusque vers 400-375), puis pour ses quartiers périphériques - comme ici au Jardin d'Hiver -, dans une reconquête des espaces habités par une communauté essentiellement indigène mais assez sensiblement hellénisée: $a$ et b, l'îlot $1 d u v^{\prime} s$. av. J.-C., avec ses grandes cours intérieures et le réseau de rues de son entourage; restitution planimétrique; $c$ à f, états au milieu et à la fin du $\mathrm{IV}^{\dagger}$ s., avec des habitations à pièces multiples et des petites cours intérieures; restitution planimétrique et maquette (échelles : $1 / 1000$ et 1/2 000 ; d'après Arcelin, 2000, p. 12 ; maquette D. Delpallilo, musée de l'Anles antique, cliché P. Arcelin, CNRS).

\section{LA THELINE GRECQUe ET L'ARELATE INDIGÈNE}

Dans ce tableau en bichromie des comportements sociaux rhodaniens de l'âge du Fer, un autre courant, jusqu'alors mal cerné par la recherche régionale, apporte une nouvelle tonalité. Différents indices nous laissent entrevoir un panorama socio-économique plus diversifié et donc plus complexe. Nous avons précédemment suggéré que l'origine du phénomène pourrait plonger ses racines dans la création d'un emporion phocéen sur le rocher d'Arles dès les années 540-530 av. J.-C., en liaison avec Marseille grecque (Arcelin, 1995, p. 333-335 et 2000 c, p. 7-10). Les fouilles des années 1980 ont mis en évidence la rapide extension du noyau initial peu après 500 , sous la forme d'amples quartiers périphériques repérés sur les pentes méridionales du site (fig. 23). Sur la base d'une argumentation architecturale ainsi que sur l'évolution des mobiliers contenus, nous avons proposé d'assimiler l'image de la vaste agglomération d'au moins 30 ha qui se dessine au ve s. à celle d'une véritable implantation coloniale grecque (une apoikia), un port au centre de la basse vallée du Rhône. Cette colonie, apparemment d'obédience marseillaise, serait la plus ancienne et la seule tentative d'installation grecque hors de la frange côtière. Son souvenir n'a été conservé dans la littérature antique qu'au travers de l'allusion poétique des vers de Festus Aviénus (Ora Maritima, v. 689-691 ; Clerc, 1927, p. 152-153). Les recherches dans le quartier du "Jardin d'Hiver " ont permis la découverte d'un îlot mis en place dès le début du v"s. (fig. 23a et b). De 23,2 $\mathrm{m}$ de large par au moins $34 \mathrm{~m}$ de longueur minimale (sans doute le double en réalité), il est entouré de rues orthonormées dont une très large de plus de $9 \mathrm{~m}$. Il est possible d'y reconnaître une platea et deux stenopoi. L'îlot comporte de vastes cours intérieures autour desquelles se distribuent les pièces d'habitation. Voies et cours sont aménagées par l'apport d'un revêtement préparé (sables, graviers et céramiques concassées) et ne présentent pas de rejets domestiques conséquents. Une métrologie identique à celles d'Agde, d'Olbia 
ou de Saint-Blaise paraît avoir été utilisée (Tréziny, 1989, p. 45). Après la récession économique du début du second âge du Fer, la structuration intérieure de l'îlot exploré sera davantage subdivisée, phénomène accompagné d'une forte augmentation des produits indigènes. $\mathrm{Si}$ la population de ce quartier périphérique de l'agglomération d'Arles devient majoritairement autochtone au cours de la première moitié du $\mathrm{IV}^{\mathrm{C}} \mathrm{s}$. av. J.-C., elle n'en demeure pas moins fortement hellénisée dans ses conceptions architecturales (véritables "maisons " à pièces multiples hiérarchisées et à petites cours intérieures, fig. 23e et f) et ses modes de vie domestiques (ainsi dans l'usage des braseros pour la cuisson alimentaire). Dans la seconde moitié du Ive s., une forte poussée démographique entraîne la réduction de la platea pour permettre l'adjonction d'au moins une rangée d'îlots supplémentaires, en limite des terrains humides (fig. 23c et d). En dépit de remaniements des espaces ouverts et couverts dans l'îlot, la structure urbaine du quartier se maintient jusqu'à une désertion, suite à un rétrécissement de la ville vers 175 av. J.-C.

Outre quelques indices ténus de la présence d'édifices monumentaux sur le rocher d'Arles dès le $\mathrm{v}^{\mathrm{e}} \mathrm{s}$. au moins, la planification orthonormée du quartier méridional fouillé, sa métrologie, la structuration des habitations à plusieurs pièces autour d'une cour et, surtout, la séparation de la vie familiale au sein des îlots du domaine collectif que représentent les rues éclairent ici les agencements d'un urbanisme régi par les notions d'espaces privés et de droit public. En dépit du synœcisme des populations présentes dans l'agglomération de Theline à partir du IV's., sans doute appelée dès lors Arelate, on observe dans ce quartier périphérique à dominante indigène une large adoption de valeurs architecturales et domestiques issues du monde méditerranéen. En somme, au début du second âge du Fer, le port d'Arles sur le Rhône n'est certainement plus, au sens juridictionnel du terme, une colonie de Marseille grecque, mais une plaque tournante économique au cœur de la basse vallée du fleuve, certainement orientée sur une activité de redistribution et d'échanges vers les Costières du Gard, les Alpilles et les régions septentrionales de proximité. En observant le degré "d'acculturation " de la population indigène de l'agglomération aux $\mathrm{IV}^{\mathrm{r}}$ et $\mathrm{III}^{\mathrm{e}} \mathrm{s}$. av. J.-C., on peut penser que l'action régionale de cette dernière a été de nature économique certes, mais également de portée culturelle. À partir du milieu du III $^{\circ}$ s., l'implication rapide d'Arles dans la dynamique naissante du commerce italien, à l'instar de Marseille, sera pour ce centre économique un facteur de renouveau, le transformant en premier relais portuaire d'une activité marchande qui s'élance à la conquête de la Gallia Comata dans la première moitié du II" $s$.

Le prestige de Massalia et l'incontournable prégnance économique, que la ville grecque a infligée à sa proche région, de même que le creuset polyculturel d'Arles ne pouvaient être sans conséquences sur les sociétés celto-ligures de leurs environnements respectifs. Mais dans quelle mesure? Deux brèves analyses et quelques exem- ples complémentaires suffiront pour saisir les implications des liens développés sur l'organisation sociale des populations concernées, perçues ici au travers de leurs habitats groupés.

\section{L'AGGLOMÉRATION DE SAINT-BLAISE À SAINT-MITRE-LES-REMPARTS (BOUCHES-DU-RHÔNE)}

Le premier exemple sera celui du site de Saint-Blaise, près de l'étang de Berre, déjà considéré précédemment, mais ici durant son ultime occupation protohistorique, entre 175 et 125 av. J.-C. L'habitat perché occupe une superficie similaire à l'état du premier âge du Fer (fig. 24), et les recherches de H. Rolland l'ont rendu célèbre en exhumant sa fortification, chemisée à la fin du second âge du Fer en grand appareil de type hellénistique (Rolland, 1951 ; Bouloumié, 1978, p. 17-20 et 1984, p. 26-43 ; Bessac, 1980 ; Bouloumié, Trériny, 1985). Si la mise en place de l'enceinte paraît désormais bien assurée vers 175-150 av. J.-C. (Bouloumié et al., 1981, p. 265 ; Rigoir, Rigoir, 1981, p. 184), la chronologie du dernier habitat et surtout la composition de la population qui l'occupait ont été longtemps discutées. Un réexamen montre que le quartier bas situé en arrière de la porte principale (fig. 24a, point 2) est, dans son dernier état, contemporain de la mise en place de la fortification (vers 175-150 av. J.-C.) et que sa population est majoritairement celto-ligure (Arcelin, Cayot, 1984, p. 63-67). C'est ce secteur, le plus amplement fouillé de l'habitat du $\mathrm{II}^{\text {" }} \mathrm{s}$., qui nous retiendra. Le plan présenté regroupe les différentes fouilles réalisées durant une vingtaine d'années. On peut en extraire plusieurs caractères primordiaux. Tout d'abord, la structuration du quartier en îlots d'environ $23 \mathrm{~m}$ de largeur pour plus de $40 \mathrm{~m}$ de longueur (fig. 24b, îlot 2). Sans avoir la régularité de ceux d'Arles, compte tenu d'un terrain ici plus contraignant, ils en sont proches par leurs dimensions et par leur apparente complexité interne. Autant que le permet la qualité des fouilles anciennes, des rassemblements de plusieurs pièces paraissent composer des habitations et, dans un cas au moins, autour d'une cour (dans l'îlot 2). Quelques salles s'ouvrent sur la rue par des seuils monolithes, aménagés pour recevoir une porte (Bouloumié, 1992, p. 29-31). On observe ensuite que les îlots sont desservis par des rues de 4 à $6 \mathrm{~m}$ de largeur aux revêtements constitués par apports de sables gréseux et compactés. Des déflecteurs taillés peuvent être disposés le long de certaines façades pour les protéger des eaux de ruissellement (Bouloumié, 1992, p. 22-24 et 38), et un système de marches est installé au droit de l'entrée principale pour conduire les pas du piéton de la voie vers un espace ouvert voisin (fig. 24b, îlot 1). Autant que les informations disponibles le permettent, ces rues ne semblent pas envahies par l'extension des usages domestiques et artisanaux. Seul un dépotoir important a été signalé sur le sol d'abandon, mais il pourrait correspondre à une accumulation en relation avec le siège qui a précédé la destruction de l'agglomération vers 125 av. J.-C. Quoi qu'il en soit, les rues sont aménagées pour faciliter la circulation des chariots et ne sont pas accaparées en permanence par un usage privé. Dernier aspect et non des moindres, ce quartier intègre un espace monumental, vers le milieu du II" s., une salle d'environ $50 \mathrm{~m}^{2}$, hypostyle, pourvue de chapiteaux en pierre de type dorique dont un exemplaire a été retrouvé sur le sol de la pièce (îlot 1) (Rigoir, Rigoir, 1983 ; Arcelin, 1992b, p. 25-26). Elle est peut-ĉtre précédée 


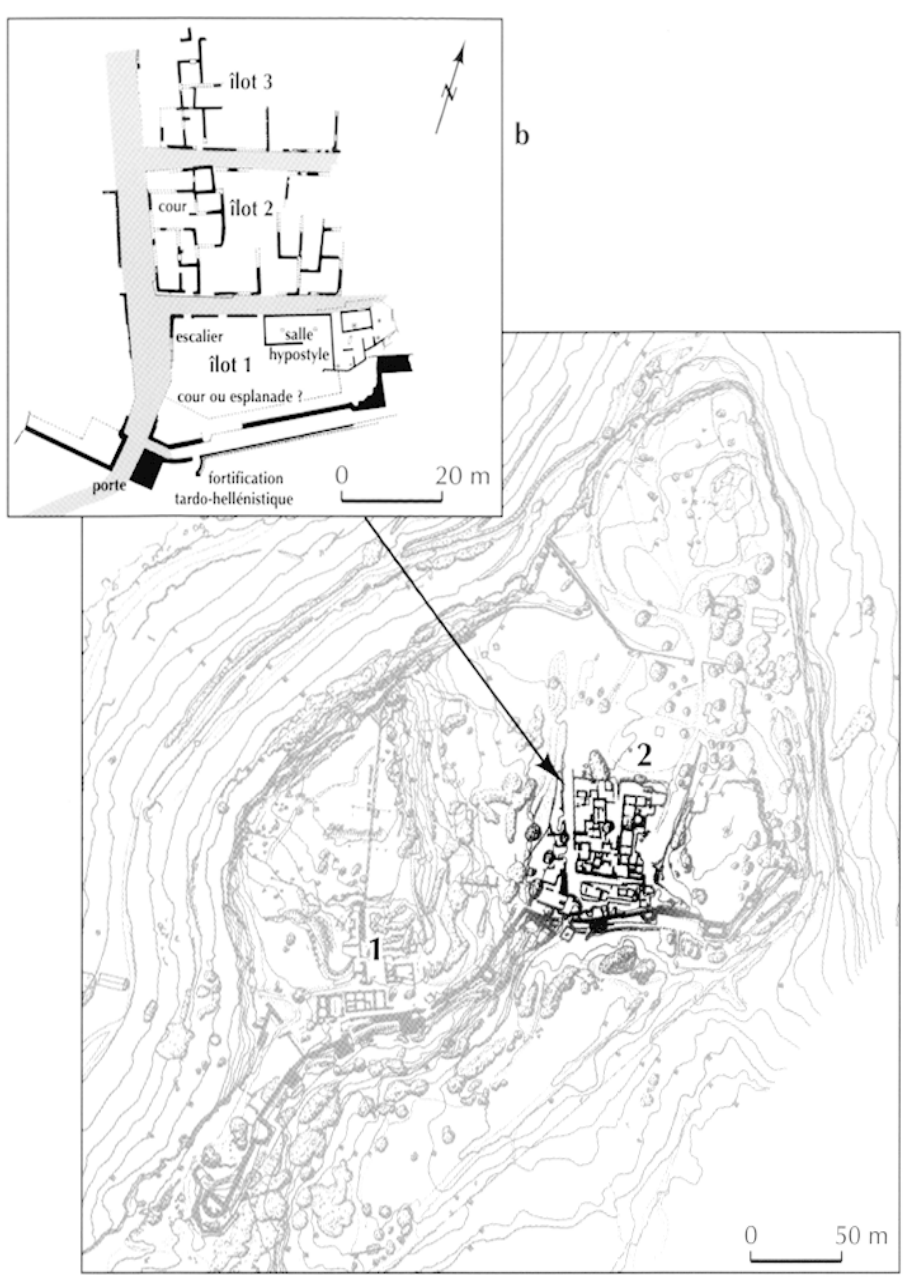

a

Fig. 24 - Mis au jour par H. Rolland, A. Dumoulin et Y. Rigoir, le quartier situé près de la porte principale de l'enceinte hellénistique de Saint-Blaise à Saint-Mitre-les-Remparts (Bouches-du-Rhône) apporte, malgré l'ancienneté des fouilles, de précieuses informations sur les modes de structuration de cette agglomération entre les années 175 et 125 av. J.-C. Les regroupements en vastes îlots comportent un certain nombre d'habitations à pièces multiples dont une au moins intégrerail une cour intérieure (îlot 2). Les rues voisines, bien que dépourvues d'un système de drainage, sont relativement larges $(4$ a $6 \mathrm{~m}$ ), avec un revêtement sablo-limoneux rapporté. Par ailleurs, outre la monumentalité bien connue de la fortification en grand appareil de type hellénistique, on relève au droit de la porte une aire (ouverte ?) à laquelle on accédait par un escalier. Elle comporte à son extrémité nord-est une vaste salle hypostyle avec chapiteaux en calcaire de type dorique. Cet espace, apparemment d'usage collectif mais dont la destination exacte demeure incertaine, vient conforter le sens des vestiges d'un temple de type gréco-italique, apparemment implanté sur la partie haute de l'habitat vers 150-125 (a, $\left.n^{\circ} 1\right): a$, plan de l'ensemble du site fortifié au Ir s. av. J.-C. ; b, détail à même époque du quartier bas $\left(n^{\prime \prime} 2\right)$ (échelle: 1/2000 pour b; d'après Arcelin et al., 1983, p. 140, fig. 3; Arcelin, 1992b, p. 24 ; Bouloumie, 1992, p. 5 et 26). d'une esplanade. Cette intégration de nature collective ou cultuelle (?), dans le premier îlot près de la porte principale, suggère fortement, à défaut de certitude archéologique, la présence de lieux publics dans l'habitat de Saint-Blaise, même modestes et d'étendues limitées. Cette information de la ville basse du site est amplifiée par les découvertes de $\mathrm{H}$. Rolland dans le puits-citerne de l'habitat haut (fig. 24a, point 1), à savoir celles de huit éléments de colonnes qui devaient appartenir à un temple de type gréco-italique et d'un imposant socle, pourvu de moulurations haute et basse (Rolland, 1956, p. 39-40). Un tel aménagement cultuel n'est pas isolé dans la proche région au second âge du Fer, si l'on en juge par les découvertes contemporaines en remploi dans un habitat de Martigues (Bessac, Chausserie-Laprée, 1992, p. 150-152). Pour conclure, Saint-Blaise apparaît à la même époque qu'Entremont comme une agglomération celto-ligure tournée à nouveau vers les activités commerciales avec la Méditerranée, ce qu'indique la part importante des céramiques tournées présentes (Arcelin, Cayot, 1984, p. 66). Il est clair que ses référents culturels ne sont pas ceux du site aixois précédent, car même si la part de la superficialité valorisante de la fortification (réalisée par des ingénieurs marseillais) ou de la structure en larges îlots est à prendre en considération, la probabilité d'habitations à pièces distribuées parfois autour d'une petite cour, l'insertion d'espaces collectifs et cultuels monumentaux comme la nature de l'usage des rues soulignent ici les prémices d'une séparation des notions de privé et de public dans la vie quotidienne de cette population et les premiers caractères de leur structuration dans un plan d'urbanisme complexe. Les pratiques guerrières et les cultes héroïques n'ont pas laissé leurs empreintes dans cet habitat du II ${ }^{\text {c }}$ s., à l'inverse de celui d'Entremont. Quoi qu'il en soit, Saint-Blaise apparaît bien isolé dans ses choix culturels au sein de la proche région de Marseille, antérieurement aux défaites de la fédération des Saluvii (entre 125 et 90 av. J.-C.) et l'on mesure par là-même la discrétion des facteurs de l'hellénisation dans cet immédiat arrière-pays de Marseille au cours du II" s. av. J.-C.

\section{LE CENTRE URBAIN DE GLANON À SAINT-Rémy-de-Provence (Bouches-du-RHôNE)}

Le deuxième habitat est encore plus connu que le précédent, bien que privé de monographie pour sa période préromaine. Il s'agit du site de Glanon implanté au débouché du vallon de Notre-Dame-de-Laval, sur un piémont septentrional des Alpilles (bilan et bibliographie in Gateau, Gazenbeek dir., 1999, p. 254-313). Des fouilles anciennes et récentes, en l'occurrence de l'analyse des vestiges du centre monumental (fig. 25) (Roth Congès, 1985, 1992a et b, 1997), mais également des quartiers d'habitation de proximité (Bouiron, 1996) ou périphériques (Agusta-Boularot et al., 1997 et 1998b), comme des traces récemment découvertes d'une vaste enceinte de la fin de l'âge du Fer (Agusta-Boularot et al., 1998a et 2000; Paillet, Tréziny, 2000), découle une information partiellement renourelée. En synthétisant l'ensemble des documents disponibles sur ce site d'occupation ancienne et de connotation 


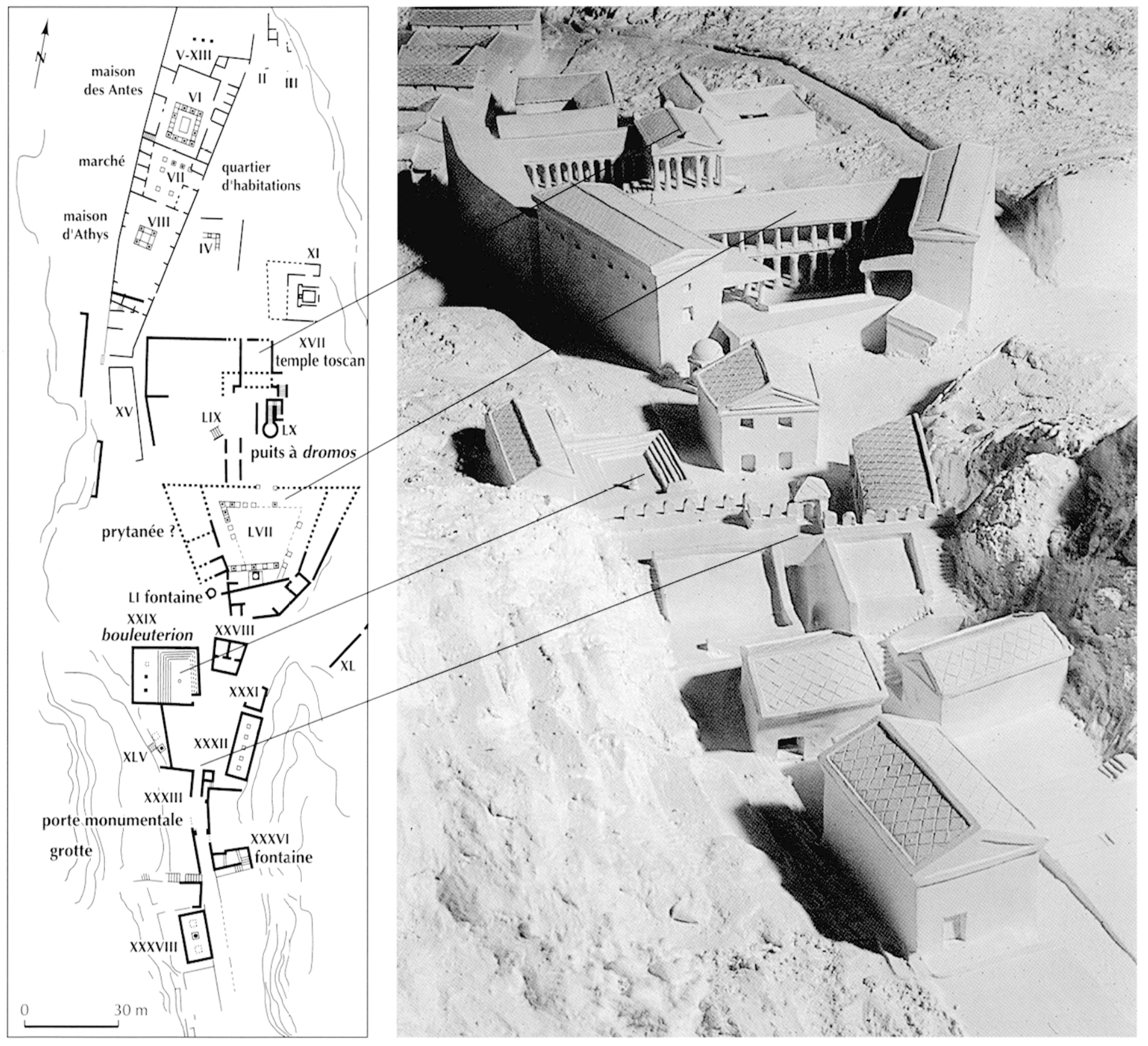

a

b

Fig. 25 - État des constructions étagées entre 150 et 75 av. J.-C. du centre monumental de Glanon à Saint-Rémy-de-Provence (Bouches-duRhône). Malgré d'énormes incertitudes dans la chronologie relative des bâtiments, les fouilles autour du temple gréco-italique et du puits à dromos, comme l'analyse générale des céramiques du site, suggèrent nettement le développement de ce centre dès le milieu du Ir' s. (ou peu après). dans une agglomération d'environ 30 ha. Temple, puits cultuel, bâtiment public à péristyle, salle d'assemblée, portique, porte monumentale, etc., résultent de pratiques politiques et religieuses développées au sein même de l'agglomération, avec des référents affichés aux valeurs d'autres cultures méditerranéennes. La classe aristocratique celto-ligure de la région des Alpilles, comparée à celle, contemporaine, présente à Eintremont, offre ici l'image d'autres rapports à la vie publique, avec un sens développé de l'évergétisme. L'autorité décisionnelle s'affiche maintenant dans l'agglomération, et les résidences domaniales sur les territoires ont dû perdre progressivement de leur intérêt au profit des prestigieuses maisons à péristyle construites dans l'habitat. Les quartiers différenciés au plan économique et social, comme les aménagements colleclifs monumentaux, recouvrent désormais une tout autre conception de l'habitat groupé, pris dans sa diversité complémentaire et ses nouveaux rapports aux territoires d'exploitation gérés dorénavant dans une dimension économique bien plus vaste: a, plan global du centre monumental; $b$, maquette de restitution topographique et architecturale du même quartier (a, échelle : $1 / 2000$; d'après Roth Congès, 1997, p. 175; b, relevé J. Bruchet, complété et cliché A. Chéné, Centre Camille-Jullian, CNRS). 
cultuelle qui remonte à l'âge du Bronze moyen et final (Arcelin, 1991), on constate durant le deuxième quart du II $^{\circ} \mathrm{s}$. une rapide amplification de l'activité d'un habitat jusqu'alors replié sur les pentes basses du mont Gaussier et à l'intérieur du vallon de Notre-Dame-de-Laval d'où jaillissent des résurgences, objets d'un culte aux divinités des eaux. C'est sans doute à cette époque que le site commence à s'amplifier fortement vers ses piémonts (Roth Congès, 1997, p. 171, fig. 6) et à s'entourer d'une enceinte qui suit les crêtes de proximité en déterminant une aire d'environ 30 ha, dont la moitié seulement est constructible (Agusta-Boularot $e t$ al., 2000, p. 186). Cette soudaine expansion n'est pas de même nature que celle des nouveaux quartiers périphériques accolés aux oppida examinés plus haut, ni de même rapport dans les superficies concernées. À Glanon, s'il y a refonte de l'habitat ancien, par exemple dans le vallon de Notre-Dame-de-Laval, c'est surtout la création de nouveaux quartiers que l'on considérera, une véritable "ville nouvelle " distribuéc autour d'un centre monumental d'environ 2 ha. D'autres secteurs périphériques, déjà partiellement occupés à l'âge du Fer, comme dans le vallon Saint-Clerg, sont restructurés à la fin du $\mathrm{II}^{\mathrm{c}} \mathrm{s}$. ou au début du $\mathrm{I}^{\mathrm{er}}$ s. av. J.-C. (AgustaBoularot $e t$ al., 1997 et 1998b). D'autres aménagements contribuent au renouvellement de l'environnement de cette vaste agglomération, telles les nécropoles établies en bordure de la voie Domitienne (Arcelin, Arcelin, 1975), un acqueduc d'amenée d'eau (Agusta-Boularot, Paillet, 1997; AgustaBoularot et al., 2000) ou l'ouverture de carrières et d'ateliers de tailleurs de pierre (Bessac, Lambert, 1989). De ce bref aperçu, on retiendra ici deux concepts nouveaux dans cet habitat des dernières décennies précédant la conquête romaine. Le premier est celui d'une spécificité des quartiers, des unités domestiques sur les périphéries et peut-être même dans des faubourgs au-delà de l'enceinte, aux édifices et lieux collectifs regroupés vers son centre. On note aussi près de ces derniers (fig. 25a, en haut), la formation d'un quartier de luxueuses habitations rassemblées autour d'une rue centrale avec collecteur de drainage, des maisons de type méditerranéen à cour et péristyle, en grand appareil de taille hellénique, avec aménagement d'un étage (Van de Voort, 1991). Mis en place au moins à la fin du $\|^{\prime \prime}$ s. (Bouiron, 1996, p. 282), il intègre un petit lieu de marché. La qualité des constructions ne laisse que peu de doute sur la présence d'une classe aristocratique dans l'agglomération, installée à quelques dizaines de mètres des symboles monumentaux de leurs pouvoirs. Le second concept émergeant est celui de la constitution même d'un tel centre et de la signification des édifices qui le composent. Sans perdre de vue les difficultés liées à la compréhension chronologique de la mise en place des différentes constructions relevées par l'archéologie, grosso modo entre les années 150-125 pour les plus anciennes aux années 75 pour les plus récentes, il faut envisager la formation de ce complexe cultuel et politique par étapes. Les premières installations seraient celles d'un temple de type toscan (fig. 25a, XVII) et d'un bâtiment à cour rectangulaire, associé à un puits voisin (Roth Congès, 1992a, p. 355-357). Viendrait ensuite (vers 110-100?), l'édification d'un somptueux complexe, un vaste bâtiment public avec des sols en opus signinum, à péristyle trapézoïdal et chapiteaux à têtes (fig. 25b, LVII), interprété comme une construction réservée aux prytanes. À la même époque se rattache un puits à dromos (LX), implanté dans l'axe du bâtiment précédent, près du temple toscan. Enfin, dans le premier quart du $\mathrm{I}^{\mathrm{cr}} \mathrm{s}$., pourraient être installés près d'une porte monumentale (Paillet, Tréziny, 2000), le portique XXXII et la salle de réunion à gradins XXIX (peut-être l'équivalent dı hmulenterion grec). Ces constructions sont couvertes de dalles en calcaire local scié (Olivier, 1982). Dans ce secteur, les chapelles XLV ont abrité pilier et stèles votives peintes de tradition régionale. On y associe des figurations en ronde-bosse de héros assis "en tailleur " découvertes à proximité (Rolland, 1968, p. 26-34 ; Roth Congès in Arcelin, Gruat et al., 2003, p. 230-233) : ces dernières sont, d'un point de vue stylistique, nettement plus anciennes (Guillaumet, Rapin, 2000, p. 82 ; Arcelin, Rapin, 2003, p. 203-207), mais elles s'intègrent sans doute dans une volonté d'exhibition publique d'une partie de l'imagerie familiale traditionnelle des grands évergètes de cette fin de l'indépendance. Comme l'habitation désormais implantée près du lieu de l'exercice du pouvoir, les symboles familiaux sortent du domaine privé pour participer de la valorisation publique des grandes familles aristocratiques. Quels que soient les détails de ces différents processus auxquels l'archéologie n'apporte pas aujourd'hui de réponses claires (Roth Congès, 2004), nous retiendrons pour notre propos que vers le milieu du II $^{\mathrm{e}} \mathrm{s}$. av. J.-C. se mettent en place les prémices d'une dynamique d'implantation nouvelle, essentiellement de plaine près de l'ancienne bourgade. Cette installation est complétée et remaniée plusieurs fois jusqu'au début de l'époque augustéenne, et survit partiellement sous le Haut-Empire. C'est sur ce site d'habitat consacré au dieu Glan (ou Glanos) et plus globalement aux cultes des eaux salvatrices, que l'on perçoit le mieux aujourd'hui l'émergence d'une politique d'organisation de l'espace bâti, toujours protégé par son enceinte. Son ampleur souligne un regroupement régional de populations, mais s'explique tout autant par la nécessité d'espaces libres, indispensables à la création d'édifices à vocation collective au cœur des quartiers d'habitation. Les aires ouvertes, même si elles ne reflètent pas encore l'esplanade de l'agora grecque, comportent des bâtiments monumentaux reprenant des modèles méditerranéens et leurs techniques d'élaboration, à défaut sans doute de toutes les valeurs culturelles qu'ils recouvrent. Leur signification est clairement religieuse, mais aussi politique à travers les lieux d'assemblée des élites que sont les bâtiments LVII et XXIX (fig. 25). À leur propos, on a souligné la permanence du fonds culturel hellénique préexistant qu'ils infèrent (Gros, 1990), mais également la part désormais plus italique que massaliote qu'ils révèlent (Gros, 1992). La structure de cet habitat n'est plus unifiée comme auparavant dans sa répartition spatiale, politique et sociologique, mais elle est, en ce sens, bien plus organisée pour répondre à une dynamique interne que ne le sont les habitats groupés, plus régulièrement planifiés, analysés plus haut. La présence d'un quartier de maisons aristocratiques, près des lieux à caractère public, souligne nettement l'emprise de cette classe sociale sur la communauté résidente, comme l'amorce d'une concentration des pouvoirs politiques décisionnels en un lieu privilégié sur les territoires d'exploitation. Nous touchons ici à la définition des premières composantes de la "ville " et de l'organisation de sa complexité tant 
pour les divinités qui s'y insèrent, avec une ostentation très méditerranéenne, que pour les hommes dans toute leur hiérarchie sociale et l'ensemble de leurs activités.

\section{LES « VILLES DES MARSEILlaIS »}

Glanon est-il un cas unique dans la basse vallée du Rhône au cours $\mathrm{du} \mathrm{II}^{\mathrm{e}}$ s. av. J.-C. ? La réponse est clairement négative, même si l'information régionale dont nous disposons est très fragmentaire. Quatre à cinq autres agglomérations présentent les caractères d'une mutation similaire. Sur la rive gauche du fleuve, les fouilles pratiquées par J. Maureau en 1928 sur le site d'Ernaginon, à Tarascon (d'après Ptolémée, II, 10, 8 ; Gateau, Gazenbeek dir., 1999, p. 412-414), laissent entrevoir la probabilité de l'existence d'un habitat de plaine, proche dans sa conception de celui de Glanon. Mais, à l'époque, le peu d'intérêt porté aux stratigraphies précises et à la chronologie des étapes de construction des maisons à péristyle et des rues dallées qui avaient été momentanément exhumées laisse planer un flou historique préjudiciable. Les recherches amorcées, de l'oppidum primitif de Saint-Gabriel vers les installations de piémont, y répondront peut-être d'ici quelques années.

Les investigations réalisées depuis un demi-siècle sous la ville actuelle d'Avignon (Vaucluse) ont mis en évidence, depuis les années 1980, des éléments d'une vaste agglomération protohistorique qui atteindrait, au II" s., au moins les 10 ha de superficic dans sa plus grande extension préromaine de coteaux, autour de l'ancien oppidum du Rocher des Doms (Carru, 2000). À défaut d'une bonne connaissance des quartiers de l'occupation de la fin de la Protohistoire dont l'importance est globalement révélée par le mobilier contemporain des coteaux de La Balance (Gagnière, Granier, 1979, p. 43), ce sont les découvertes de 1975, rue Racine, près de l'église Saint-Agricol, que nous retiendrons. À l'emplacement du futur forum de la ville romaine, une voie longeant un mur en grand appareil de technique hellénistique recouvrait un égout maçonné dont les dépôts de comblement remontent à la fin du $\mathrm{II}^{\mathrm{C}} \mathrm{s}$. ou au tout début du I ${ }^{\mathrm{cr}}$ s. av. J.-C. (Gauthier, 1984, p. 408-409 ; Carru, 2000, p. 206). La qualité du mur et de la couverture de l'égout paraît devoir être mise en rapport avec l'agencement d'un aménagement monumental de l'agglomération contemporaine.

Avenio, comme Kabellio/Cavaillon, font partie des «villes de Massalie ", selon Artémidore, l'une comme l'autre valorisée, à l'instar de Glanon, par un monnayage propre. Si l'on n'a pas encore repéré le centre politique et religieux de Cavaillon à l'époque tardo-hellénistique et si l'on n'en cerne pas non plus les limites même approximatives, un quartier de la nouvelle ville installée en plaine au pied du vieil oppidum de SaintJacques a fait l'objet de fouilles préventives en 1993 (Dufraigne, $2000 \mathrm{~b}$ ). Des îlots d'habitation et d'usage artisanal sont séparés par de larges voies, complétées ponctuellement d'une petite place d'environ $100 \mathrm{~m}^{2}$. Un bassin, avec son système d'arrivée d'eau, puis d'évacuation, révèle un souci d'aménagement collectif du quartier. D’après le mobilier des premiers niveaux, la mise en place initiale remonte au milieu du II"s. av. J.-C. Dans un des îlots, des pièces paraissent disposées autour d'une cour intérieure. Dans un autre, la présence d'une famille aristocratique a laissé la trace nominale de l'un de ses membres dans une des pièces qui composent sa maison, au travers d'une inscription en gallo-grec incluse dans le décor incrusté d'un revêtement de sol en pseudo-opus signinum. Cet aménagement unique a été daté de la première moitié du $\mathrm{I}^{\mathrm{er}} \mathrm{s}$. av. J.-C. (Lejeune, Lambert, 1996 ; Dufraigne, 2000b, p. 201, fig. 4).

Sur l'autre rive du fleuve, l'agglomération de Nîmes est un oppidum majeur dont l'enceinte du II $^{\circ}$ s. englobe le MontCavalier et l'ensemble de ses pentes méridionales jusqu’à ses piémonts, soit une superficie minimale d'environ 30 ha, un espace enclos comparable à celui de Glanon. Comme pour ce dernier et d'ailleurs l'ensemble des exemples précédents, sa position en bordure d'un axe de circulation est certainement un élément déterminant de cette soudaine transformation, bien que le poids des traditions religieuses et politiques ne soit certainement pas absent de ce processus de mutation structurelle. Il est intéressant de noter que cette enceinte est le résultat d'un tracé bien plus ancien qui couvre au moins les IV" et III s. av. J.-C., sans pour cela que l'intégralité de l'espace intérieur ait été bâti, bien au contraire (Monteil, 1999, p. 314-317). Seule Arles peut lui être comparée à cette époque et dans cette région. L'habitat $\mathrm{du}_{\mathrm{II}}{ }^{\mathrm{e}} \mathrm{s}$. demeure dans les limites antérieures, mais les constructions semblent s'étendre désormais sur les parties anciennement cultivées (ibid., p. 324-325). Une unité d'habitation a été partiellement fouillée sous la place Jules-Guesde. Les pièces multiples s'organisent autour d'une cour simple (ibid., p. 260-261 et 335 ; Célié et al., 1994, p. 386), à l'instar de ce que l'on connaît à la même époque vers le Languedoc central, par exemple dans le vaste habitat côtier de Lattes (Py, 1996, p. 235; Chazelles, 1999, p. 487-490). C'est à partir du début du I Ir s. av. J.-C. que l'information devient un peu plus conséquente, avec le quartier de Villa Roma où apparaissent d'importants îlots et quelques vestiges d'habitations à cour, pourvues de systèmes de drainage, mais malheureusement très mal conservées (Monteil, 1999, p. 104-107). Un bâtiment monumental à portique a été fouillé à proximité (ibid., p. 106-109; Guillet et al., 1992, p. 58-77). $\mathrm{Au}$ total, et faute d'informations conséquentes, l'architecture et la structuration de l'habitat de Nîmes au II $^{\text {" }}$ s. sont toujours très mal connues. Cependant, les premiers indices révèlent une dynamique dans l'architecture domestique très parallèle à celle des autres grandes agglomérations de la rive gauche du Rhône (Monteil, 1999, p. 338-340 ; Verdin, 2003, p. 568-570). Reste à en mesurer la portée au plan de la monumentalité édilitaire et du degré d'urbanisation de cette ville naissante au statut juridique affirmé sur sa région (Strabon, Géographie, IV, 1, 12 ; Goudineau, 1976a).

En définitive, cette puissante mutation culturelle amorcée autour du milieu du II $^{\circ}$ s. av. J.-C. dans la basse vallée du Rhône est un phénomène initialement lié à quelques agglomérations que leurs antériorités, économiques ou cultuelles, et leurs positions favorables près d'axes de circulation majeurs (telle la voie Domitienne) contribuent à promouvoir comme centres juridictionnels des territoires de proximité. Le texte plus tardif de Strabon pour Nîmes ne laisse guère de doute et l'on comprend mieux, dans cette perspective évolutive, la portée du qualificatif de $\pi o ́ \lambda \varepsilon \imath \varsigma$ M $\alpha \sigma \sigma \alpha \lambda i \alpha \varsigma$ attribué par Artémidore à quelques agglomérations dont celles de Cavaillon ct certainement d'Avignon (apud Étienne de Byzance, Ethniques). Outre 
que ce géographe souligne des liens puissants au plan économique, ce que confirmeraient les monnayages frappés par Marseille au nom de ces villes, l'existence probable d'un fredus, qui lierait Avignon à la cité phocéenne, sous-entendrait également des liens politiques réels (Goudineau, 1976b). Enfin, leur répartition géographique, au centre de la basse vallée du Rhône, ne relève certainement pas du simple hasard. Il paraît évident désormais que les soudaines expressions architecturales du II"s. découlent d'une lente mais active assimilation antérieure de valeurs culturelles méditerranéennes (bilan, in Arcelin, 2003). Au cœur de cette aire, la vaste agglomération d'Arles, port économique actif et lieu de synœcisme culturel, a incontestablement dû jouer le rôle d'un catalyseur dans la gestation du phénomène aux IV $^{r^{*}}$ et III ${ }^{\mathrm{e}} \mathrm{s}$. av. J.-C. Si, dans cette dernière agglomération, les fouilles actuelles n'ont pas encore fourni les éléments d'aménagements collectifs monumentaux pour ces deux siècles, leur présence à la fin du $\mathrm{II}^{\circ} \mathrm{s}$. ou au début du I ${ }^{\mathrm{cr}} \mathrm{s}$. av. J.-C. . est une réalité au centre de l'agglomération sous le futur forum augustéen (Heijmans, 1991, p. 172-174 ; Arcelin, 1995 , p. 328 et $336-337 ; 2000$ c, p. 15-19).

\section{L'AGGLOMÉRATION EST L'IMAGE D'UNE SOCIÉTÉ}

De cette quête des caractères susceptibles de définir les prémices de l'émergence du phénomène urbain en Gaule méridionale, nous avons voulu concentrer notre réflexion sur la basse vallée du Rhône qui nous est apparue comme une région géographiquement unifiée et très interdépendante d'un même partenaire commercial durant plusieurs siècles. Dans la pérennisation perceptible de tels rapports économiques et culturels, il est clair que les bouleversements politiques méditerranéens, puis l'intrusion du commerce italien dès la seconde moitié du III $^{e}$ s. av. J.-C. et sa remarquable expansion après 200, tant au plan régional que vers des zones plus septentrionales, ont été des facteurs de rupture des équilibres préexistants. De fait, ils ont accéléré des processus culturels sous-jacents que quelques rares foyers avaient amorcés au début du second âge du Fer et même très certainement dès l'extrême fin du premier.

Tout en se remémorant brièvement les fluctuations du mode de l'habitat groupé au cours de l'âge du Fer et le fait qu'il n'en est pas le scul sur les territoires, nous avons cherché à dégager les caractères mêmes de leurs implantations et de leurs principes structurants, sans perdre de vue la réalité rurale de leur environnement immédiat. La première constatation est que l'élaboration des concepts organisationnels de l'habitat groupé remonte à la seconde partie du premier âge du Fer, au $\mathrm{VI}^{\mathrm{C}} \mathrm{s}$. sur la côte, et plus généralement vers la fin du $\mathrm{V}^{\mathrm{C}} \mathrm{s}$. ailleurs. Quelle que soit l'étendue couverte par ces habitats, souvent modestes et inférieurs à 10 ha, perchés et fortifiés, c'est le choix d'une trame rationalisée autorisant le maximum de concentration de population par unité spatiale qui constitue l'élément normatif de la très grande majorité des installations connues. On recherchera sans succès dans la pérennisation de ce système au second âge du Fer des composantes humaines et productives autres que celles intimement liées à des communautés foncièrement rurales, des éleveurs et des agriculteurs (Schallin, 1997, p. 39). Force est de les considérer selon une vision très égalitariste au travers de la modestie répétitive des aménagements architecturaux, de leur vie domestique et d'un petit artisanat d'autoconsommation. Jusque dans le courant du II's. av. J.-C. où des évolutions relatives sont perceptibles dans les habitats les plus dynamiques, on ne trouve pas, tant au sein des espaces bâtis que de leur structuration planimétrique, une autre image que celle d'une population de petits propriétaires ou d'ouvriers agricoles pratiquant une activité d'artisanat complémentaire, mais indispensable aux besoins du quotidien. Par ailleurs, il n'est pas évident, bien au contraire, que le stockage des surplus agricoles comme produit de l'échange ait été confié à la garde de ces lieux fortifiés, comme le constate indirectement M. Py (1993, p. 218 et 220$)$.

Si l'organisation coercitive des planimétries géométriques rigoureuses qui apparaissent à partir du III $^{\mathrm{e}}$ s. et l'embellissement des fortifications qui les accompagnent révèlent une hiérarchisation sociale forte, si les textes antiques laissent entrevoir l'émergence à cette époque d'une classe aristocratique et militaire équestre aux pouvoirs héréditaires, la présence et les formes de l'exercice de son autorité ne se manifestent pas au sein des habitats groupés, les caractères de l'enceinte n'ayant qu'une valeur informative vers le regard des territoires alentours. C'est en effet sur ces derniers, au sein d'installations domaniales dont nous proposons quelques possibilités, que l'aristocratie doit résider au second âge du Fer, à la suite de ses lignages des siècles antérieurs. Dans la basse vallée du Rhône, à la différence des évolutions amorcées dès le IV" $\mathrm{s}$. dans le Languedoc central et occidental, l'habitat groupé, quelle que soit son ampleur, est avant tout assimilable à un "bourg " agricole, représentant pour l'ensemble de la communauté territoriale une puissance productive et un vecteur économique par le jeu des foires et marchés, forcément de proximité compte tenu d'une absence d'espaces ouverts conséquents dans l'enceinte. C'est aussi un lieu de forte connotation militaire, par ses défenses et les hommes mobilisables en cas de nécessité. Comme pour les habitats groupés du Levant ibérique jusqu'au $\mathrm{III}^{\mathrm{e}}$ s. av. J.-C. (Jacob, 2000, p. 738-741), parler d'urbanisme pour désigner la régularisation planimétrique de ces bourgs, bourgades et villages (ces $\alpha \omega \dot{\omega} \mu i ̈$ pour reprendre la désignation de Strabon à propos des oppida de la région de Nîmes, cf. Géographie, IV, 1, 12), ce serait leur accorder l'image de fonctions qu'ils ne possèdent pas, les considérer comme lieux de rassemblement de l'ensemble des composantes de la société et de leur organisation réciproque. On doit donc se résoudre à considérer que l'unité de la ventilation sociale des communautés protohistoriques demeure généralement, à la veille de la romanisation des régions du bas-Rhône, à l'échelle de leurs territoires d'exploitation et de parcours. Ces agglomérations ne représentent pas des " protovilles ", tout au plus leurs précurseurs dans le droit fil d'un phénomène curopéen récurrent depuis la fin du Néolithique ! C'est là un trait commun de la ruralité celtique qui, au-delà des différences intraculturelles, relie le Midi au reste de la Gaule (Collis, 1999, p. 78-80).

Il est d'autant plus intéressant de constater dans ce courant de continuité, l'émergence tardive d'une autre voie engendrée 
par l'évolution propre d'une part de la société dont les dirigeants ont amorcé une mutation culturelle antérieurement au début du II" s. C'est indiscutablement à partir de leurs activités commerciales et des liens établis depuis longtemps avec les cultures méditerranéennes, à l'instar des témoignages épigraphiques du Languedoc occidental (Lejeune et al., 1988), que cette classe aristocratique et les membres de son entourage seront amenés à modifier leur échelle de valeurs, à reléguer celle jugée trop sclérosante de l'héroïsme guerrier au profit de l'enrichissement par le négoce et de l'affirmation par l'évergétisme. Le lieu idéal pour l'expression de cette nouvelle puissance sociale, à la ressemblance des autres régions méditerranéennes que le commerce amène à fréquenter, c'est la
" ville ", " ce lieu de résidence où siège l'autorité chargée d'arbitrer entre les pouvoirs des corps sociaux " (Bonello, 1998, p. 5). Le concept d'urbanisme trouve ici son véritable sens, celui de l'organisation spatiale des composantes de la société réunies en ce lieu privilégié du territoire (Smith, 1972, p. 567568 ; Vink, 1997, p. 112-118), avec ses espaces publics, politiques et religieux, comme autant de marques symboliques fortes des formes du pouvoir de cette nouvelle aristocratie. Le phénomène, en gestation dans les sociétés centro-rhodaniennes du second âge du Fer, n'acquiert pourtant ces facultés d'expression comme les moyens de les traduire dans l'architecture et le monumental qu'avec le développement de leurs relations au commerce et à la culture de l'Italie romaine.

\section{BIBLIOGRAPHIE}

\section{Agusta-Boularot S., Panllet J.-L.}

1997 : " L'alimentation en eau de Glanum. État de la question et recherches en cours ", in Les aqueducs de la Gaule romaine et des régions voisines, Actes du colloque du centre A. Piganiol, Limoges, 1996, Caesarodunum, 31, p. 21-72.

Agusta-Boularot S., Gazenbeek M., Marcadal Y., Paillet J.-L.

1997 : "Saint-Rémy-de-Provence, Glanum ", Bilan scientifique de la région Provence-AlpesCôte d'Azur, 1997, p. 91-92.

1998a : "Glanum, l'extension de la ville et sa périphérie ", Les Dossiers d'archéologie, 237, p. 20-25.

1998b : "Saint-Rémy-de-Provence, Glanum ", Bilan scientifique de la région Provence-AlpesCồle d'Azur, 1998, p. 107-109.

2000 : "Alimentation en eau et système défensif de l'oppidum de Glanum à l'époque préromaine ", in ChaussirifLaPRÉE J. (DIR.), Le temps des Gaulois en Provence, Catalogue d'exposition, Martigues, musée Ziem, p. 185-188.

\section{ARCELIN P.}

1984 : «Évolution des rapports sociaux dans la basse vallée du Rhône aux $\mathrm{II}^{\mathrm{r}}$ et $\mathrm{I}^{\mathrm{er}} \mathrm{s}$. av. n. è. ", in Dalbigikey A. (DIR.), Archéo logie el rapports sociaux en Gaule. Protohistoire et Antiquité, Actes de la table ronde de Besanson, 1982, Paris, L.es Belles I.ettres (coll. Annales littéraires de l'université de Besançon, 290), p. 185-218.

1986a: "Le territoire de Marseille grecque dans son contexte indigène ", in BATs M., TrF́:INy H. (DIR.), Le territoire de Marseille grecque, Actes de la table ronde d'Aix-enProvence, 1985, Aix-en-Provence, PUP (coll. Études massaliètes, 1), p. 43-104.

1986b : "Activités maritimes des sociétés protohistoriques du midi de la Gaule", in L'exploitation de la mer, Acies des $V T$ rencontres internationales d'archéologie et d'histoire d'Antibes, 1985, Valbonne, APDCA, p. 11-29.

1987 : « L'habitat d'Entremont : urbanisme et modes architecturaux ", in CoLTAG:NE. D. (ÊD.), Archéologie d'Entremont au musée Granet, Aix-en-Provence, éd. musée Granet, p. 57-98.

1989 : "Le second âge du Fer en Provence", in Moni.N J.P. (DIR.), Le temps de la Préhistoire, 1, Paris, Société préhistorique française et Dijon, Archéologia, p. $477-479$

1991 : "Céramiques campaniennes et dérivées régionales tardives de Glanum (Saint-Rémy-de-Provence, B.-du-Rh.). Questions culturelles et chronologiques", Documents d'archéologie méridionale, 14, 1991, p. 205-238.

1992a : "Société indigène et propositions culturelles massaliotes en basse Provence occidentale ", in Bats M., Bertc(C)HI G., Conciès G., TrézINy H. (DIR.), Marseille grecque et la Gaule, Actes des colloques internationaux de Marseille, $18-23$ mai 1990, Lattes/Aix-en-Provence, ADAM/PUP (coll. Études massaliètes, 3), p. 305-336.

1992b: "Salles hypostyles, portiques et espaces cultuels d'Entremont et de SaintBlaise (B.-du-Rh.) ", Documents d'archéologie méridionale, 15, 1992, p. 13-27.

1995 : "Arles protohistorique, centre d'échanges économiques et culturels ", in ARCFIIIN P., BatS M., GARCIA D., Marchand (., Schwailifr M. (mir.). Sur les pas des Grecs en Occident. Hommages à André Nickels, Lattes/Paris, ADAM/Errance (coll. Études massaliètes, 4), p. 325-338.

1999a : "Entre Salyens, Cavares et Volques: peuplement protohistorique et dyna- mique culturelle dans la région AlpillesMontagnette ", in GATEAC $F$., GAZENBEeK M. (DIR.), Les Alpilles et la Montagnette, Paris, Académie des inscriptions et belles-lettres (coll. Carte archéologique de la Gaule, 13/2), p. 61-78.

1999b: " L'habitat dans l'image sociale des Gaulois du Midi. La question des résidences aristocratiques ", in BRAFMF.R F., Cl.euziou S., Coudart A. (DIr.), Habitat et société, Actes des XIX rencontres internationales d'archéologie et d'histoire d'Antibes, 22-24 oct. 1998, Antibes, APDCA, p. $439-479$.

2000a : "Expressions cultuelles dans la Gaule méridionale du premier âge du Fer ", in JANIN T. (DIR.), Mailhac et le premier âge du Fer en Europe occidentale. Hommages à Odette et Jean Taffanel, Actes du colloque international de Carcassonne, sept. 1997, Lattes, ARALO (coll. Monographies d'archéologie méditerranéenne, 7), p. 271-290.

2000b: "Honorer les dieux et glorifier ses héros. Quelques pratiques cultuelles de la Provence gauloise ", in ChausseritLAPRÉf. J. (DIR.), Le temps des Gaulois en Provence, Catalogue d'exposition, Martigues, musée Ziem, p. 92-103.

2000c : "Arles protohistorique, agglomération et structuration urbaine ", in BAUDAT M. (DIR.), lispaces et urbanisme à Arles, des origines à nos jours, Actes du colloque d'Arles, 1998, Arles, Groupe archéologique arlésien, p. 7-23.

2001 : “Territoires et habitats dans l'évolution des sociétés celtiques de la Gaule méditerranéenne ", in Brirro(AI-RaNiel. L., GaRdes P. (DIR.), Celtos e Iberos. Las poblaciones protohistónicas de las (aalias e Hispania, Actes de la table ronde de Madrid, janv. 1998, Madrid, Real Academia de la Historia, 
Casa de Velásquez (coll. Bibliotheca archaeologia hispana, 8), p. 137-160.

2003 : "Les poleis massalias d'Étienne de Byzance et les mutations culturelles de la Protohistoire récente dans la basse vallée du Rhône ", in BATS M. IT AL. (DIR.), Peuples et territoires en Gaule méditerranéenne. Hommage à Guy Barruol, Montpellier (coll. Suppl. à la Revue archéologique de Narbonnaise, 35), p. 131-145.

2004 : «Entremont et la sculpture du second âge du Fer en Provence ", in ARCEl.IN P., CONGÈs G. (DIR.), " Dossier : La sculpture protohistorique en Provence et les régions voisines ", Documents d'archéologie méridionale, 27, 2004, p. 71-84.

ARCelin P., ARCELIN C.

1975 : "Les sépultures préromaines de Saint-Rémy-de-Provence (Bouches-duRhône) ", Revue archéologique de Narbonnaise, VIII, p. 67-135.

arcelin P., Arcelin-Pradelle C., Gascó Y. 1982 : « Le village protohistorique du MontGarou (Sanary, Var). Les premières manifestations de l'impérialisme marseillais sur la côte provençale ", Documents d'archéologie méridionale, 5, 1982, p. 53-137.

\section{ARCELIN P., Blaustein M.}

1998 : « La salle hypostyle d'Entremont. Propositions architecturales pour une restitution en 3D ", Documents d'archéologie méridionale, 21, 1998, p. 41-43 et cédérom.

ARCELIN P., BRÉMOND J.

1977 : « Le gisement protohistorique du Mont-Valence, commune de Fontvieille (B.-du-Rh.) ", Cypsela, 2, p. 161-172.

ARCelun P., Cayot A.

1984 : "Réflexions sur l'abandon de l'agglomération hellénistique de Saint-Blaise (Saint-Mitre-les-Remparts, B.-du-Rh.) ", Revue archéologique de Narbonnaise, XVII, p. 53-70.

\section{Arcelin P., Chausserie-Laprée J.}

2003 : "Sources antiques et images de l'archéologie dans le Sud-Est gaulois ", in Mavdy B., SAulce A. DE (DIR.), Les marges de l'Armorique à l'âge du Fer. Archéologie et histoire: culture matérielle et sources écrites, Actes du $23^{\circ}$ colloque de l'Association française pour l'étude de l'âge du Fer, Nantes, 1999, Nantes (coll. Suppl. à la Revue archéologique de l'Ouest, 10), p. 255-268.

arcelin P., Chausserie-Laprée J., Nin N.

1993 : « Céramique non tournée des ateliers des rives de l'étang de Berre ", in Py M. (DIR.), Dicocer. Dictionnaire des céramiques antiques en Méditerranée nordoccidentale, Lattes, ARALO (coll. Lattara, 6), p. 257-259.

Arcelin P., Congés G., Willaume M.

1990 : « Aix-en-Provence, Entremont », Gallia Informations, p. 127-131

2001 : Les Gaulois de Provence. L'oppidum d'Entremont, site multimédia, Paris, ministère de la Culture et de la Communication (coll. Grands sites archéologiques, 12), http://www. entremont.culture.gouv.fr

\section{ARCELIN P., DEDET B.}

1985 : “Les enceintes protohistoriques du Midi méditerranéen, des origines à la fin du $\mathrm{II}^{\mathrm{e}}$ s. av. J.-C. ", in DF.DET B., Py M. (DIR.), Les enceintes protohistoriques de Gaule méridionale, Caveirac, ARALO, p. 11-37. Arcelin P., Dedet B., Schwaller M.

1992 : «Espaces publics, espaces religieux protohistoriques en Gaule méridionale ", Documents d'archéologie méridionale, 15 , 1992, p. 181-242.

Arcelin P., Gruat P. et al.

2003 : " La France du Sud-Est ", in ARcEl.IN P., Bruneac J.-L. (DIR.), " Dossier : Cultes et sanctuaires en France à l'âge du Fer ", Gallia, 60, p. 169-241.

arcelin P., Pradelle C., Rigoir J., Rigoir Y. 1983 : « Note sur des structures primitives de l'habitat protohistorique de Saint-Blaise (Saint-Mitre-les-Remparts, B.-du-Rh.) ", Documents d'archéologie méridionale, 6, 1983, p. 138-143.

ARCELIN P., RAPIN A

2002 : « Images de l'aristocratie du second âge du Fer en Gaule méditerranéenne. À propos de la statuaire d'Entremont ", in Guichard V., PERRIN F. (DIR.), L'aristocratie celte à la fin de l'âge du Fer (du It" s. av. J.-C. au Ir s. apr. J.-C.), Actes de la table ronde du CAE du Mont-Beuvray, 1999, Glux-en-Glenne (coll. Bibracte, 5), p. 29-66.

2003 : "Considérations nouvelles sur l'iconographie anthropomorphe de l'âge du Fer en Gaule méditerranéenne ", in BcChSENSCHUTZ O., Bllard A. Chardenoux M.-B., Ginoux N. (Dir.), Décors, images et signes de l'âge du Fer européen, Actes du XXVI colloque de l'association française pour l'étude de l'âge du Fer Saint-Denis, 2002, Tours, FERAC (coll. Suppl. à la Revue archéologique du Centre de la France, 24), p. 183-219.

ARCELIN P., Sourisseau J.-C.

$1990:$ : La diffusion des amphores massaliètes en Provence occidentale ", in BATS M (DIR.), Les amphores de Marseille grecque Chronologie et diffusion (Vr-fr s. av. J.-C.), Actes de la table ronde de Lattes, 1989, Lattes/Aix-en-Provence, ADAM/PUP (coll. Études massaliètes, 2), p. 191-205.

ARCELiN-Pradelle C.

1984 : La céramique grise monochrome en Provence, Paris, éd. du CNRS (coll. Suppl. à la Revue archéologique de Narbonnaise, 10), 171 p., $73 \mathrm{pl}$.

Arcelin-Pradelle C., Dedet B., Py M.

1982 : « La céramique grise monochrome en Languedoc oriental ", Revue archéologique de Narbonnaise, XV, p. 19-67.
ARNOLD B.

1992 : «Villages du Bronze final sur les rives du lac de Neuchâtel ", in Mordast C.. RICHARI) A. (DIR.), L'habitat et l'occupation du sol à l'âge du Bronze en Europe, Actes du colloque international de Lons-le-Saunier, 1990, Paris, CTHS (coll. Documents préhistoriques, 4), p. 303-312

ARTHUis R., AMBERT P.

1997 : “ Des étangs, un petit lac, de vastes paluds, une prairie assainie: l'évolution naturelle et artificielle des cuvettes périglaciaires dans la dépression de Tras-lePuy (Gard) durant l'Holocène ", in Burnolf J., Bravard J.-P., Cholqler G. (DIR.), La dynamique des paysages protohistoriques, antiques, médiévaux et modernes, Actes des XVII rencontres internationales d'archéologie et d'histoire d'Antibes, 19-21 oct. 1996, Sophia-Antipolis, APDCA, p. 351-364.

AUDOUZE F., BUCHSENSCHUTZ $O$.

1989 : Villes, villages et campagnes de l'Europe celtique. Du début du II millénaire à la fin du pr s. av. J.-C., Paris, Hachette (coll. Bibliothèque archéologique, 1989), $362 \mathrm{p}$.

Barruol G., PY M.

1978 : « Recherches récentes sur la ville antique d'Espeyran à Saint-Gilles-duGard ", Revue archéologique de Narbonnaise, XI, p. 19-100.

Barthès P., Bocquenet J.-P., Rancoule G. 1995 : «Prospection-inventaire dans le bassin de l'Aude entre Carcassonne et Narbonne ", in GLIlAINE J. (DIR.), Temps et espace dans le bassin de l'Aude, du Néolithique à l'âge du Fer, Toulouse, Centre d'anthropologie, p. 93-164.

BaTS M.

1986 : " Le vin italien en Gaule aux $\mathrm{H}^{\mathrm{e}-\mathrm{I}^{\mathrm{er}}} \mathrm{s}$. av. J.-C. Problèmes de chronologie et de distribution ", Dialogues d'histoire ancienne, 12, p. 391-430.

1989 : « La Provence protohistorique ", in FÉvrier P.-A., Bats M., Camps G., Fixot M., GLyon J., Riser J. (DIR.), La Provence des origines à l'an mil. Histoire et archéologie, Rennes, Ouest-France, p. 168-256.

1992 : « Marseille, les colonies massaliètes et les relais indigènes dans le trafic le long du littoral méditerranéen gaulois $\left(\mathrm{V}^{\mathrm{e}}-\mathrm{I}^{\mathrm{er}} \mathrm{s}\right.$. av. J.-C.) ", in Bats M., Bertucchi G., Congès G., TrÉZINY H. (DIR.), Marseille grecque et la Gaule, Actes des colloques internationaux de Marseille, 18-23 mai 1990, Lattes/Aix-en-Provence, ADAM/PUP (Travaux du Centre Camille-Jullian, 11 et coll. Études massaliètes, 3), p. 263-278.

1996 : « Les Grecs en Gaule et en Corse ", in Pliglifese. Carratelli. G. (Dir.), Grecs en Occident, Milan, Bompiani, p. 577-584.

1998 : " Marseille archaïque. Étrusques et Phocéens en Méditerranée nord-occiden- 
tale ", Mélanges des Écoles françaises d'Athènes et de Rome, 110, 2, p. 609-633. BENOIT F.

1968 : " Résultats historiques des fouilles d'Entremont (1946-1967) ", Gallia, XXVI, 1, p. 1-31.

Bérato J.

1997 : "L'âge du Fer dans le Var ", Annales de la Société des sciences naturelles et d'archéologie de Toulon et du Var, 49, p. 141-153.

BÉRATO J., BorRÉANI M.

2000 : "Les formes de l'habitat protohistorique dans le Var ", in ChalsserieI APRÉE. J. (DIR.), le temps des Gaulois en Provence, Catalogue d'exposition, Martigues, musée Ziem, p. 113-116.

Bérato J., Borréani M. avec la collab. de Demontes J.-L., KROL V.

2000 : "Habitat et enclos du v" s. av. J.-C. groupés le long d'une voie au Petit Campdumy, Flassans-sur-Issole, Var ", Documents d'archéologie méridionale, 23, 2000 , p. 145-156.

Bérato J., Borréani M., Gébara C., MICHEL J.-M.

1995 : " L'âge du Fer dans la dépression permienne, et dans les massifs des Maures et de l'Estérel (Var) ", Documents d'archéologie méridionale, 18,1995 , p. 45-77 et cédérom.

Bérato J., Martina-Fieschi D., Ribot H., THĖVENY J.-M.

1996 : "Le sondage 1 de l'oppidum protohistorique de la Courtine (Ollioules, Var)", Préhistoire et anthropologie méditerranéennes, 5, p. 57-83.

Berger J.-F., Brochier J.-L., JUNG C., Odiot T.

1997 : «Données paléogéographiques et données archéologiques dans le cadre de l'opération de sauvetage archéologique du TGV-Méditerranée ", in Burnouf J., BraVARI) J.P., ChOlQuer G. (DIR.), la dynamique des paysages protohistoriques, antiques, médiévaux et modernes, Actes des XVIr rencontres internationales d'archéologie et d'histoire d'Antibes, 19-21 oct. 1996, Sophia-Antipolis, APDCA, p. 155-183.

BERNARD L.

2000 : "L'habitat préromain du Verduron", in ChALSSERIF-I APREFE J. (DIR.), Le temps des Gaulois en Provence, Catalogue d'exposition, Martigues, musée Ziem, p. 158-160.

\section{BERTONCELlo F.}

2002 : " La cité de Fréjus (Var, France): modalités de l'implantation romaine et dynamiques territoriales ", in GARCIA D., VERIJN F. (DIR.), Territoires celtiques. Espaces et territoires des agglomérations protohistoriques d'Europe occidentale, Actes du XXIV colloque international de l'Association française pour l'étude de l'âge du Fer, Marligues, 2000, Paris, éd. Errance, p. 150-159.

\section{Bertoncello F., Gazenbeek M}

1997 : "Dynamique du peuplement en moyenne montagne : le massif des Maures (Var) entre le deuxième âge du Fer et la fin de l'Antiquité ", in BtroctF J., Bravard J.-P., CholQler G. (DIR.), la dynamique des paysages protohistoriques, antiques, médiévaux et modernes, Actes des XVII rencontres internationales d'archéologie et d'histoire d'Antibes, 19-21 oct. 1996, Sophia-Antipolis, APDCA, p. 601-620.

BESSAC J.-C.

1980 : "Le rempart hellénistique de SaintBlaise (Saint-Mitre-les-Remparts, B.-du$\mathrm{Rh}$.$) : technique de construction ",$ Documents d'archéologie méridionale, 3, 1980, p. 137-157.

1986 : "Carrières antiques du Bois des Lens (Gard). Inventaire préliminaire ", Revue archéologique de Narbonnaise, 19, p. 159-182.

1996 : La pierre en Gaule narbonnaise et les carrières du Bois des Lens (Nîmes), Ann Arbor, Michigan (coll. Suppl. au Journal of Roman Archaeology, 16), 319 p.

Bessac J.-C., Chausserie-Laprée J.

1992 : "Documents de la vie spirituelle et publique des habitats de Saint-Pierre et de l'île à Martigues (B.-du-Rh.) ", Documents d'archéologie méridionale, 15, 1992, p. 134157.

BessaC J.-C., LAMBERT N.

1989 : "La pierre à Glanum ", in " Glanum, cité grecque et romaine de Provence", Les Dossiers de l'archéologie, 140, p. 8-13.

BiLLaud Y.

1999 : " Lapradc, Lamottc-du-Rhônc (Vaulcluse) : un habitat de plaine à architecture de terre au Bronze final $2 b$ ", Bulletin de la Sociêté préhistorique franşaise, 96, 4, p. $607-621$.

Blasco S., BuXó I CAPDEvila R. (DIR.)

1998 : El graner de l'Empordà. Mas Castellar de Pontós a l'edat del Ferro, Girona, museu d'arqueologia de Catalunya, $92 \mathrm{p}$.

BoIsSINOT P.

1984 : " Les constructions en terre au $\mathrm{II}^{\mathrm{s}} \mathrm{s}$. av. J.-C. sur l'oppidum du Baou-Roux (Bouc-Bel-Air, B.-du-Rh.) ", Documents d'archéologie méridionale, 7, 1984, p. 79-96.

1989 : « Habitats et habitations à la fin de l'âge du Bronze provençal ", in Habitats et structures domestiques en Méditerranée occidentale durant la Protohistoire, Pré-actes du colloque international d'Arles, 1989, Lattes, IAPMO, p. 41-44.

1990 : "Le Baou-Roux ", in Voyage en Massalie. 100 ans d'archéologie en Gaule du Sud. Marseille, Musées/Edisud, p. 90-99.

1998 : "La réinterprétation du "sanctuaire" de Roquepertuse ", in Fifl RYAICARAY K. (DIR.), "Les Provençaux de l'âge du Fer ". Archéologia, 351, p. 42-45.

2000a : "L'environnement et la construction des paysages ", in Chacsserif-l LAPRÉ: J.
(DIR.), Le temps des Gaulois en Provence, Catalogue d'exposition, Martigues, musće Ziem, p. 26-30.

2000b: "L'habitat de Roquepertuse ", in Chat sstrif-I apríf: J. (DIR.), Ie lemps des Gaulois en Provence, Catalogue d'exposition, Martigues, musée Ziem, p. 151-159.

2004 : “Usage et circulation des éléments lapidaires de Roquepertuse ", in ARcilliN P. Covoris G. (DIR.), " Dossier : Ia sculpture protohistorique en Provence et les régions voisines ", Documents d'archéologie méridionale, 27, 2004, p. 49-62.

BOISSINOT P., BRoChIER J.-E.

1997 : "Pour une archéologie du champ ", in Choclulir G. (DIR.), Les formes des paysages -3-L'analyse des systèmes spatiaux, Paris, éd. Errance, p. 35-56.

Boissinot P., Gantés L.-F. avec la part. de GASSEND J.-M.

2000 : « La chronologie de Roquepertuse. Propositions préliminaires à l'issue des campagnes 1994-1999 ", Documents d'archéologie méridionale, 23, 2000, p. 249-271.

BONELLO Y.-H.

1998 : La ville, Paris, PUF (coll. Que sais-jc? $3047), 128 \mathrm{p}$.

BouIRON M.

1996 : “ Glanum (B.-du-Rh.) ", in La maison urbaine d'époque romaine. Atlas des maisons de Gaule Narbonnaise, Avignon, Conseil général de Vaucluse (coll. Documents d'archéologie vauclusienne, 6), p. 279-323.

1999 : "Plans par période ", in BOt:IRON M., Gunichl:R A., Pasivi M. (DIR.), Marseille. Trames el paysages urbains de (iyptis au Roi René, Pré-actes du colloque de Marseille, nov. 1999, Marseille, p. 47-71.

BouloumiÉ B.

1978: " Ein eisenzeitliches Oppidum in der Provence ", Antiketuelt, 9, 3, p. 17-24.

1984 : « Un oppidum gaulois à Saint-Blaise en Provence ", Les Dossiers d'histoire et d'archéologie, $84,98 \mathrm{p}$.

1992 : Saint-Blaise (fouilles H. Rolland). L.habitat protohistorique. Les céramiques grecques, Aix-en-Provence, PUP, $280 \mathrm{p}$.

Bouloumié B., Fincker M., Tréziny H.

1981 : "Le rempart hellénistique de SaintBlaise -II- Sondage stratigraphique de la campagne 1981 ", Acta Antiqua Academiae Scientiarum Hungaricae, XXIX, 1-4, p. 227-266.

Bouloumié B., TréZiny H.

1985 : " Saint-Blaise (Saint-Mitre-les-Remparts, B.-du-Rh.) ", in DI:I)ET B., PY M. (DIR.), l.es enceintes protohistoriques de (ancle méridionale, Caveirac, ARAI.O (coll. (ahicr, 14), p. $107-110$

BRUN J.-P.

1990 : "Des terrasses de culture massaliotes sur l'île de Porquerolles? ”, in Promalsal. M. (DIR.), " lagriculture en 
terrasses sur les versants méditerranéens; histoire, conséquences sur l'évolution du milieu ", Méditerranée, 3-4, p. 13-15.

1993 : "I.oléiculture et la viticulture antique en Gaule : instruments et installation de production ", in AMot:RETTI M.-C., BRL:. J.-P. (DIR.), La production du vin et de l'huile en Méditerranée, Athènes (coll. Suppl. au Bulletin de correspondance hellénique, 26), p. 307-341.

1999 : "Introduction ", in BRLN J.-P., Borríani M. (DIR.), Le Var, Paris, Académie des inscriptions et belles-lettres (coll. Carle archéologique de la Gaule, 83/1), p. $64-204$.

\section{BRUN J.-P., BorrÉANI M. (DIR.)}

1999 : Le Var, Paris, Académie des inscriptions et belles-lettres, 1999, 2 vol. (coll. Carte archéologique de la Gaule, 83/1 et 83/2), $984 \mathrm{p}$.

Brun J.P., Charrière J.-L., Congès G.

1998 : "L'huilerie de l'îlot lll et les pressoirs d'Entremont ", Documents d'archéologie méridionale, 21, 1998, p. 44-57 et cédérom.

Brun J.-P., Congès G., Pasqualini M. (DiR.)

1993 : Les fouilles de Taradeau. Le Fort, L'Ormeau et Tout-Egau, Paris, ćd. du CNRS (Suppl. à la Rerue archéologique de Narbonnaise, 28), $286 \mathrm{p}$.

BRUN P.

1987 : Princes et princesses de la Celtique. Le premier âge du Fer en Europe (850-450 ar. J.-C.), Paris, éd. Errance, $220 \mathrm{p}$.

1992 : "L'influence grecque sur la société celtique non méditerranéenne ", in Bats M., Bertlcechi G., Congês G., TRÉ:IINY H. (DIR.), Marseille grecque et la Gaule, Actes des colloques internationaux de Marseille, 18-23 mai 1990, Lattes/Aix-enProvence, ADAM/PUP (Travaux du Centre Camille-Jullian, 11 et coll. Études massaliètes, 3), p. 389-399.

1993 : «La complexification sociale en Europe pendant l'âge du Fer: essai de modélisation ", in Daubigivey A. (DIR.), Fonctionnement social de l'âge du Fer. Opérateurs et hypothèses pour la France, Actes de la table ronde internationale de Lons-le-Saunier, 1990, Lons-le-Saunier, Centre jurassien du Patrimoine, p. 275-289.

1997 : “Les résidences princières” : analyse du concept ", in BRIN P., Chatme B. (DIR.), Vix et les éphémères principautés celtiques. Les ir et ir s. av. J.-C. en Europe centre-occidentale, Actes du colloque de Châtillon-sur-Seine, 1993, Paris, éd. Errance (coll. Archéologie aujourd'hui, 1997), p. 321-330.

BUCHSENSCHUTZ $\mathbf{O}$.

1990 : "Urbanisme et oppida ", in Dutal. A., LE BiHAX J.-P., MÉ.X:Z Y. (DIR.), Les Gaulois d'Armorique. La fin de l'âge du Fer en Europe tempéré, Actes du XII' colloque de l'Association française pour l'étude de l'âge du Fer, Quimper; 1988, Rennes (coll. Suppl. à la Revue archéologique de l'Ouest, 3), p. 191-194.

1999 : "Caractères spécifiques de l'habitat celtique: une architecture sans pierre; une société complexe sans ville ", in Braemer f., Clelziol S., Coytart A. (DIR.), Habitat et société, Actes des $X I X^{e}$ rencontres internationales d'archéologie et d'histoire d'Antibes, 22-24 oct. 1998, Antibes, APDCA, p. 353-361.

Buchsenschutz O., Colin A., Gruel K., RALSTON I. B. M.

1993 : " Approche du territoire au second âge du Fer ", in Daubigney A. (DIR.), Fonctionnement social de l'âge du Fer: Opérateurs et hypothèses pour la France, Actes de la table ronde internationale de I.ons-le-Saunier, 1990, Lons-le-Saunier, Centre jurassien du Patrimoine, p. 247-258.

Buchsenschutz O., Guillaumet J.-P.

1989 : " Habitats et économie de l'âge du Fer : les oppida ", in Archéologie de la France. 30 ans de découvertes, Paris, Réunion des musées nationaux, p. 274-275.

Camps-Fabrer H., Colomer A., Coularou J., Courtin J., Coutel R., D'Anna A., GUTHERZ X.

1984 : « Les enceintes du Néolithique à l'âge du Bronze dans le sud-est de la France", in WAI.DRE.N J. (DIR.), The Deya Conference of Prehistory, 1983, BAR, International Series, 229 , p. 339-362.

1985 : "Les techniques de construction en pierres sèches dans le sud-est de la France, de la fin du Néolithique au début de l'âge du Bronze ", in Histoire des techniques et sources documentaires. Méthode d'approche et expérimentation en région méditerranéenne, Actes du colloque du Groupement d'intérêt scientifique d'Aix-en-Provence, 1982, Aix-enProvence, Université de Provence (coll. Cahier du Groupement d'intérêt scientifique, 7), p. 13-24.

\section{Carozza L.}

1996 : «Vendres, Portal-Vielh », Bilan scientifique de la région Languedor-Roussillon, 1996, p. 143-144.

Carozza L., Burens A.

1995 : « Le site de Buzerens à Bram (Aude) : habitat du Chalcolithique et du premier âge du Fer ", in GLIIAINE J., VAQuer J. (DIR.), L'habitat néolithique et protohistorique dans le sud de la France, Toulouse, École des hautes études en sciences sociales (coll. Séminaires du Centre d'anthropologie, 1995), p. 63-65.

Carozza L., Burens A., Fry S.

2000 : "Bram-Buzerens: un habitat agricole du Premier Âge du Fer ", in Gascó J., ClatsTre: F. (DIR.), Habitals, économies et sociétés du nord-est méditerranéen de l'âge du Bronze au premier âge du Fer, Actes du colloque international de Carcassonne, 1994, Paris,
Société préhistorique française (coll. Congrès préhistoriques de France, XXIV), p. 199-210.

Carozza L., Burens A., Fry S., NicolPICHARD S.

1998 : “Ferme, hameau, village: l'habitat rural protohistorique dans le bassin de l'Aude (du IX s. au ve s. av. J.-C.) ", in MaunÉ S. (DIR.), Recherches récentes sur les établissements ruraux protohistoriques en Gaule méridionale ( $I X^{\top}-I I I^{\prime} s$ av. J.-C.), Actes de la table ronde de Lattes, 1997, Montagnac, Monique Mergoil (coll. Protohistoire européenne, 2), p. 131-157.

CARRU D.

2000 : " Occupations préaugustéennes d'Avignon ( $\left(\mathrm{v}^{\mathrm{e}-\mathrm{I}^{\mathrm{er}}}\right.$ s. av. J.-C. $)$ ", in Chacssfrif-L APRÉ. J. (DIR.), Le temps des Gaulois en Provence, Catalogue d'exposition, Martigues, musée Ziem, p. 205-208.

Castelly G., Comps J.-P., Kotarba J., Pezin A. (DIR.)

1997 : Voies romaines du Rhône à l’̀̀tre: via Domitia et via Augusta, Paris, Maison des sciences de l'Homme (coll. Documents d'archéologie française, 61), $299 \mathrm{p}$.

CAyot A.

1984 : "La céramique campanienne de SaintBlaise (Saint-Mitre-les-Remparts, B.-duRh.) ", Documents d'archéologie méridionale, 7, 1984, p. 53-78.

Célié M., Garmy P., Monteil M.

1994 : «Enceintes et développement urbain : Nîmes antique, des origines au $\mathrm{I}^{\mathrm{er}} \mathrm{s}$. apr. J.-C. ", Journal of Roman Archaeology, 7, p. $383-396$.

\section{Chabal L.}

1997 : Forêts et sociétés en Languedoc (Néolithique. final, Antiquité tardive). L'anthracologie, méthode et paléoécologie, Paris, Maison des sciences de l'Homme (coll. Documents d'archéologie française, 63), $188 \mathrm{p}$.

\section{Chabot L.}

1983 : «L'oppidum de la Cloche aux PennesMirabeau (Bouches-du-Rhône). Synthèse des travaux effectués de 1967 à 1982 ", Reuue archéologique de Narbonnaise, XVI, p. 39-80.

1992 : " Ia citerne collective du village de la Cloche, Les Pennes-Mirabeau (B.-duRh.) ", Documents d'archéologie méridionale, 15, 1992, p. 126-130.

1996 : «Une aire cultuelle sur l'oppidum de la Cloche aux Pennes-Mirabeau (Bouchesdu-Rhône). Les enseignements de la zone sommitale ", Rerue archéologique de Narbonnaise, 29, p. 233-284.

2000 : "L'oppidum de la Cloche ", in Chalsstrif-L Lapré. J. (DIR.), le temps des Gaulois en Provence, Catalogue d'exposition, Martigues, musée Ziem, p. 161-166.

2004 : Loppidum de La Cloche (Les PennesMirabeau, B.-du-Rh.), Montagnac, 
Monique Mergoil (coll. Protohistoire européenne, 7), $350 \mathrm{p}$.

\section{Chausserie-Laprée J.}

1997 : " La maison et le village au temps des Gaulois du Midi. Recherches récentes à Martigues (B.-du-Rh.) ", in ARCELIN P. (DIR.), La publication archéologique sur cédérom, Paris, ministère de la Culture et de la Communication (dossier $n^{\circ} 5$ ).

2000 : " Le village gaulois de Saint-Pierre-lesMartigues ", in Chaussterie-LAPRÉE J. (DIR.), Le temps des Gaulois en Provence, Catalogue d'exposition, Martigues, musée Ziem, p. 171-176.

Chausserie-LaPrée J. (DIR.)

2000 : Le temps des Gaulois en Provence, Catalogue d'exposition, Martigues, musée Ziem, $280 \mathrm{p}$.

Chausserie-Laprée J., NiN N

1990 : « Le village protohistorique du quartier de l'île à Martigues (B.-du-Rh.). Les espaces domestiques de la phase primitive (début $v^{*}$ s.-début ${ }^{\prime \prime}{ }^{c}$ s. av. J.-C.) -ILes aménagements domestiques ", Documents d'archéologie méridionale, 13, 1990 , p. $35-136$

1995 : « La céramique grise monochrome de l'habitat protohistorique de l'île à Martigues (B.-du-Rh.) ", in ARCEIIN P., Bats M., Garcia D., Marchand G., Schwad.ler M. (DIR.), Sur les pas des Crecs en Occident. Hommages à André Nickels, Lattes/Paris, ADAM/Errance (coll. Études massaliètes, 4), p. 339-362.

Chausserie-Laprée J., NiN N. (DiR.)

1988 : "Le village gaulois de Martigues ", Les Dossiers d'histoire et d'archéologie, 128, $98 \mathrm{p}$.

Chausserie-Laprée J., Nin N., Domallain L.

1984 : " Le village protohistorique du quartier de l'île à Martigues (B.-du-Rh.). Urbanisme et architecture de la phase primitive ( $\mathrm{V}^{\mathrm{c}}$ - III" s. av. J.-C.) -I- Urbanisme et fortification ", Documents d'archéologie méridionale, 7, 1984, p. 27-52.

\section{Chazelles C.-A.}

1997 : " Montlaurès (Narbonne. Aude). Le bilan de six années de fouilles (19891994) ", in U(ooloN D. (DIR.), Languedoc occidental protohistorique. Fouilles et recherches récentes (Vr-Nr s. av. J.-C.), Aix-en-Provence, Publications de l'univ. de Provence, p. 23-44.

1999 : " Les maisons de l'âge du Fer en Gaule méridionale, témoins de différentes identités culturelles et reflets d'une certaine disparité sociale ", in BrakmFr F., Clectziou S., Coldant A. (Dir.), Habitat et société, Actes des XIX rencontres internationales d'archéologie et d'histoire d'Antibes, 22 24 oct. 1998, Antibes, APDCAA, p. 481-498.

\section{Chazelles-Gazzal C.-A}

1997 : Les maisons en terre de la Gauie méridionale, Montagnac, Monique Mergoil (coll. Monographies Instrumentum, 2), $231 \mathrm{p}$.
Clerc M.

1927 : Massalia. Histoire de Marseille dans l'Antiquité des origines à la fin de l'Empire romain d'Occident, I, Marseille, Taccussel, $480 \mathrm{p}$.

Colus J.

1984a : Oppida. Earliest Towns North of the Alps, Sheffield, Department of Prehistory and Archaeology, $254 \mathrm{p}$.

1984b: The European Iron Age, London, Batsford Ldt, $192 \mathrm{p}$.

1999 ( $3^{\text {th }}$ ed. 1995) : "States without centres? The middle La Tène period in temperate Europe ", in ARNOI.D B., GIBSON D. B. (EDS), Celtic chiefdom, Celtic state. The evolution of complex social systems in Prehistoric Europe, Cambridge, University Press (coll. New directions in Archaeology), p. $75-80$

CoNGÈs G.

1987 : "La céramique ", in COLTAGNE D. (ED.), Archéologie d'Entremont au musée Granet, Aix-en-Provence, éd. musée Granet, p. 143-163.

2004 : « La statuaire d'Entremont : réflexions sur d'anciennes découvertes ", in Arcein P., Congès G. (IIR.), "Dossier: La sculpture protohistorique en Provence et les régions voisines ", Documents d'archéologie méridionale, 27, 2004, p. 63-70.

\section{Constans L.-A.}

1921 : Arles antique, Paris, De Boccard (coll. Bibliothèques des Écoles françaises d'Athènes et de Rome, 119), 426 p.

CoUTAGNE D. (ÉD.)

1987 : Archéologie d'Entremont au musée Granel, Aix-en-Provence, éd. musée Granet, $264 \mathrm{p}$.

\section{D'ANNa A., Gutherz X. (DIR.)}

1989 : Enceintes, habitats ceinturés, siles perchés du Néolithique au Bronze moyen dans le sud de la France et les régions voisines, Actes de la table ronde de Latles et Aix-en-Provence, 1987, Montpellier (coll. Mémoire de la Société languedocienne de Préhistoire, 2), $240 \mathrm{p}$.

\section{DeDET B.}

1987 : Habitat et vie quotidienne en Languedoc au milieu de l'âge du Fer: L'unité domestique $n^{n} I$ de Gailhan, Gard, Paris, éd. du CNRS (coll. Suppl. à la Rerue archéologique de Narbonnaise, 17), $230 \mathrm{p}$.

1989 : "Le second âge du Fer dans le Languedoc méditerranéen ", in MOHIN J.-P. (DIR.), Le temps de la Préhistoire, I, Dijon, Société préhistorique française et Archéologia, p. 474-477.

1990 : "Une maison à absides sur l'oppridum de Gailhan (Gard) au milieu du v" s. avant J.-C. La question du plan absidial en Gaule du Sud ". Gallia, 47, p. 29-55.

1999 : «Le Gard protohistorique ", in Provost M. lit at. (DIr.), Le Gard, Paris, Académic des inscriptions et belles-lettres (coll. Carte archéologique de la Gaule, 30/2), p. $60-80$.

Dedet B., Mahieu É., Sauvage L

1997 : "L'espace cultuel et funéraire du premier âge du Fer de Vestric en Languedoc oriental (Vestric-et-Candiac, Gard) ", Bulletin de la Societé préhistorique francaise, 94, 4, p. 581-608.

Dedet B., Sauvage $L$.

1998: " L.es enclos fossoyés du vi" siècle avant J.-C. au Cauquillous (Montpellier, Hérault) ", Bulletin de la Sociélé préhistorique franfaise, 95, 4, p. 565-580.

Domergue C., Hesnard A., Passelac M.

2002 : "Les échanges commerciaux dans le Toulousain : l'exemple de VieilleToulouse ", in Pall.I.ER J.-M. (DIR.), Tolosa. Nouvelles recherches sur Toulouse et son territoire dans l'Antiquité, Rome, École française (coll. École française de Rome, 281), p. 193-197.

DUBY G.

1980 : "France rurale, France urbaine: confrontation ", in DLBY G. (DIR.), Histoire de la France urbaine -1- La ville antique, Paris, Le Seuil, p. 9-35.

DUFRAIGNe J.-J.

2000a : "Fouilles récentes à Entremont ", in Chalsserite-Laprík. J. (DIR.), le temps des Gaulois en Provence, Catalogue d'exposition, Martigues, musée Ziem, p. 139-142.

2000b: "L'habitat préromain de la place du Cloître à Cavaillon ", in Chatssitrit:LAPRÉF. J. (DIR.), Le temps des Giauiois en Provence, Catalogue d'exposition, Martigues, musée Ziem, p. 199-202.

Duval $\mathbf{S}$.

1998 : "L'habitat côticr de Tamaris (B.-duRh.). Bilan des recherches et étude du mobilier des fouilles de Ch. Lagrand ", Documents d'archéologie méridionale, 21, 1998, p. 133-180.

2000 : "L'habitat côtier de Tamaris ", in ChalsSERIE-I Aprit. J. (DIR.), le lemps des Gaulois en Provence, Catalogue d'exposition, Martigues, muséc Ziem, p. 167-170.

2003 : «L'habitat archaïque du cap Tamaris", in LANDES C. IT Al. (DIR.), Les Étrusques en France. Archéologie et collections, Catalogue d'exposition, Lattes, IMAGO, p. 81-84.

\section{Egloff M.}

1981 : « Versunkene Dörfer der Urnenfelderzeit im Neuenburger See : Forschungen der Luftbildarchäologie ", Archäologisches Korrespondenzblatt, 11, p. 55-63.

Escallon G., Dufraigne J.J.

1997: Un habitat de plaine du second âge du Fer dans la moyenne tallee du Rhône, Lapalud, Les Contras (Vaucluse), Aix-en-Provence, Document final de synthèse, SRA-PACA.

FÉl.LSAT J.

1987 : "Inventaire des monnaies trouvees sur l'oppidum du Baou-Roux (Bouches-du- 
Rhône) de 1907 à 1981 ", Revue archéologique de Varbonnaise, 20, p. 99-141.

Feugère M.

1993 : "Des parures el des hommes. Économic et société en Gaule méridionale à travers l'exemple des parures celtiques du Midi ", in Dal'BIGNEY A. (1)IR.), Fonctionnement social de l'âge du Fe: Opérateurs et hypothèses pour la France, Actes de la table ronde internationale de Lons-leSaunier, 1990, Lons-le-Saunier, Centre jurassien du Patrimoine, p. 43-55.

Feugère M., Dedet B., Leconte S., Rancoule G.

1994 : "L.es parures du $\mathrm{v}^{*}$ au II" s. av. J.C.C. en Gaule méridionale: composantes indigènes, ibériques et celtiques ", in "L Lâge du Fer en Europe sud-occidentale, Actes du colloque de l'Association française pour l'étude de l'âge du Fer, Agen, 1992 ", Aquitania, XII, p. 237-281. FICHES J.-L.

1989 : “Tombes et monuments lapidaires dans l'espace rural arécomique (III"${ }^{\mathrm{cr}}$ s. av: n. è.) ", in Mélanges Pierre lévếque -2- Anthropologie et société, Paris, Les Belles Lettres, p. 207-235.

1996 : Ambrussum, une étape de la voie domiLienne en Lunellois, Montpellier, Presses du I anguedoc, $96 \mathrm{p}$.

FICHTL S.

2000 : La ville cellique. Les oppida de 150 av. J.-C. à 15 apr. J.-C., Paris, éd. Errance, $190 \mathrm{p}$.

FISCHER $\mathbf{F}$.

1999 ( $3^{\text {th }}$ ed. 1995) : " The Farly (elts of West Central Europe: the semantics of social structure ", in ARNold B., GIBSON D. B. (I:Ds), Celtic chiefdom, Celtic state. The evolution of complex social systems in Prehistoric Europe, Cambridge, Lniversity Press (coll. New directions in Archaeology), p. 34-40.

GaGnière S., Granier J.

1979): Histoire d'Avignom, Aix-en-Provence, Edisud, 726 p.

GaILledrat E.

1997 : Les lbères, de likbre à l'Héraull $\left(\mathrm{NI}^{\mathrm{r}}-\mathrm{N} \mathrm{N}^{e}\right.$ s. av. J.-(.), Lattes, ARALO (coll. Monographies d'archéologie méditerranécunc, 1), $336 \mathrm{p}$.

2000 : " Courants commerciaux et partenaires méditerranéens entre le Languedoc occidental et la péninsule Ibérique au premier âge du Fer ", in JANox T. (DIR.), . Wailhac et le premier âge du Fer en Europe occidentale. Hommages à Odetle et Jean Taffanel, Actes du colloque international de Carcassomne, sept. 1997, Lattes, ARALO (coll. Monographies d'archéologie méditerranéenne, 7), p. 261-270.

\section{Gantès L.-F.}

1990a: "Notre-Dame-de-Pitié ", in Voyage en Massalie. 100 ans d'archéologie en Gaule du Sud, Marseille, Musćes/Edisud, p. 72-77.

1990b : "Teste-Nègre", in Voyage en Massalie. 100 ans d'archéologie en Gaule du Sud, Marscillc, Musćcs/Edisud, p. 78-88.

1992 : " L'apport des fouilles récentes à l'étude quantitative de l'économie massaliète ", in Bars M., Bertucchi G., CoNciès G., Tríziny H. (DIR.), Marseille grecque et la Gaule, Actes des colloques internationaux de Marseille, 18-23 mai 1990, Lattes/Aix-en-Provence, ADAM/PUP (Travaux du Centre Camille-Jullian, 11 et coll. Études massaliètes, 3), p. 171-178.

\section{Gantès L.-F., Moliner M.}

1990 : "Abords de l'ćglise Saint-Laurent ", in Gantès L..-F., Moliner M. IET Al.. (DIR.), Marseille: itinéraire d'une mémoire. Cinq années d'archéologie municipale, Marseille, musée d'Histoire, p. 9-10.

\section{GARCIA D.}

1997 : " Le peuplement protohistorique: l'âge du Fer (725-100 av. J.-C.) dans les Alpes-de-Haute-Provence ", in Bérard G. liT Al. (DIR.), Les Alpes-de-Haute-Provence, Paris, Académie des inscriptions et belleslettres (coll. Carte archéologique de la Gaule, 04), p. 58-60.

2000a: "Formes d'habitat préromaines en Gaule méridionale. L'apport des piémonts héraultais ", in DEDFT B., Grlat P., Marchand G., Py M., SChwatili: M. (DIR.), Aspects de l'âge du Fer dans le sud du Massif central, Actes du $X X I^{r}$ colloque international de l'Association française pour l'élude de l'âge du Fer, ConquesMontrozier, 1997, Lattes, ARALO (coll. Monographies d'archéologie méditerranéenne, 6), p. 193-201.

2000b: «Urbanisation et société en Gaulc méridionale au premier âge du Fer ", in JANiN T. (DIR.), Mailhac et le premier âge du Fer en Europe occidentale. Hommages à Odette et Jean Taffanel, Actes du colloque international de Carcassonne, sept. 1997, Lattes, ARAI.O (coll. Monographies d'archéologie méditerranéenne, 7) p. 25-34.

2000c : «Économie et réseau protohistoriques dans le nord-est du monde ibérique (Roussillon et Languedoc occidental, vi"$\mathrm{II}^{\mathrm{c}}$ s. av. J.-C.) ", in Actes du colloque Economia en el Món Ibèric, (Suppl. à Saguntum, 3) p. 69-79.

2000d: "The Process of Urbanization in Southern Gaul during the Early Iron Age ", in Guichard V., Sifters S., LRBA. O. H. (DIR.), Les processus d'urbanisation à l'âge du Fer; Actes du colloque de Glux-en-Glenne, 1998, Glux-en-Glenne, Centre archéologique européen (coll. Bibracte, 4), p. 49-60.
2003 : " Espaces sacrés et genèse urbaine chez les Gaulois du Midi ", in BaTs M. IIT AI.. (DIR.), Peuples et territoires en Gaule méditerranéenne. Hommage à Guy Barruol, Montpellier (coll. Suppl. à la Revue archérlogique de Narbonnaise, 35), p. 223-232.

Gascó J.

2000 : " L'enceinte du Cros (CaunesMinervois, Aude) à la transition de l'âge du Bronze et du premier âge du Fer », in Gascó J., Claustre. F. (Dir.), Habitats, économies et sociétés du nord-est méditerranéen de l'âge du Bronze au premier âge du Fer; Actes $d u$ colloque international de Carcassonne, 1994, Paris, Société préhistorique française (coll. Congrès préhistoriques de France, XXIV), p. 211-221.

Gateau F.

1990 : "Amphores importées durant le II" s. av. J-C. dans trois habitats de Provence occidentale: Fntremont, Le Baou-Roux, Saint-Blaise ", Documents d'archéologie méridionale, 13, 1990, p. 163-183.

Gateau F., Gazenbeek M. (Dir.)

1999 : « Les Alpilles et la Montagnette », Paris, Académie des inscriptions et belles-lettres (coll. Carte archéologique de la Gaule, 13/2), $464 \mathrm{p}$.

Gauthier M.

1984 : "Informations archéologiques de la circonscription de Provence-Alpes-Côte d'Azur ", Gallia, 42, 2, p. 405-434.

Ginouvis O., Janin T., Vidal L., Poupet P. 1990 : "Paléosols et structures agraires enfouies : quelques exemples d'approche du paysage rural ", in FICHES J.-L., VA.I DER LEELW S. E. (DIR.), Archéologie et espaces, Actes des $X^{e}$ rencontres internationales d'archéologie et d'histoire d'Antibes, 19-21 oct. 1989, Juan-les-Pins, APDCA, p. 383-418.

GODELIER M.

1999 : "Chefferies et États, une approche anthropologique ", in RuBY P. (DIR.), I.es princes de la Protohistoire et l'émergence de l'État, Actes de la table ronde internationale de Naples, 1994, Naples-Rome (coll. Centre Jean-Bérard, 17 et École française de Rome, 252), p. 19-30.

Goudineau C.

1976a : "Le statut de Nîmes et des Volques Arécomiques ", Revue archéologique de Narbonnaise, IX, p. 105-114.

1976b : "Sur un mot de Cicéron ou Avignon et le domaine de Marseille ", in Mélanges offerts à J. Heurgon, Rome (coll. Bibliothèque de l'École française de Rome, 27), p. 325-332.

1978 : " La Gaule transalpine », in Nicol.t. C. (DIR.), Rome el la conquête du monde méditerranéen (264-27 av. J.-C.) -2- Genèse d'un empire, Paris, Presses universitaires de France (coll. Nouvelle Clio, $8^{\text {bis }}$, p. 679-699. 
1980 : « La ville antique. Les antécédents : y a-t-il une ville protohistorique ? La Gaule méridionale ", in DLBy G. (DIR.), Histoire de la France urbaine, 1, Paris, Le Seuil, p. 141-193.

Gransar F., Auxiette G., Desenne S., Hénon B., Le Guen P., Pommepuy C.

1999 : «Essai de modélisation de l'organisation de l'habitat au cours des cinq derniers siècles avant notre ère dans la vallée de l'Aisne ", in Bratemer F., Clecziol: S., Coldart A. (DIR.), Habitat et société, Actes des XIX rencontres internationales d'archéologie et d'histoire d'Antibes, 22 24 oct. 1998, Antibes, APDCA, p. 419-438.

Gras M.

2000 : « Les Étrusques et la Gaule méditerranéenne ", in JANIN T. (DIR.), Mailhac el le premier âge du Fer en Europe occidentale. Hommages à Odette et Jean Taffanel, Actes du colloque international de Carcassonne, sept. 1997, Lattes, ARALO (coll. Monographies d'archéologie méditerranéenne, 7), p. 229-241.

Gros P.

1987: « Un programme augustéen : le centre monumental de la colonie d'Arles ", Jahrbuch des Deutschen Archäologischen Instituts, 102, p. 339-363.

1990 : « Les siècles hellénistiques en Gaule transalpine; le problème des relais culturels et politiques ", in Akten des XIII. Internationalen Kongresses für Klassische Archäologie, Berlin, 1988, Mainz, Deutsches Archäologisches Institut, p. 101-111.

1992 : « Rome ou Marseille ? Le problème de l'hellénisation de la Gaule transalpine aux deux derniers siècles de la République ", in Bats M., Bertucchi G., Congeis G., TRÉzINY H. (DIR.), Marseille grecque et la Gaule, Actes des colloques internationaux de Marseille, 18-23 mai 1990, Lattes/Aix-enProvence, ADAM/PUP (Travaux du Centre Camille-Jullian, 11 et coll. Études massaliètes, 3), p. 369-379.

Gros P., TORelli M.

1988 : Storia delléurbanistica. ll mondo romano, Bari, Laterza, 466 p.

Gruat P., Marty G.

2000 : " Habitat et peuplement en Rouergue durant l'âge du Fer: premières tendances ", in Detott B., Grlat P., Makchand G., Py M., S(Hwal...r M. (DIR.), Aspects de l'âge du Fer dans le sud du Massif central, Actes du $X X I^{r}$ colloque international de l'Association francaise pour l'étude de l'âge du Fer, ConquesMontrozier, 1997, Lattes, ARALO (coll. Monographies d'archéologie méditerranéenne, 6), p. 27-50.

Gruat P., Marty G., Marchand G. et al.

2003 : " Systèmes de fortification de l'habitat de hauteur du Puech de Mus à SainteEulalie-de-Cernon (Aveyron) au $v^{k}$ s. av:
J.-C. ", Documents d'archéologie méridionale, 26, 2003, p. 63-157.

Guilaine J., Rancoule G.

1996 : "Les relations méditerranéennes précoloniales et les débuts de l'âge du Fer languedocien. Les influences puniques en Languedoc occidental ", Complutum, 7, p. 125-140.

Guillaume M., Maufras O., Vasselin B., VOYez C.

2002 : « Marseille, tunnel de la Major ", Bilan scientifique de la région Provence-Alpes-Côte d'Azur, 2002, p. 111-114.

Guillaumet J.P., RaPin A.

2000 : "L'art des Gaulois du Midi ", in Chausserie-Laprée J. (DIR.), Le temps des Gaulois en Provence, Catalogue d'exposition, Martigues, musée Ziem, p. 79-83.

Guillet E., Leliève V., Paillet J.-L., Piskorz M., Recolin A., Sove F.

1992 : “ Un monument à portique tardohellénistique près de la source de la Fontaine à Nîmes (Gard) ", Documents d'archéologie méridionale, 15, 1992, p. 57-89.

\section{Heijmans M.}

1991 : "Nouvelles recherches sur les cryptoportiques d'Arles et la topographie du centre de la colonie ", Revue archëologique de Narbonnaise, 24, p. 161-200.

hermary A., Hesnard A., Tréziny H. (Dir.) 1999 : Marseille grecque (600-49 av. J.-C.). La cilé phocéenne, Paris, éd. Errance (coll. Hauts lieux de l'histoire), $184 \mathrm{p}$.

\section{HesnaRd A.}

1999 : « La ville hellénistique (III- $-\mathrm{I}^{\mathrm{er}} \mathrm{s}$. av. J.-C.) ", in Hermary A., Hes.iard A., TRÉ.7INY H. (DIR.), Marseille grecque (600-49 av. J.-C.). I.a cité phocéenne, Paris, éd. Errance (coll. Hauts lieux de l'histoire), p. 119-141.

Huot J.-L., Thalmann J.-P., Valbelle D.

1990 : Naissance des cités, Paris, Nathan (coll. Origines), $352 \mathrm{p}$.

JACOB $\mathbf{P}$.

2000 : Les villes de la façade méditerranéenne de la péninsule Ibérique, du $\mathrm{N}^{*}$ s. av. J.-C: à la fin du $r^{r}$ s. de n. è. Processus d'urbanisation et struclures urbaines, Villeneuve-d'Ascq, Presses universitaires Septentrion (coll. Thèse à la carte), 2 vol., 774 p., 184 fig., 54 pl.

JALLOT L.

1998 : “ Montpellier, Port Marianne/Jacques Coeur II ", Bilan scientifique de la région Languedoc-Roussillon, 1998, p. 116-117. JANNORAY J.

1955 : Ensérune. Contribution à l'étude des civilisations préromaines de la Gaule méridionale, Paris, De Boccard (coll. Bibliothèques des Écoles françaises d'Athènes et de Rome, 181), 492 p., LXXI pl.
JOHNSON A. W., EARLE T. K.

1987 : The Evolution of Human Societies : from foraging Croup to agrarian State, Stanford, Stanford University Press, $360 \mathrm{p}$.

\section{LANDURÉ C.}

2000 : " La Capelière, un habitat fluvial en Camarguc ", in Chausstrie-Laprél J. (DIR.), Le temps des Gaulois en Provence, Catalogue d'exposition, Martigues, musée Ziem, p. 182-184.

Lejeune M., Lambert P.Y.

1996 : " Compléments gallo-grecs : Cavaillon ", Ėtudes celtiques, XXXII, p. 131-137.

Lejeune M., PoulllouX J., Solier Y.

1988 : «Étrusque et ionien archaïques sur un plomb de Pech Maho (Aude) ", Rerue archéologique de Narbonnaise, 21, p. 19-59.

Leveau P., Heinz C., Laval H., Marinval P., Medus J.

1991 : « Les origines de l'oléiculture en Gaule du Sud. Données historiques, archéologiques et botaniques ", Revue diarchéométrie, 15 , p. 83-94.

LOQUI E. M. DE

1839: Recherches sur les ruines d'Entremonts (situées près d'Aix, Bouches-du-Rhône) et sur. les mours des Salyens, Aix-en-Provence, F. Guigne, $51 \mathrm{p}$.

MARCADAL Y.

1992 : "Une salle collective des Caisses de Saint-Jean à Mouriès (B.-du-Rh.) ", Documents d'archéologie méridionale, 15 , 1992, p. 28-30.

2000 : "Les nécropoles de Mouriès ", in Chalsserik-Laprí. J. (DIR.), le lemps des Gaulois en Provence, Catalogue d'exposition, Martigues, musée Ziem, p. 244-247.

Marcadal N., Marcadal Y., Paillet J.-L. et al.

2003 : "La nécropole protohistorique et galloromaine de Servanes-Cagalou ( $\mathrm{I}^{\mathrm{er}}$ s. av. J.-C.-III' s. apr. J.-C.) à Mouriès (B.-duRh.) : sépultures et monuments funéraires ", Documents d'archéologie mériaionale, 26, 2003, p. 251-348.

MARINVAL P.

1997 : «Vigne sauvage et vigne cultivée dans le bassin méditerranéen. Émergence de la viticulture. Contribution archéobotanique ", in L'histoire du vin. Une histoire de viles, Paris, Office international de la vigne et du vin, p. 137-172.

2000 : "Agriculture et structuration du paysage agricole à Marseille grecque et dans les sociétés indigènes aux premier et second âges du Fer ", Pallas, 52, p. 183-194.

MAUNÉ S.

1998a: "Un concept, une table ronde: les établissements ruraux protohistoriques en Gaule méridionale ", in Macké S. (DIR.), Recherches récentes sur les établissements ruraux protohistoriques en Gaule méridionale (IX'-IIT s. av. J.-C.), Actes de la 
table ronde de Lattes, 1997, Montagnac, Monique Mergoil (coll. Protohistoire européenne, 2), p. 3-8.

1998b : "Les établissements ruraux des $\mathrm{II}^{\circ} \mathrm{et}$ It's. av.J.-C. en Languedoc central. Études de cas et perspectives ", in MAlNÉ S. (1)IR.), Recherches recentes sur les établissements ruraux protohistoriques en Gaule méridionale (IX-III s. av. J.-(.)), Actes de la table ronde de Lalles, 1997, Montagnac, Monique Mergoil (coll. Protohistoire européenne, 2), p. 45-72.

1998c: "Occupation du sol ", in Fruçìre. M. I:T M.. (DIR.), "Signes de la romanisation ", Revue archéologique de Narbonnaise, 31, p. 301-306.

1999 : "Nouvelles découvertes d'établissements ruraux protohistoriques à Fontès (Hérault) (VI"-T" s. av. J.-C.) ", Archéologie en Languedoc, 23, p. 111-119.

MAUNÉ S. (DIR.)

1998 : Les campagnes de la cité de Béziers dans l'Antiquité (partie nord-orientale; If s. av. J.-C.-Ir s. apr:J.-C.), Montagnac, Monique Mergoil (coll. Archéologie et histoire romaine, 1), $580 \mathrm{p}$.

MÉnez Y., ARRamond J.-C.

1997 : «L'habitat aristocratique fortifié de Paule (Côtes-d'Amor) ", Ciallia, 54, p. 119-155.

MÉnEZ Y. avec la collab. de GIOT P.-R., Laubenheimer F., Le Goff E., Vendries C.

1999 : "I.es sculptures gauloises de Paule (Côtes-d'Armor) ", Gallia, 56, p. 357-414.

Mertens D., Greco E.

1996: "L'urbanisme dans la Grande Grèce",

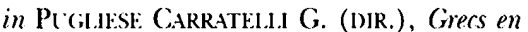
Occident, Milano, Bompiani, p. 243-262.

\section{MOLINER M.}

1999 : "Sous la place des Pistoles, des niveaux d'habitat de l'époque grecque à nos jours ", in Hesward A., Moliner M., Conche F., Botiron M. (Dir.), Parcours de villes. Marseille: 10 ans d'archéologie, 2600 ans d'histoire, Catalogue d'exposition, Marseille, musée d'Histoire, Aix-enProvence, Edisud, p. 80-89.

\section{MONTEIL M.}

1999 : Nimes antique et sa proche campagne. Étude de topographie urbame et periurbaine (fin it's. av. J.-C./vr s. apr. J.-C.), Lattes, ARALO (coll. des Monographies d'archéologie méditerranéenne, 3), $528 \mathrm{p}$.

Monteil M., Poupet P., Sauvage L.

1990 : "I Les structures agraires antérieures à l'urbanisme augustéen à Nîmes, ZAC des Halles (Gard) ", Dialogues d'histoire ancienne, 16, 2, p. 349-355.

\section{MORRIS I. M.}

1991 : "The Early Polis as City and State ", in Rich J., Wallace-Hadril. A. (ems), City and Country in the Ancient World, London/New-York, Routledge, p. 25-57.
NIN N.

1999 : "Les cspaces domestiques en Provence durant la Protohistoire. Aménagements et pratiques rituelles du $\mathrm{vt}^{\mathrm{c}}$ s. av. n. c̀. à l'époque augustéenne ", Documents d'archéologie méridionale, 22, 1999, p. 221-278.

2000 : "Un fossé rituel à Aix-en-Provence? ", in Chalsserie-Lapréf. J. (DIR.), Le temps des Gaulois en Provence, Catalogue d'exposition, Martigues, musée Ziem, p. 266-269.

Nuninger L., Raynaud C.

1998 : " La Vaunage (Gard) à l'âge du Fer : questions de méthode et de traitement de la documentation ", in MAL'NÉ S. (DIR.), Recherches récentes sur les établissements ruraux protohistoriques en Gaule méridionale (II'-IIT s. av. J.-C.), Actes de la table ronde de Lattes, 1997, Montagnac, Monique Mergoil (coll. Protohistoire européenne, 2), p. 9-28.

2000 : "Dynamique et système de peuplement en Vaunage (Gard) du VII" au Ives. av. J.-C. ", in JANIN T. (DIR.), Mailhac et le premier âge du Fer en Europe occidentale. Hommages à Odette et Jean Taffanel, Actes $d u$ colloque international de Carcassonne, sept. 1997, Lattes, ARALO (coll. Monographies d'archéologie méditerranéenne, 7), p. 35-52.

Olivier A.

1982: "Dalles de toiture en pierre sciée à Glanum : "opus pavonaceum" ? ", Revue archéologique de Narbonnaise, XV, p. 69-98.

Paillet J.-L., TrézinY H.

2000 : "Le rempart hellénistique et la portc charretière de Glanum ", in Chat sstritLAPRÉE. J. (DIR.), Le temps des Gaulois en Provence, Catalogue d'exposition, Martigues, musée Ziem, p. 189-190.

\section{Passelac M.}

1983 : "L'occupation des sols en Lauragais à l'âge du Fer et pendant la période gallo-romaine: acquis, problèmes et méthodes ", in le Lauragais, histoire et archéologie, Montpellier, Fédération historique du Languedoc méditerranéen et du Roussillon, p. 29-63.

\section{Pétrequin P., Viellet A., Illert N.}

1999 : "Le Néolithique au nord-onest des Alpes : rythmes lents de l'habitat, rythmes rapides des techniques et des styles? ", in Brakmer F., Cilelziou S., Coldart A. (DIR.), Habitat et société, Actes des $X I X^{\prime}$ rencontres internationales d'archéologie. et d'histoire d'Antibes, 22-24 oct. 1998, Antibes, APDCA, p. 297-323.

Pion P., Auxiette G., Boureux M., Brun P., Demoule J.-P., Pommeruy C., Rober B.

1990 : « De la chefferie à l'État? Territoires et organisation sociale dans la vallée de l'Aisne aux âges des métaux (2200-20 av. J.-C.) ", in FICHES J.-L., VAN DER L.FFC'W S. E. (DIR.), Archéologie et espaces,
Actes des $X^{r}$ rencontres internationales d'archéologie et d'histoire d'Antibes, 19-21 oct. 1989, Juan-les-Pins, APDCA, p. 183-260.

Piotrowska D., Piotrowsk W.

1990 : "Biskupin : un habitat fortifié de la plaine polonaise daté de la transition Bronze-Fer ", in Un monde villageois. Habitat et milieu naturel en Europe de 2000 ì 500 av. J.-C., Lons-le-Saunier, Section d'archéologie de la Société d'émulation du Jura, p. 191-200.

Plassot E., Desbat A.

2003 : " Le site de la rue du Souvenir à Lyon ", in Polx M., Savar-Glerriz H. (DIR.), Lyon avant Lugdunum, Catalogue d'exposition, Lyon, Gollion, éd. Infolio, p. $130-133$

Py M.

1978 : L'oppidum des Castels à Nages (Gard) (fouilles 1958-1974), Paris, éd. du CNRS (coll. Suppl. à Gallia, XXXV), 363 p.

1990a: Cullure, économie et société protohistoriques dans la région nîmoise, Rome, École française, 2 vol. (coll. Bibliothèque de l'École française de Rome, 131), 952 p.

1990b: " La diffusion des amphores massaliètes sur le littoral du Languedoc oriental ", in BATS M. (DIR.), Les amphores de Marseille grecque. (ihronologie et diffusion (VT-tr s. av. J.-C.), Actes de la table ronde de Lattes, 1989, Lattes/Aix-en-Provence, ADAM/PUP (coll. Études massaliètes, 2), p. 73-86.

1992a : "Les fanums des Castels à Nages et de Roque-de-Viou (Gard) ", in "Dossier : Espaces et monuments publics protohistoriques de Gaule méridionale ", Documents d'archéologie méridionale, 15, 1992, p. 44-49.

1992b: " Les tours monumentales de la région nîmoise ", in " Dossier : Espaces et monuments publics protohistoriques de Gaule méridionale ", Documents d'archéologie méridionale, 15, 1992, p. 117-125.

1993 : Les Gaulois du Midi. De la fin de l'âge du Bronze à la conquête romaine, Paris, Hachette, $288 \mathrm{p}$.

1994 : «Les céramiques d'époque protohistorique (Ne-II s. av. n. è.) ", in GARCIA D. ET AL. (DIR.), Exploration de la ville portuaire de Lattes, Lattes, ARALO (coll. Lattara, 7), p. 205-332

1996 : "Les maisons protohistoriques de L.attara ( $\mathrm{N}^{\mathrm{r}}-\mathrm{I}^{\mathrm{er}} \mathrm{s}$. av. n. è.). Approche typologique et fonctionnelle ", in Pr M. (DIR.), Lrbanisme et archilecture dans la ville antique de Lattes, Lattes, ARAIO (coll. Lattara, 9), p. 141-258.

2003 : " La Liquière (Calvisson, Gard) ", in LANDES C. liT AI.. (DIR.), Les Étrusques en France. Archéologie et collections, Catalogue d'exposition, Lattes, IMAGO, p. 107-115 
Py M., Adroher A., Sanchez C., Barbéran S., Raux S.

1999 : " Le faciès de la céramique lattoise du IV s. av. n. è. ", in PY M. (DIR.), Recherches sur le quatrième siècle avant notre ère à Lattes, Lattes, ARALO (coll. Lattara, 12), p. 287-438.

Py M., BuXó I Capdevila R.

2001 : " La viticulture en Gaule à l'âge du Fer ", in Brun J.-P., LAUBENheimer F. (DIR.), "Dossier: La viticulture en Gaule ", Gallia, 58, p. $29-43$.

Py M. avec la collab. de LASSAlLE V., VarÈne P., Bessac J.-C., Columeau P.

1981 : Recherches sur Nimes préromaine. Habitats et sépultures, Paris, éd. du CNRS (coll. Suppl. à Gallia, XLI), 244 p.

Py M., Lebeaupin D. avec la collab. de Duday H., Fabre V., Tillier A.-M.

1989 : "Stratigraphie du Marduel (SaintBonnet-du-Gard) -IV- Lcs nivcaux des IV $^{e}$ et III $^{*}$ s. av. n. è. sur le Chantier Central ", Documents d'archéologie méridionale, 12, 1989, p. 121-190.

Py M. avec la collab. de Py F., SAuzet P., TendiLLE C. ET AL.

1984 : La Liquière (Calvisson, Gard). Village du premier âge du fier en Languedoc oriental, Paris, éd. du CNRS (coll. Suppl. à la Reoue archéologique de Narbonnaise, 11), 363 p.

Py M., Roure R. avec la collab. de Alonso Martínez N., Bessac J.-C., Gardeisen A., PiQués G.

2002 : "I.e Cailar (Gard). Un nouveau comptoir lagunaire protohistorique au confluent du Rhôny et du Vistre ", Documents d'archéologie méridionale, 25, 2002, p. 171-214.

Py M., Vignaud A.

1998 : "Voie et habitat protohistoriques de Peyrouse à Marguerittes (Gard) ( $v^{*}$ siècle avant notre ère) ", Documents a"archéologie méridionale, 21, 1998, p. 181-196.

Rancoule G.

1992 : " Habitat rural des $1 I^{\mathrm{e}}$ et $\mathrm{I}^{\mathrm{er}}$ siècles en Minervois oriental et en Narbonnais ", Bulletin de la Sociêté d'études scientifiques de l'Aude, XCII, p. 7l-79.

1993 : “ Les marges occidentales du Languedoc ibérisé: l'Aude intérieure ", Documents d'archéologie méridionale, 16 , 1993, p. 41-46.

Rancoule G., Schwaller M.

1994 : “Apports ou influences continentales cn Langucdoc occidental. Recensement, chronologie et réflexions ", in "L Lâge du Fer en Europe sud-occidentale, Actes du colloque de l'Association française pour l'étude de l'âge du Fer, Agen, 1992 ", Aquitania, XII, p. 223-235.

RAPIN A., SCHWaller M.

1987 : "Contribution à l'étude de l'armement celtique: la tombe 163 d'Ensérune
(Hérault) ", Reque archéologique de Narbonnaise, 20, p. 155-183.

RECHERCHE ARCHÉOLOGIQUE EN FRANCE (LA)

1997 : Bilan 1990-1994 el programmation du Conseil national de la recherche archéologique en France, Ministère de la Culture, direction du Patrimoinc, sous-dircction de l'Archéologie, Paris, Maison des sciences de l'Homme, $460 \mathrm{p}$.

\section{REILLE J.-L.}

1998 : "L'importation des meules en basalte dans le secteur de Martigues au deuxième âge du Fer. Identification pétrographique des sources ", Documents d'archéologie méridionale, 21, 1998, p. 237-244.

1999 : «Détermination pétrographique de l'origine des meules de Lattes au IVte siècle avant notre ère. Changements et contrastes dans les importations ", in PY M. (DIR.), Recherches sur le quatrième siècle avant notre ère à Lattes, Lattes, ARALO (coll. Lattara, 12), p. 519-522.

\section{RéTIF M.}

2000 : " Le mobilier métallique de l'habitat protohistorique de l'île de Martigues, B.-du-Rh. ( $v^{*}-I^{*}$ s. av. J.-C.) ", Documents d'archéologie méridionale, 23, 2000, p. 157-208.

RIGOIR J., RIGOIR Y.

1981 : "Sondage au pied du rempart de SaintBlaise (Saint-Mitre-les-Remparts, B.-duRh.) ", Documents d'archéologie méridionale, 4, 1981, p. 179-184.

1983 : "Le chapiteau préromain de SaintBlaise (Saint-Mitre-les-Remparts, B.-du$\mathrm{Rh}$.$) ", Documents d'archéologie méridionale,$ 6, 1983, p. 143-145.

Rolland H.

1951 : Fouilles de Saint-Blaise (Bouches-du-Rhône), Paris, éd. du CNRS (coll. Suppl. à (iallia, III), 290 p., 186 fig., 2 plans.

1956 : Fouilles de Saint-Blaise (Bouches-du-Rhône), 1951-1956, Paris, éd. du CNRS (coll. Suppl à Gallia, VII), 95 p., 56 fig., IV plans.

1968 : "Nouvelles fouilles du sanctuaire des Glaniques ", in Hommage ì Fernand Benoit, II, Revue des Études ligures, XXXIV, $1-3$, p. $7-34$.

ROLley C.

1992 : "I Ie rôle de la voie rhodanienne dans les relations de la Gaule et de la Méditerranée (VII ${ }^{\mathrm{c}} \mathrm{v}^{*}$ s. av. J.-C.) ", in Bats M., Bertucchl G., Conciès G., TREZIINY H. (DIR.), Marseille grecque et la Gaule, Actes des colloques internationaux de Marseille, 18-23 mai 1990, lattes/Aixen-Provence, ADAM/PUP (Travaux du Centre Camille-Jullian, 11 et coll. Études massaliètes, 3), p. 41 1-418.

Roth Congès A.

1985: " Glanum préromaine : recherche sur la métrologie et ses applications dans l'urbanisme et l'architecture ", Revue archéologique de Narbonnaise, 18, p. 189-220. 1992a : " Le centre monumental de Glanon ou les derniers feux de la civilisation salyenne ", in Bats M., BerTuCCHI G., Congìs G., TRÉZINY H. (DIR.), Marseille grecque et la Gaule, Actes des colloques internationaux de Marseille, 18-23 mai 1990, Lattes/ $\Lambda$ ix-en-Provence, ADAM/PUP (Travaux du Centre Camille-Jullian, 11 et coll. Études massaliètes, 3), p. 351-367.

1992b : « Nouvelles fouilles à Glanum (19821990) ", Journal of Roman Archaeology, 5, p. 39-55.

1997 : « La fortune éphémère de Glanum : du religieux à l'économique. À propos d'un article récent", Gallia, 54, p. 157-202.

2004 : « Le contexte archéologique de la statuaire de Glanon (Saint-Rémy-deProvence, Bouches-du-Rhône) ", in ARCElin P., CONGÈs G. (DIR.), "Dossier: La sculpture protohistorique en Provence et les régions voisines ", Documents d'archéologie méridionale, 27, 2004, p. 23-43.

ROUARD E.

1851 : Bas-reliefs gaulois trouvés à Entremont près d'Aix-en-Provence, Recueil de l'Académie d'Aix, VI, 104 p., 3 pl., 1 fac-similé.

Salviat F.

1987 : "La sculpture d'Entremont ", in Coutagne D. (ÉD.), Archéologie d'Entremont au musée Granet, Aix-en-Provence, éd. du musée Granet, p. 164-239.

SCHALUIN A.-L.

1997 : «Urban Centres, Central Places and Nucleation in Greek Islands versus the Greek Mainland ", in DAMGAARI) ANDERSEN H., Horsiets H. W., HolbyNifi.sf... S., RATHJE A. (EDS), Urbanization in the Mediterranean in the $9^{\text {th }} 106^{\text {th }}$ centuries $B C$, Copenhage, Museum Tusculanum Press (coll. Acta hyperborea, 7), p. 17-44.

SÉjalon P., Dedet B. avec la collab. de Escallon G., GardeISEN A.

2003 : "Les trois enclos funéraires de Mas de Vignole VII à Nîmes, Gard ( $v^{*}$ s. av. J.-C.) ", Documents d'archéologie méridionale, 26, 2003, p. 43-61.

SMITH M. G.

1972 : "Complexity, Size and Urbanization ", in U(ko) P. J.. Trinciham R., Dimbl.kby G. W. (EDs), Man, Settlement and Urbanism, Cambridge, p. 567-574.

SourisseaU J.-C.

1997 : Recherches sur les amphores de Provence et de la basse vallée du Rhône aux époques archaïue et classique (fin vir-début $N^{*}$ s. ar. J.-C.), Thèse d'université, Aix-en-Provence, univ. de Provence, 3 vol. dactyl.

2000a: "L.es importations d'amphores grecques à Marseille aux $\mathrm{VT}^{\mathrm{e}}$ et $\mathrm{V}^{\mathrm{r}} \mathrm{s}$. av. J.-C.: bilan quantitatif ", in CABRERA BONET P., SANTOS RtTOLAZA M. (DIR.), Ceraimiques jönies d'època arcaica: centres de producció $i$ comercialització al Mediterrani 
occidental, Actes de la taula rodona celebrada a Empuries, 1999, Barcelona, museu de Empuries (coll. Monografies emporitanes, 11), p. 137-146.

2000b: «La Provence et les échanges commerciaux au premier âge du Fer ", in Chal'sserde-Luprée J. (DIR.), le temps des Gaulois en Provence, Catalogue d'exposition, Martigues, musée Ziem, p. 59-66.

\section{TCHERNIA A.}

1983: "Italian Wine in Gaul at the end of the Republic ", in GaRisfy P., HopkIss K., WITtaker C. R. (f.los), Trade in the Ancient Economy', I.ondon, Chatto \& Windus, p. $87-104$.

TRÉMENT F.

1999 : Archéologie d'un paysage. Les étangs de Saint-Blaise (Bouches-du-Rhône), Paris, Maison des sciences de l'Homme (coll. Documents d'archéologie française, 74), $314 \mathrm{p}$.

\section{TRÉZINY H.}

1989 : « Mćtrologic, architecture et urbanisme dans le monde massaliète ", Rezue archéologique de Narbonnaise, 22, p. 1-46.

1999 : "L.es fortifications grecques en Occident à l'ćpoque classique (491-322 av. J.-C.) ", Pallas, 51, p. 241-282.

UgOLINI D.

1993 : "Civilisation languedocienne et ibérisme : un bilan de la question ( $\mathrm{V}^{\mathrm{T}} \mathrm{I}^{\mathrm{e}}-\mathrm{IV}^{\mathrm{e}}$ siècles avant J.-(.) ", Documents d'archéologie méridionale, 16, 1993, p. 26-40.

\section{Ugolini D., Oune C. ET AL.}

1998 : "Ia "ferme" protohistorique de Sauvian (Hérault), Casse-Diables, zone 2 (V"-IN" s. av. J.-C.) ", in MALNí S. (DrR.), Recherches récentes sur les établissements ruraux protohistoriques en Gaule méridionale (IX-IIIt s. av. J.-C.), Actes de la table ronde de Lattes, 1997, Montagnac,
Monique Mergoil (coll. Protohistoire europíenne, 2), p. 93-119.

VAN DE VOORT J.-F.

1991 : " La maison des Antes de Glanum (B.du-Rh.): analyse métrologique d'une maison à péristyle hellénistique ", Rernue archéologique de Narbonnaise, 24, p. 1-17.

\section{VERDIN F.}

1995: Ies Salyens et leurs territoires, Thèse d'université, Aix-en-Provence, univ. de Provence, 3 vol., 470 p., 202 pl., fiches d'inventaire.

1999 : "Occupation du sol et pression démographique indigène autour de Marseille au second âge du Fer ", in Bellascol:RTVAi.dHi:R M., Corvisif.r J.-N. (DIR.), La démographie historique antique, Arras, Artois Presses, p. 51-68.

2000: " I a ferme-grenier de Coudounèu ", in Chatsstrit-Lapkík J. (Dir.), le temps des Gaulois en Provence, Catalogue d'exposition, Martigues, musée Ziem, p. 147-150.

2003 : "Glanum et Nîmes: un même processus d'urbanisation, des destinées différentes ", in B.ATs M. E:T At.. (DIR.), Peuples et territoires en Gaule méditerranéenne. Hommage à Guy Barruol, Montpellier (coll. Suppl. à la Revue archéologique de Narbonnaise, 35), p. 565-573.

VERDIN F. avec la collab. de BRIEN-POITEVIN F., Chabal L., Marinval P., Provansal M.

1996-1997: " Coudounèu (Lançon-deProvence, Bouches-du-Rhône): une ferme-grenier et son terroir au $\mathrm{v}^{\mathrm{c}} \mathrm{s}$. avant J.-C. ", Documents d'archéologie mérdionale, 19-20, 1996-1997, p. $165-198$ et cédérom.

\section{VERNET J.-L.}

1997 : L.homme et la forêt méditerranéenne, de la Préhistoire à nos jours, Paris, éd. Errance (coll. L.es Hespérides), 248 p.
Vidal L., Pomarèdes H., Sauvage L.

1996: "Traces matériclles de la mise en valeur et de l'aménagement des campagnes aux portes de Nîmes : les parcellaires antiques de la plaine du Vistre ", in Choteltik (;. (1)IR.), les formes du paysage -2- Archéologie des parcellaires, Actes du colloque d'Orléans, 1996, Paris, éd. Errance, p. 57-66.

VILLARD F.

1960 : La céramique grecque de Marseille $\left(1 \%-\|^{\circ}\right.$ s.). Essai d'histoire économique, Paris, De Boccard (coll. Bibliothèques des Écoles françaises d'Athènes et de Rome, 195$), 178$ p., 58 pl. h. t.

VINK M. C. V.

1997 : "Urbanization in Late and SubGeometric Greece: abstract considerations and concrete case studies of Fretria and Zagora c. $700 \mathrm{BC}$; ", in Damganad A.jofrser H., Horsidas H. W., Hoc by-Nifis.s. S., RathJ: A. (EDS), Urbanization in the Mediterranean in the $9^{\text {h }}$ to $6^{\text {th }}$ centuries BC, Copenhage, Muscum Tusculanum Press (coll. Acta hyperborea, 7), p. 111-141.

VLADÁR J.

1973 : "Osteuropäische und Mediterrane Einflüssc im Gebiet der Slowakei während der Bronzezcit ", Slovenská Archaeológia, 21, p. 253-357.

Willaume M.

1987 : " l.es objets de la vie quotidienne ", in Coc RAGNe D. (F.), Archéologie d'Entremont au musée Granet, Aix-en-Provence, éd. du muséc Granet, p. 106-141.

1998 : "Les objets de la vie quotidienne à Entremont chez Fernand Benoit et aujourd'hui ". Documents d'archéologie méridionale, 21, 1998, p. 58-61. 